\title{
3D Nonlinear Mixed Finite-element Analysis of RC Beams and Plates with and without FRP Reinforcement
}

\author{
BY \\ MOHAMMAD M. HOQUE
}

\begin{abstract}
A Thesis
Submitted to the Faculty of Graduate Studies in Partial Fulfillment of the Requirements for the Degree of
\end{abstract}

MASTER OF SCIENCE

Department of Civil Engineering

University of Manitoba

Winnipeg, Manitoba, Canada

Thesis Advisor: Professor N. Rattanawangcharoen, Ph.D., P.Eng.

(C) Copyright by M. Hoque, 2006 


\begin{abstract}
Three 3D nonlinear finite-element (FE) models are developed to study the behavior of concrete beams and plates with and without externally reinforcement of fibre reinforced polymer (FRP). Ramtekkar's mixed layer-wise 3 dimensional (3D) 18-node FE model (108 degrees-of-freedom, DOFs) is modified to accommodate the nonlinear concrete and elasto-plastic steel behaviour. Saenz's stress-strain equation is used for material nonlinearity of concrete. As in any 3D mixed FE analysis, the run time using the model can be computationally expensive. Two additional layer-wise 18-node FE models: Displacement FE model (54 DOF) and transitional FE model (81 DOF) are developed. The displacement FE model is based on purely displacement field, i.e. only displacement components are enforced throughout the thickness of the structures. The transitional FE model has six DOF (three displacement components in the coordinate axis direction and three transverse stress components $-\tau_{x z}, \tau_{y z}, \sigma_{z}$ where $\mathrm{z}$ is the thickness direction) per node in the upper surface and only three DOF (three displacement components in the coordinate axis direction) per node in the bottom surface. The overall intention for developing the two additional element models is to investigate the result quality with the reduction of computational time by using elements with less DOF in less critical part of structure. In this study we limited our effort to investigate the quality of the results rather than efficiency of the models. The analysis of reinforced concrete (RC) beam strengthened with FRP and composite plate using these models are verified against the experimental results and the results from the commercial software, ANSYS respectively. Several parametric studies are done on composite RC beam and composite plate.
\end{abstract}




\section{Acknowledgement}

I would like to express my sincere appreciation and gratitude to my advisor Dr. Nipon Rattanawangcharoen for his guidance for the past two years, and for suggesting the topic of this thesis. His constant encouragement and suggestions guided me during the course of this research. I greatly appreciate his invaluable help with all aspect of this thesis as well as future possible publication of the journal paper. Also I like to acknowledge his continuous financial support. I would also like to thank Dr. Arvind Shah for his continuous help and encouragement during the course of this thesis. His guidance helped me to understand many important areas of this thesis. I would like to thank Dr. Meera N.K. Singh for agreeing to be on my committee and for her valuable comments.

Special acknowledgement to Veto Varma, Yang Liu and Nibong Ungkurapinan for their unsolicited assistance. I would like to thank Mr. Ward and are grateful for all the reviewers' comments.

Financial support from the NSERC, Canada, Discovery Grant RGPIN 261642 and the University of Manitoba is gratefully acknowledged.

Finally, I would like to thank my parents for believing in me and for their continuous support. Special thank to my wife Zakia for her inspiration and understanding in finishing last part of the research. Sometimes, I feel that without her help my thesis may not have come to the end. 


\section{Table of Contents}

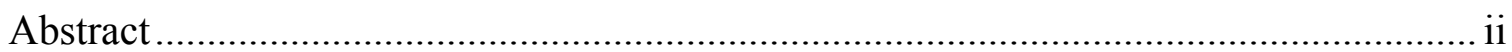

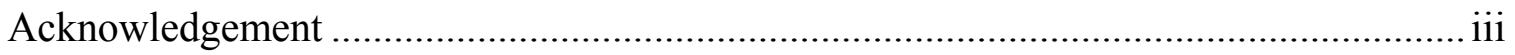

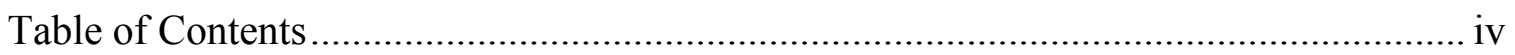

List of Tables .......................................................................................................... vii

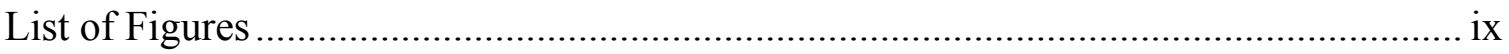

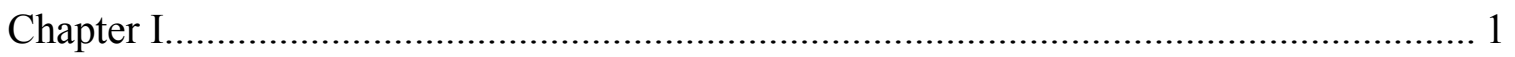

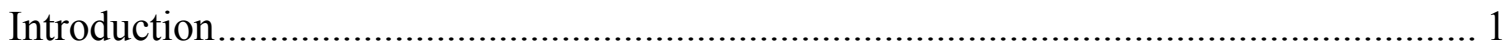

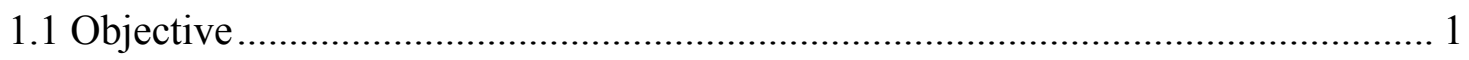

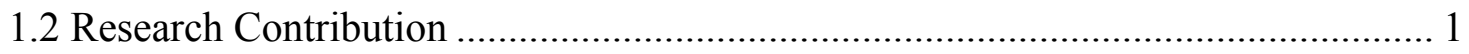

1.3 Scope

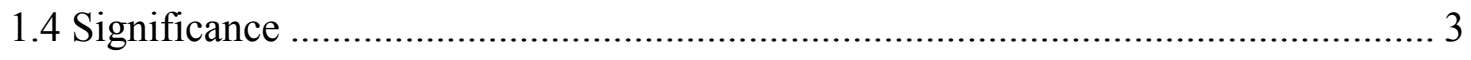

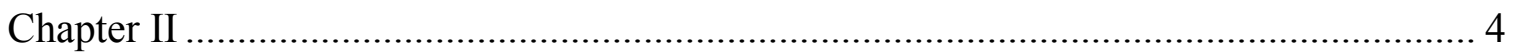

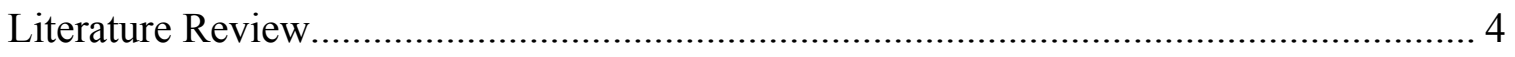

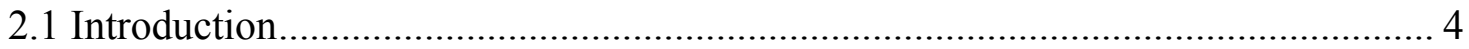

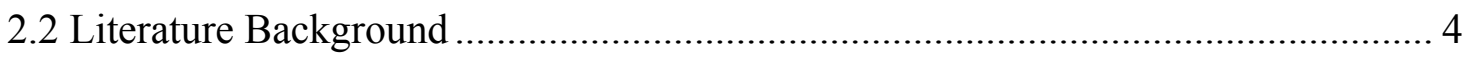

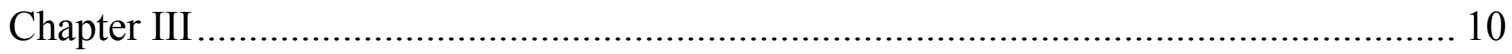

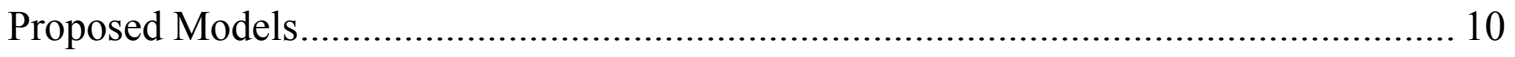

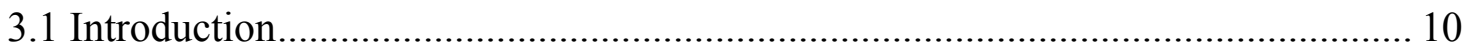

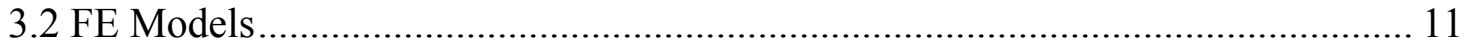

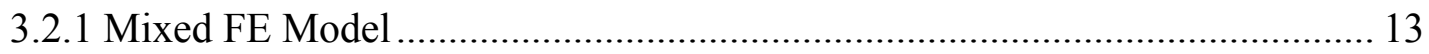

3.2.1.1 Constitutive Equations .......................................................................... 14 


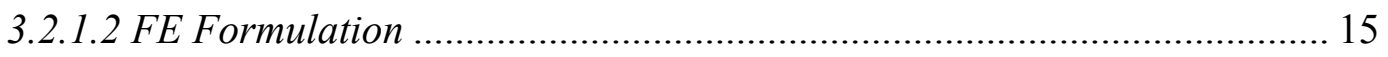

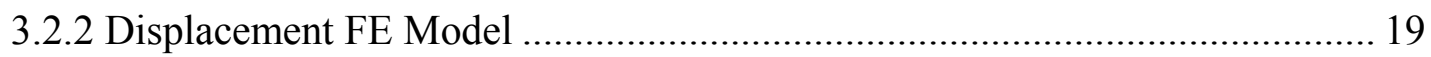

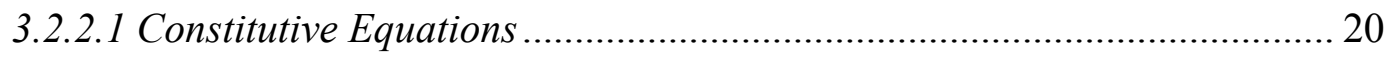

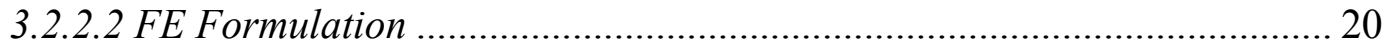

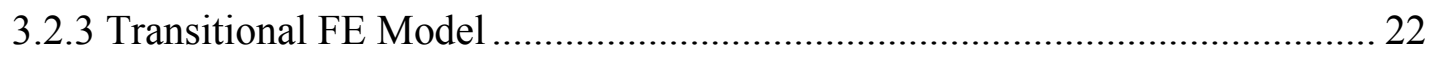

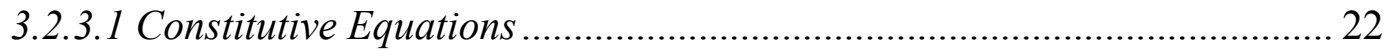

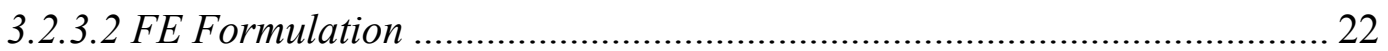

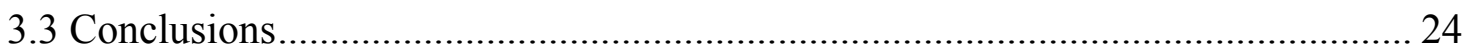

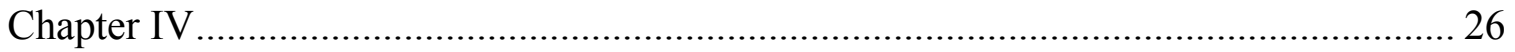

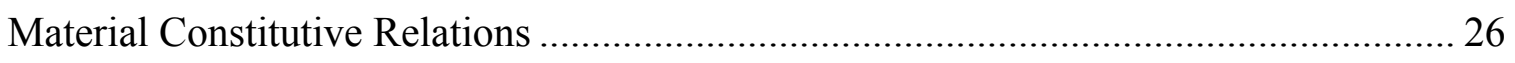

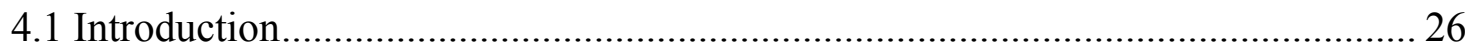

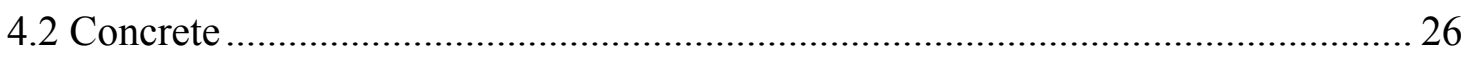

4.2.1 Compressive behavior ................................................................................ 26

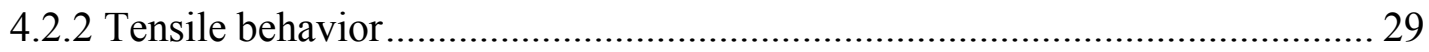

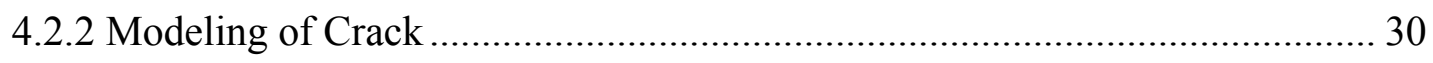

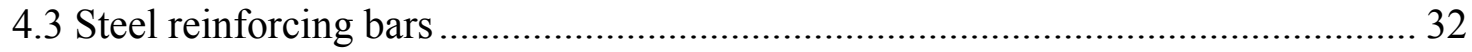

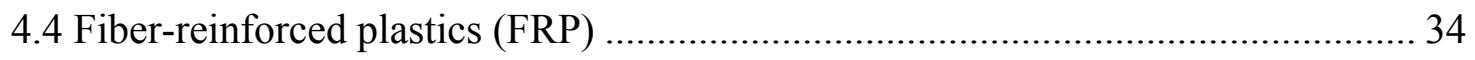

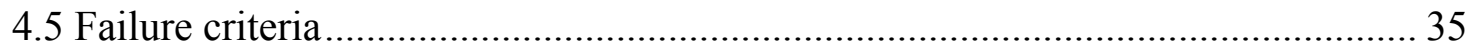

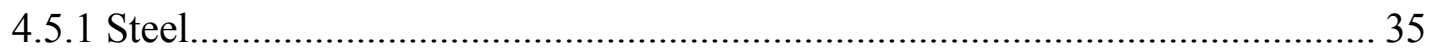

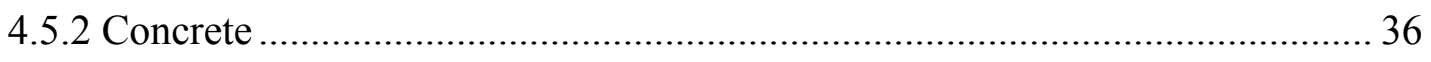

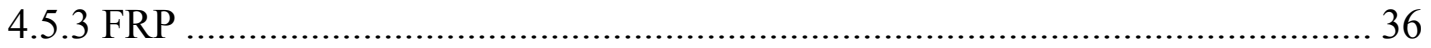

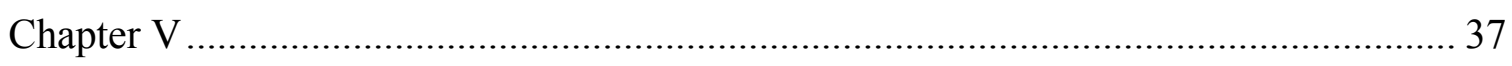

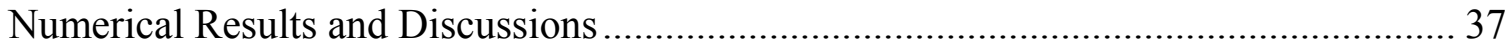




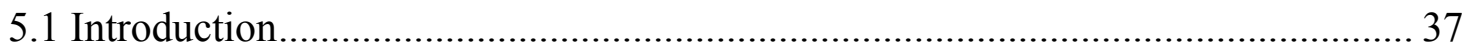

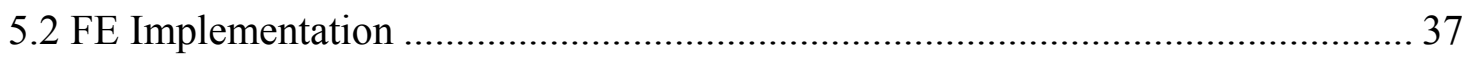

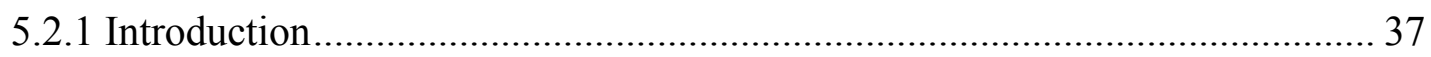

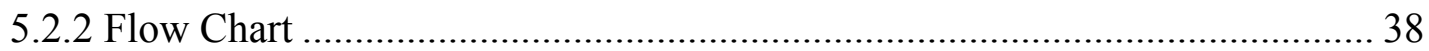

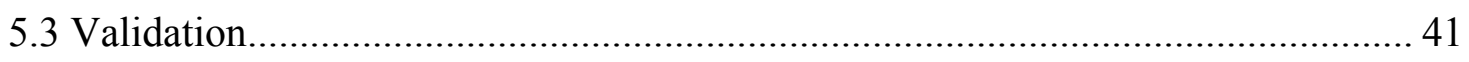

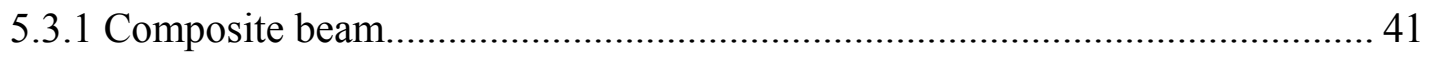

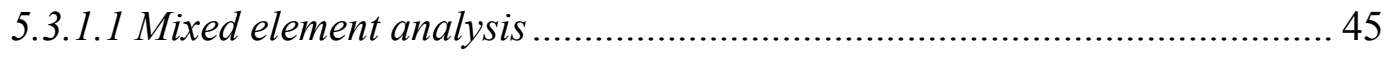

5.3.1.2 Analysis by using displacement model and combined model: ................. 46

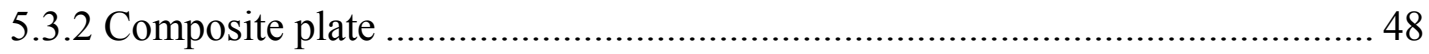

5.3.2.1 Mixed model, Displacement model, and ANSYS Analysis ...................... 51

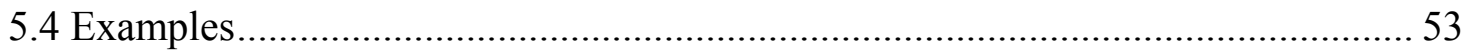

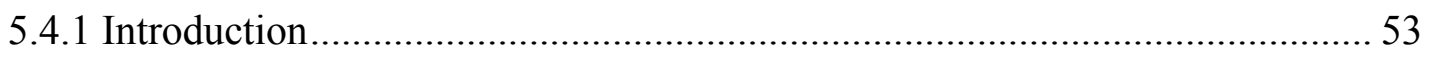

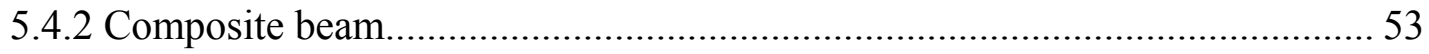

5.4.2.1 Number of FRP layers ............................................................... 53

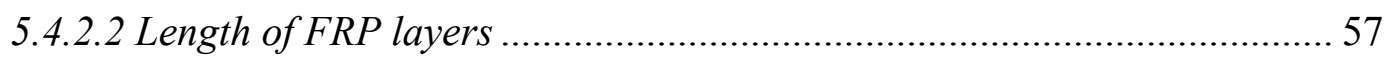

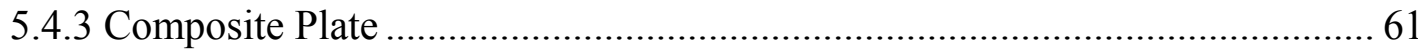

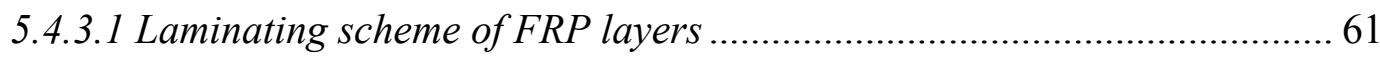

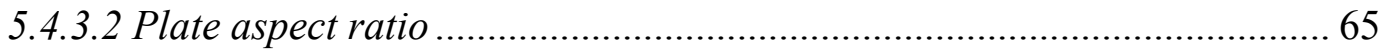

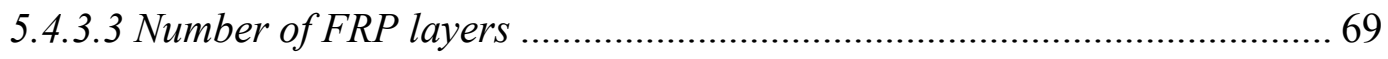

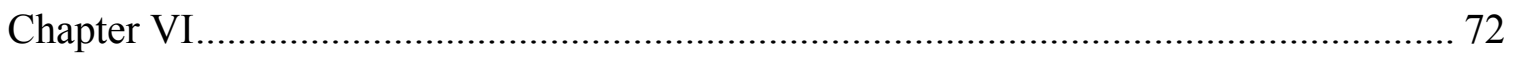

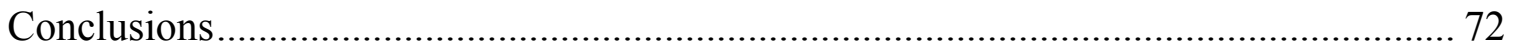

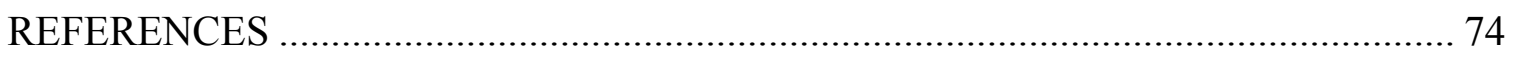

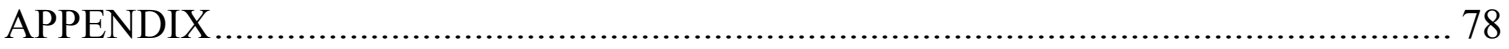




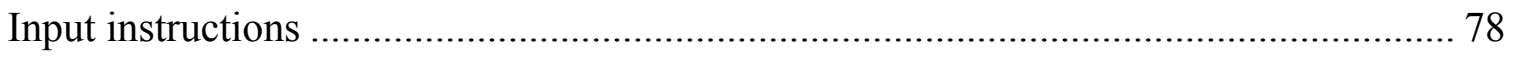

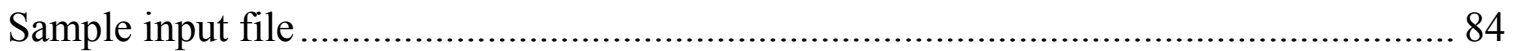

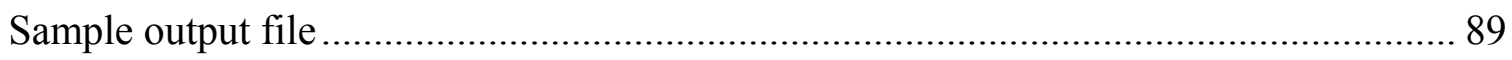




\section{List of Tables}

Table 5.1: Boundary condition for RC composite beam............................................. 44

Table 5.2: Boundary condition for composite plate ............................................... 51

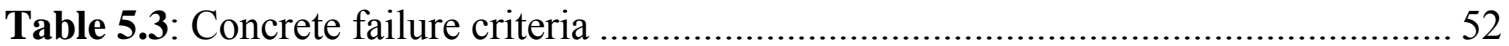




\section{List of Figures}

Figure 3.1: (a) Laminated plate and global reference axes and (b) Geometry of 18-node

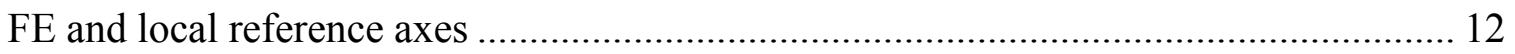

Figure 4.1: Uniaxial Stress-strain Curve for Concrete............................................... 28

Figure 4.2: Tension Stiffening Model........................................................................ 30

Figure 4.3: Uniaxial stress-strain relation for steel................................................. 32

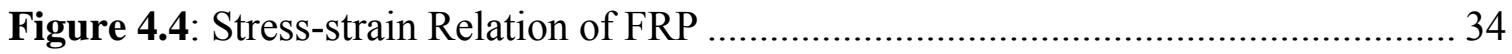

Figure 5.1: Flow chart for incremental displacement and stress calculation ................... 39

Figure 5.2: Flow chart of concrete constitutive matrix calculation ................................ 40

Figure 5.3: Geometry of a simply-supported beam under four-point load test (all

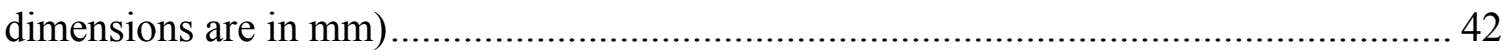

Figure 5.4: FE mesh used in the result validation....................................................... 44

Figure 5.5: FE mesh for mixed analysis .................................................................. 45

Figure 5.6: Load-deflection curves of RC beams strengthened with three FRP layers

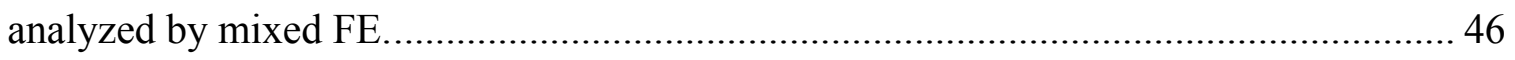

Figure 5.7: FE mesh for displacement and combined element model analysis ............... 47

Figure 5.8: Load-deflection curves of RC beams strengthened with three FRP layers

analyzing by displacement and combined FE under four-point load. .............................. 48

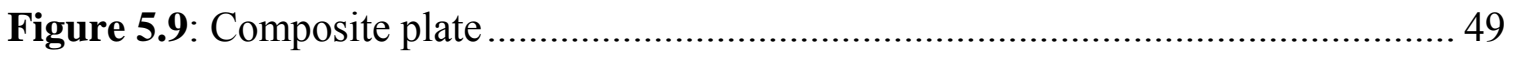

Figure 5.10: FE modeling and mesh for composite plate ………................................. 50

Figure 5.11: Load-deflection curves for analysis of composite plate .............................. 52

Figure 5.12: Load-deflection curve of RC beams strengthened with variable number of

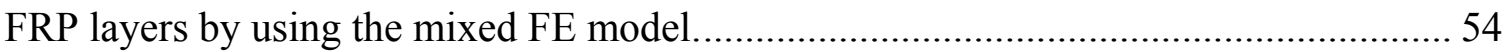


Figure 5.13: Load-deflection curve of RC beams strengthened with variable number of

FRP layers by using the combined model 55

Figure 5.14: Load-deflection curve of RC beams strengthened with variable number of FRP layers by using the displacement model. 55

Figure 5.15: Ultimate load ratio versus number of FRP layers for simply supported RC beam with and without FRP layers. 56

Figure 5.16: Maximum mid span deflection ratio versus number of FRP layers for simply supported RC beam with and without FRP layers. 57

Figure 5.17: Load-deflection curves of a simply-supported beam with varying length of FRP reinforcement by using the mixed FE model. 58

Figure 5.18: Load-deflection curves of a simply-supported beam with varying length of FRP reinforcement by using mixed element model by using the combined model 58

Figure 5.19: Load-deflection curves of a simply-supported beam with varying length of FRP reinforcement by using mixed element model by using the displacement model .... 59 Figure 5.20: Ultimate load ratio versus percent of FRP length for simply supported RC beam. 60

Figure 5.21: Maximum mid span deflection ratio versus percent of FRP length for simply supported RC beam.

Figure 5.22: Load-deflection curves of a simply-supported plate with four-ply FRP reinforcement having fibre-orientation angle of $[\beta] /[-\beta] /[\beta] /[-\beta]$ by using the mixed FE model. 
Figure 5.23: Load-deflection curves of a simply-supported plate with four-ply FRP reinforcement having fibre-orientation angle of $[\beta] /[-\beta] /[\beta] /[-\beta]$ by using the combined model.

Figure 5.24: Load-deflection curves of a simply-supported plate with four-ply FRP reinforcement having fibre-orientation angle of $[\beta] /[-\beta] /[\beta] /[-\beta]$ by using the displacement element model. 63

Figure 5.25: Ultimate load ratio of a simply-supported plate with externally reinforced

FRP laminates having different fibre-orientation angles of $[\beta] /[-\beta] /[\beta] /[-\beta]$ 64

Figure 5.26: Maximum mid span deflection ratio of a simply-supported plate with externally reinforced FRP laminates having different fibre-orientation angles of $[\beta] /[-\beta] /[\beta] /[-\beta]$ 65

Figure 5.27: Load-deflection curves for concrete plate strengthened with FRP for layers orientation: 0/0/0 and 0/90/0 by using the mixed FE model. 66 Figure 5.28: Load-deflection curves for concrete plate strengthened with FRP for layers orientation: $0 / 0 / 0$ and $0 / 90 / 0$ by using the combined model. 66

Figure 5.29: Load-deflection curves for concrete plate strengthened with FRP for layers orientation: $0 / 0 / 0$ and $0 / 90 / 0$ by using the displacement model.

Figure 5.30: Ultimate load ratio versus length-width ratio $(a / b)$ curves for two types of FRP layers orientation $(0 / 90 / 0$ and $0 / 0 / 0)$ 68

Figure 5.31: Maximum mid span deflection ratio versus length-width ratio $(a / b)$ curves for two types of FRP layers orientation $(0 / 90 / 0$ and $0 / 0 / 0)$ 68

Figure 5.32: Load-deflection curves for concrete plate strengthened with variable number of FRP layers by using the mixed model. 
Figure 5.33: Load-deflection curves for concrete plate strengthened with variable number of FRP layers by using the combined model.............................................. 70

Figure 5.34: Load-deflection curves for concrete plate strengthened with variable number of FRP layers by using the displacement model........................................ 70 Figure 5.35: Ultimate load ratio and maximum mid span deflection ratio versus number of FRP layers for concrete plate strengthen with FRP 71 


\section{Chapter I}

\section{Introduction}

\subsection{Objective}

The objective of this research work is to develop a three-dimensional (3D) nonlinear finite-element (FE) program by using efficient sophisticated FEs in order to accurately simulate nonlinear reinforced concrete $(\mathrm{RC})$ beams and plates with and without fibre reinforced polymer (FRP) reinforcement.

\subsection{Research Contribution}

Three 18-node elements were introduced. The first model was originally developed by Ramtekkar et al. (2002) and is modified in this study to incorporate material nonlinearities, smeared cracked concept, and smeared reinforcement. The second FE model is based purely on displacement field. Only displacement components are assumed throughout the thickness of the structure. Transverse stress is not considered in this model. In the third model, three nodal displacement components in the coordinate axis direction and three nodal transverse stress components are used as degrees-of-freedom (DOFs) per node on one surface where as three nodal displacement components in the coordinate axis direction per node are used as DOFs on the opposite surface. The overall intention for developing the last two element models is to reduce the computational time 
by using a fewer DOFs element in a less critical part of the structure, and a higher DOFs element in a more critical part of the structure (local-global strategies). Because the top and bottom surface of the structure are critical in nature, we are interested in both displacements and stresses in that area. We will combine all three models and refer as combined model. In the combined model, we use modified Ramtekkar's (Ramtekkar et al. 2002) mixed FE model in top and bottom surfaces, and in the rest of the area we use the displacement element model. Between these two different element model types, we use the transitional element model. This assembly overcomes the drawback of the Ramtekkar model by reducing the computational time. Then, the nonlinearity of concrete material is added by using Saenz's (Saenz and Luis 1964) stress-strain formulation in the FE framework. Steel is considered as a bilinear elasto-plastic material and smeared uniformly over the elements. Only unidirectional stress is considered along the direction of the bars. The new models are verified by analyzing RC beam strengthened with FRP, and a composite concrete plate. A set of numerical results are provided for future study.

\subsection{Scope}

A 3D FE analysis program is written in FORTRAN language for analyzing RC structures. Nonlinearity of concrete material is added in the code. With this FE tool, it is possible to perform layer-wise analysis of RC beams and plates, composite structures like RC beams and plates strengthened with FRP sheet on the bottom, laminated plates etc. The geometric nonlinearity and bond-slip phenomena are not considered in this present model. From the analysis, load-deflection, load-stress, stress-strain, and failure mode information of the structures can be obtained. As the transverse stresses are considered as 
nodal unknown variables, we get the transverse stresses directly from the elastic solution. This means the point-wise recalculation by integrating the equilibrium equation does not need to be performed.

\subsection{Significance}

The mechanical behavior of composite concrete structures is difficult to analyze by an analytical model, as it becomes increasingly complex to consider the nonlinear behavior of the composite material. FE analysis is an efficient solution to overcome the problems. In this research, 3D 18-node layer wise mixed FE models are used for nonlinear analysis of concrete structures. Although the model has the benefit of obtaining the transverse stress directly from the elastic solution, it is often computationally very expensive. To

overcome this draw back, local-global strategies were introduced by developing the combined FE model. 


\section{Chapter II}

\section{Literature Review}

\subsection{Introduction}

FE has been an important tool in the analysis of both simple concrete structures, such as RC beam, column, slab, etc., and complex concrete structures, such as offshore wall, deep beam, shear wall, FRP strengthened RC structures etc. The development of large memory capacity computers allows the analysis of more complex concrete structures with both material and geometric nonlinearities using FE with significant amount of accuracy. Considerable amount of work has been reported in recent literature on the development and application of finite-element models for RC structures

\subsection{Literature Background}

Al-Taan and Ezzadeen (1995) developed a numerical procedure based on the FE method for the geometric and material nonlinear analysis of RC members. A frame element with a composite layer system was used to model the structure. For the nonlinear solution, an incremental-iterative technique based on Newton-Raphson's method was employed. Only the displacement components were considered as DOFs where a parabolic interpolation 
function for axial displacement, and cubic interpolation function for other displacement was used. The numerical solutions of a number of reinforced fibrous concrete beams were compared with published experimental test results and showed a good agreement. To see the monotonic behavior of RC beams and beam-column assemblages, Kwak and Filippou (1997) introduced a FE model. In this model, concrete and reinforced bars were represented by separate material models. Another model was used between reinforcement bars and concrete to describe the behavior of the composite RC material. The concrete was modeled by eight-node elements with $3 \times 3$ Gauss integration. The reinforcement was modeled by the two-node truss element. Between these two, a bond link element was used. Improved cracking criteria derived from fracture mechanics principles was used as the basis for developing this smeared finite- element model. Later Kwak and Kim (2002) introduced a new FE model for beams based on the moment-curvature relations of RC sections including the bond-slip and tension softening branch. They used the well established Timoshenko beam theory in the analysis. Bhatt and Kader (1998) presented a 2D parabolic isoparametric quadrilateral FE based on the tangent stiffening method for predicting the shear strength of RC rectangular beams. Wang and Hsu (2001) developed the FE analysis program FEAPRC from FEAP by introducing a new set of constitutive models for analyzing RC beams. The fixed-angle softened-truss model (FA-STM), which assumes cracks develop along the direction of principal compressive stresses applied at initial cracking, and that cracks are fixed at this angle thereafter, was used in the new set of constitutive models. The numerical results for beams, panels and framed shear walls were compared with the experimental results. Recently, Abbas et al (2004) presented a 3D nonlinear FE model for RC structures under impact loading. They used an elasto 
visco-plastic two surface model in the FE. The reinforcement was smeared as a two dimensional membrane of equivalent thickness. The layer was assumed to resist only the axial stresses in the direction of the bars. A simply supported beam with dynamic point loading was considered for numerical verification. Then experimental and numerical analyses were done on a circular plate with impact loading.

Considerable work has been reported in recent literature relating to the development and application of FE procedures for RC slabs, plates, panels, and shells. Vecchio (1989) developed a nonlinear FE procedure to predict the response of RC structures. A smeared crack approach was included for concrete. A secant stiffness approach was used in the procedure incorporating the constitutive relations for concrete. Only low order FE analysis was used in the procedure. Numerical results were verified with the experimental data for square panels, deep beams and perforated walls. Later Polak and Vecchio (1993) modified the FE model for analysis of RC shell structures. In this adapted model, a 42 DOFs heterosis type degenerate isoparametric quadrilateral element was developed using a layered-element formulation. During the same time, Vecchio et al. (1993) investigated the thermal load effect on RC slabs by nonlinear FE analysis. In the FE analysis they considered the concrete tension stiffening effect. Hu and Schnobrich (1990) derived a set of constitutive equations suitable for incremental FE analysis, and developed a nonlinear material model for cracked RC structures. This model was able to describe the postcracking behavior of RC structures. Reinforcement was treated as an equivalent uniaxial layered material placed at the depth of the centerline of the bar. For concrete nonlinear behavior, Saenz's (Saenz and Luis, 1964) stress-strain curve was used. The model 
considered smeared crack representation, rotating crack approach, tension stiffening, stress degrading effect for concrete parallel to the crack direction, and shear retention of concrete on the crack surface. The model was verified against a set of experimental data of RC panels.

Cerioni and Mingardi (1996) introduced a FE model for analysis of a RC foundation plate, where the RC plate was modeled with materially nonlinear layered FEs. Jiang and Mirza (1997) developed a rational numerical model for the nonlinear analysis of RC slabs. Material nonlinearities for both concrete and steel were considered. In the model, a RC slab was first divided into a number of composite elements, and each of the composite elements was then assembled into a single concrete plate element and a small number of steel beam elements. Kirchhoff thin plate theory was used in the plate element. Very recently, Phuvoravan and Sotelino (2005) presented a FE model for nonlinear analysis of RC slabs that combined a four node Kirchhoff shell element for concrete with two-node Euler beam elements for the steel reinforcement bars. A rigid link was considered between these two element types. This model takes care of the exact location of steel reinforcement bars.

Over the last decade, civil engineers have become very interested in the use of FRP due to its positive characteristics over the steel reinforcement. A large number of experiments on the topic were done in this time period. Many researchers also focus on the development of finite-element models for the analysis of FRP RC structures. Shahawy et al. (1996) used a 2-dimensional non-linear FE computer program for analyzing beams 
strengthened with carbon fiber reinforced plastic (CFRP). Nitereka and Neale (1999) developed a nonlinear FE layered model to predict the complete load-deformation response of RC beams strengthened in flexure by composite materials. This model considered both material and geometric nonlinearities. The numerical results confirmed the effectiveness of using externally bonded fiber reinforced composite laminates as a viable technique for strengthening concrete beams in flexure. Ferreira et al. (2001) presented an FE model for analyzing RC beams with FRP re-bars. They used the first order shear deformation theory in the analysis of concrete shells reinforced with internal composite unidirectional re-bars. The concrete was modeled with smeared crack concepts. A perfect plastic and a strain-hardening plasticity approach were used to model the compressive behavior of the concrete. A dual criterion for yielding and crushing in terms of stresses and strains was considered. For tension in concrete, the influence that the cracked concrete zones had on the structural behavior was considered. Smeared crack model was used. The response of concrete under tensile stresses was assumed to be linear elastic until the fracture surface was reached. A sudden and total release of the normal stress in the affected direction, or its gradual relaxation according to the tensionstiffening diagram was adopted after cracking had occurred. Cracking in two principal stress directions in the plane of the structure was considered. In this model, the reinforcing bars were modeled as layers of equivalent thickness, having strength and stiffness characteristics in the bar direction only. In tension, it is elastic up to failure. The FE was implemented in the degenerated shell element by considering the theory discussed above. The model was verified against the experimental data for simply supported concrete beams reinforced with composites re-bars. A good agreement 
between the experimental and numerical results for beams was obtained. Supaviriyakit et al. (2004) developed a FE model to analyze RC beams strengthened with externally bonded FRP plates. The concrete and reinforcing steel were modeled together by 8 -node 2D isoparametric plane stress $\mathrm{RC}$ elements. The $\mathrm{RC}$ element considered the effect of cracks and reinforcing steel as being smeared over the entire element. Perfect compatibility between cracked concrete and reinforcing steel was considered. The FRP plate was modeled as a 2D elasto-brittle element. As the epoxy is usually much stronger than the concrete, it was assumed a full compatibility between FRP and concrete. The model was verified against the experimental data of load-deformation, load capacity and failure mode of the FRP strengthen beam. Fanning (2001) used commercial software ANSYS to analyze reinforced and post-tensioned concrete beams. Hu et al. (2004) introduced a proper constitutive model to simulate nonlinear behavior of RC beams strengthened by FRP. They used the FE program ABAQUS. Reliable constitutive models for steel reinforcing bars and concrete are available in the material library. Only the nonlinearity of the FRP was added to ABAQUS as an external subroutine by the researchers. To model the nonlinear in-plane shear behavior, the nonlinear stress-strain relation for a composite lamina suggested by Hahn and Tsai (1973) was adopted. Tsai and $\mathrm{Wu}$ (1971) failure criteria were also used in the model. During the FE analysis, a perfect bonding between FRP and the concrete was assumed. The model was verified for load-deflection data of RC beams strengthened by FRP. 


\section{Chapter III}

\section{Proposed Models}

\subsection{Introduction}

Three 18-node 3D FE models have been introduced in the present formulation consisting the followings: 1) both displacement and transverse stress as nodal DOFs, 2) only displacement as nodal DOFs, and 3) only displacement in one side and both displacement and transverse stress on opposite side as nodal DOFs, by using the Hamilton's principle. In the first model developed by Ramtekkar et al (2002), for analyzing composite laminated plates, the transverse stress quantities $\left(\tau_{x z}, \tau_{y z}\right.$ and $\sigma_{z}$ where $z$ is the thickness direction) had been invoked from the assumed displacement fields by using the concept of 3D theory of elasticity. Because the transverse stress components were the nodal DOFs in the present FE model, their computations are not required the integration of equilibrium equations which otherwise reduces the accuracy in the determination of these stresses. Moreover, it can appropriately model a composite laminated member of any number of lay-ups of different materials as it satisfies exactly, the requirements of through thickness continuity of transverse stress and displacement fields.

Drawback of such 3-dimensional mixed FE models is often attributed to their being computationally expensive. To avoid this expense, this study introduced two models. One consists only the displacement as nodal DOFs and the other consists the displacement on one side, and displacement and transverse stress on the opposite side as nodal DOFs. In 
the analysis of composite structures, combination of three models can eliminate the computational expense. Furthermore, due to the advent of high-speed computers, this drawback can be minimized to a great extent.

\subsection{FE Models}

In the development of FE models in this study, an anisotropic plate consisting of $N$ orthotropic layers is considered, as shown in Figure 3.1(a). The plate has been discretized in to a number of 3D elements. Each element lies within a layer and no element crosses the interface between any two successive layers. 


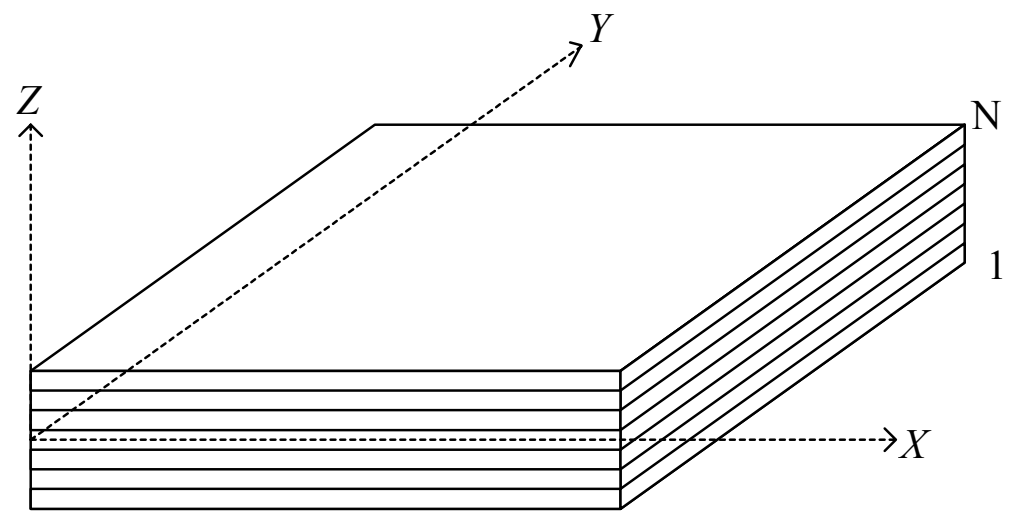

(a)

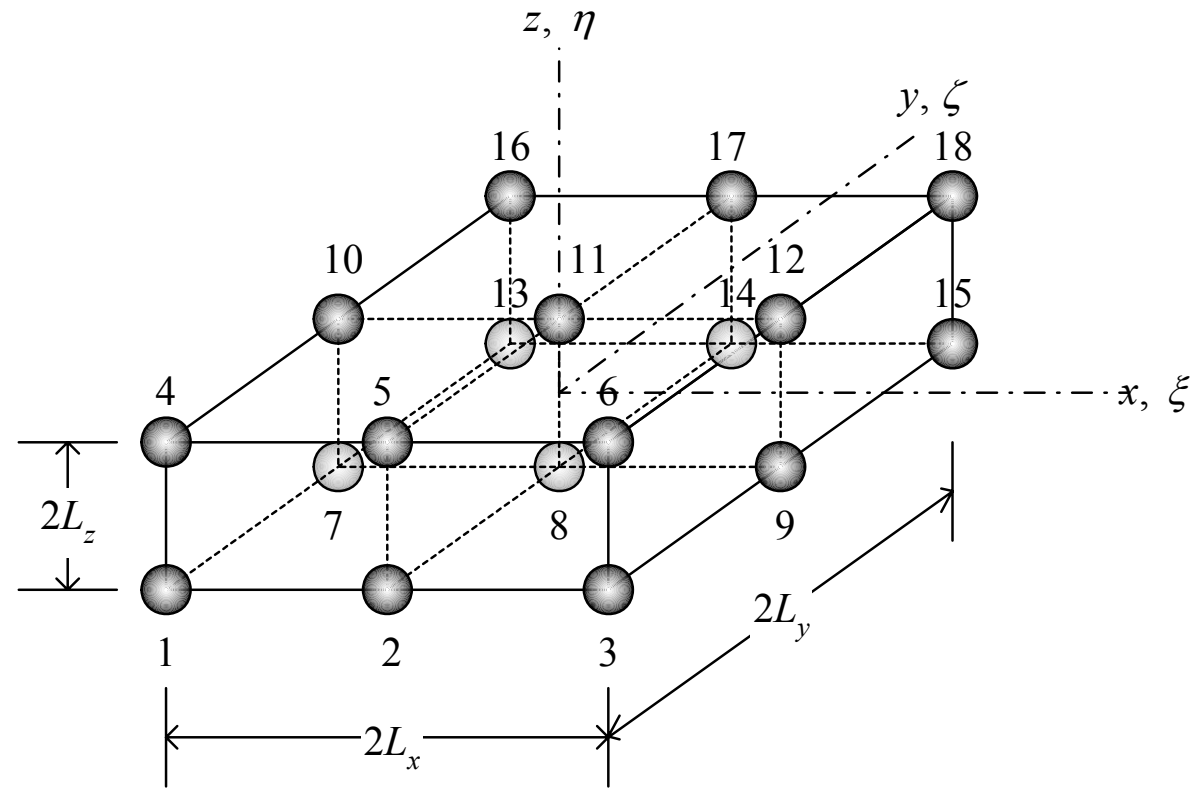

(b)

Figure 3.1: (a) Laminated plate and global reference axes and (b) Geometry of 18-node FE and local reference axes 


\subsubsection{Mixed FE Model}

This section presents an 18-node 3D mixed FE model shown in Figure 3.1(b) developed by Ramtekkar et al (2002). The displacement fields $u(x, y, z), v(x, y, z)$ and $w(x, y, z)$ are considered to have quadratic variation along the plane of the plate and cubic variation in transverse direction. The displacement fields can be expressed as,

$$
\begin{gathered}
u_{k}(x, y, z)=\sum_{i=1}^{3} \sum_{j=1}^{3} g_{i} h_{j} a_{0 i j k}+z \sum_{i=1}^{3} \sum_{j=1}^{3} g_{i} h_{j} a_{1 i j k}+z^{2} \sum_{i=1}^{3} \sum_{j=1}^{3} g_{i} h_{j} a_{2 i j k}+z^{3} \sum_{i=1}^{3} \sum_{j=1}^{3} g_{i} h_{j} a_{3 i j k} \\
k=1,2,3
\end{gathered}
$$

where

$$
\begin{aligned}
& g_{1}=\frac{\xi}{2}(\xi-1), g_{2}=1-\xi^{2}, g_{3}=\frac{\xi}{2}(1+\xi), \quad \xi=x / L_{x} \\
& h_{1}=\frac{\delta}{2}(\delta-1), \quad h_{2}=1-\delta^{2}, \quad h_{3}=\frac{\delta}{2}(1+\delta), \quad \delta=y / L_{y}
\end{aligned}
$$

and

$$
u_{1}=u \quad u_{2}=v \quad u_{3}=w
$$

Further, the generalized co-ordinates $a_{m i j k}(m=0,1,2,3 ; i, j, k=1,2,3)$ are functions of $z$ and the elements' coordinate axes $x, y, z$ are parallel to the global coordinate $X, Y, Z$, respectively.

It may be noted that the variation of displacement fields has been assumed to be cubic along the thickness of element although there are only two nodes along ' $z$ ' axis of an element (Figure 3.1(b)). Such a variation is required for invoking transverse stress components $\sigma_{z}, \tau_{x z}$ and $\tau_{y z}$ as the nodal DOFs in the present formulation. Further, it also ensures parabolic variation of transverse stresses through the thickness of an element. 


\subsubsection{Constitutive Equations}

Each layer in the composite has been considered to be in a 3D state of stress so that the constitutive relation for a typical $i^{\text {th }}$ layer with reference to the material local coordinate axes $(1,2,3)$ can be shown to be,

$$
\left\{\begin{array}{l}
\sigma_{1} \\
\sigma_{2} \\
\sigma_{3} \\
\tau_{12} \\
\tau_{13} \\
\tau_{23}
\end{array}\right\}^{i}=\left[\begin{array}{cccccc}
C_{11} & C_{12} & C_{13} & 0 & 0 & 0 \\
& C_{22} & C_{23} & 0 & 0 & 0 \\
& & C_{33} & 0 & 0 & 0 \\
\text { Sym. } & & & C_{44} & 0 & 0 \\
& & & & C_{55} & 0 \\
& & & & & C_{66}
\end{array}\right\}^{i}\left\{\begin{array}{c}
\epsilon_{1} \\
\epsilon_{2} \\
\epsilon_{3} \\
\gamma_{12} \\
\gamma_{13} \\
\gamma_{23}
\end{array}\right\}^{i}
$$

where $\left(\sigma_{1}, \sigma_{2}, \sigma_{3}, \tau_{12}, \tau_{13}, \tau_{23}\right)$ are the stresses and $\left(\epsilon_{1}, \epsilon_{2}, \epsilon_{3}, \gamma_{12}, \gamma_{13}, \gamma_{23}\right)$ are the linear strain components referred to the layer coordinates $(1,2,3)$ and $C_{m n}$ 's $(m, n=1, \ldots$, 6) are the elastic constants of the $i^{\text {th }}$ layer.

The stress-strain relations for the $i^{\text {th }}$ layer can be written in the global coordinates $X, Y, Z$ as,

$$
\{\sigma\}=[D]\{\in\}
$$

Here

$$
\{\sigma\}=\left[\begin{array}{llllll}
\sigma_{x} & \sigma_{y} & \sigma_{z} & \tau_{x y} & \tau_{x z} & \tau_{y z}
\end{array}\right]^{T}
$$

and

$$
\{\in\}=\left[\begin{array}{llllll}
\epsilon_{x} & \epsilon_{y} & \epsilon_{z} & \gamma_{x y} & \gamma_{x z} & \gamma_{y z}
\end{array}\right]^{T}
$$

are the stress and strain vectors with respect to the layer axes and

$$
[D]=\left[\begin{array}{c|c}
D_{i j} & 0 \\
\hline 0 & D_{l m}
\end{array}\right] \quad \begin{aligned}
& i, j=1,2,3,4 \\
& l, m=5,6
\end{aligned}
$$

are the 3D elasticity constants for $i^{\text {th }}$ layer with respect to the global reference axes, (Figure 3.1(a)). 


\subsubsection{FE Formulation}

The transverse stresses can be obtained from the constitutive Eq. (3.6a) and straindisplacement relations as,

$$
\begin{gathered}
\left\{\begin{array}{l}
\tau_{x z} \\
\tau_{y z}
\end{array}\right\}=\left[\begin{array}{ll}
D_{55} & D_{56} \\
D_{56} & D_{66}
\end{array}\right]\left\{\begin{array}{l}
\gamma_{x z} \\
\gamma_{y z}
\end{array}\right\}=\left[\begin{array}{ll}
D_{55} & D_{56} \\
D_{56} & D_{66}
\end{array}\right]\left\{\begin{array}{l}
\frac{\partial u}{\partial z}+\frac{\partial w}{\partial x} \\
\frac{\partial v}{\partial z}+\frac{\partial w}{\partial y}
\end{array}\right\} \\
\sigma_{z}=D_{13} \in_{x}+D_{23} \in_{y}+D_{33} \in_{z}+D_{34} \gamma_{x y}=D_{13} \frac{\partial u}{\partial x}+D_{23} \frac{\partial v}{\partial y}+D_{33} \frac{\partial w}{\partial z}+D_{34}\left(\frac{\partial u}{\partial y}+\frac{\partial v}{\partial x}\right)
\end{gathered}
$$

From Eq. (3.7), following equations can be obtained

$$
\begin{aligned}
& \frac{\partial u}{\partial z}=\frac{1}{\Delta}\left[D_{66} \tau_{x z}-D_{56} \tau_{y z}\right]-\frac{\partial w}{\partial x} \\
& \frac{\partial v}{\partial z}=-\frac{1}{\Delta}\left[D_{56} \tau_{x z}-D_{55} \tau_{y z}\right]-\frac{\partial w}{\partial y}
\end{aligned}
$$

where

$$
\Delta=D_{55} D_{66}-D_{56}^{2}
$$

Similarly Eq. (3.8) can be rewritten as

$$
\frac{\partial w}{\partial z}=\frac{1}{D_{33}}\left[\sigma_{z}-D_{13} \frac{\partial u}{\partial x}-D_{23} \frac{\partial v}{\partial y}-D_{34}\left(\frac{\partial u}{\partial y}+\frac{\partial v}{\partial x}\right)\right]
$$

The displacement fields $u(x, y, z), v(x, y, z)$ and $w(x, y, z)$ expressed in Eq. (3.1), can now be further expressed in terms of nodal variables by using Eqs. (3.9), (3.10) and (3.12) respectively, as

$$
u_{k}(x, y, z)=\sum_{n=1}^{18} g_{i} h_{j}\left(f_{q} u_{k n}+f_{p} \widehat{u}_{k n}\right)
$$


where ' $n$ ' is the node number in the $3 \mathrm{D}$ element, shown in the Figure 3.1(b). $u_{k n}(k=1,2$, 3 and $n=1,2, \ldots, 18)$ are the nodal displacement variables whereas $\widehat{u}_{k n}$ contains the nodal transverse stress variables.

Here, $i=1,2,3$ for the nodes with $\xi=-1, \xi=0$ and $\xi=1$, respectively.

$j=1,2,3$ for the nodes with $\delta=-1, \delta=0$ and $\delta=1$, respectively.

$q=1,2$ and $p=3,4$ for the nodes with $\eta=-1$ and $\eta=1$, respectively.

$$
\begin{gathered}
f_{1}=\frac{1}{4}\left(2-3 \eta+\eta^{3}\right) \\
f_{2}=\frac{1}{4}\left(2+3 \eta-\eta^{3}\right) \\
f_{3}=\frac{L_{z}}{4}\left(1-\eta-\eta^{2}+\eta^{3}\right) \\
f_{4}=\frac{L_{z}}{4}\left(-1-\eta+\eta^{2}+\eta^{3}\right) \\
\eta=z / L_{z} ; \quad \widehat{u}_{k n}=\frac{\partial u_{k n}}{\partial z}
\end{gathered}
$$

Finally Eq. (3.13) yields the displacement fields $u(x, y, z), v(x, y, z)$ and $w(x, y, z)$ in terms of the nodal DOFs as

$$
\{u\}=[N]\{q\}
$$

where

$$
\begin{gathered}
\{u\}=\left[\begin{array}{llll}
u & v & w
\end{array}\right]^{T} \\
{[N]=\left[\begin{array}{llllll}
\underline{N}_{1} & \underline{N}_{2} & \cdots & \underline{N}_{n} & \cdots & \underline{N}_{18}
\end{array}\right]} \\
\{q\}=\left[\begin{array}{llllll}
q_{1}^{T} & \underline{q}_{2}^{T} & \cdots & \underline{\sim}_{n}^{T} & \cdots & q_{18}^{T}
\end{array}\right]^{T} \\
\left\{q_{n}\right\}=\left[\begin{array}{lllllll}
u_{n} & v_{n} & w_{n} & \left(\tau_{x z}\right)_{n} & \left(\tau_{y z}\right)_{n} & \left(\sigma_{z}\right)_{n}
\end{array}\right]^{T}
\end{gathered}
$$

and 


$\left[\underline{N}_{n}\right]=\left[\begin{array}{l|l|l|l|l|l}g_{i} h_{j} f_{q} & 0 & -g_{i}^{\prime} h_{j} f_{p} & \frac{D_{66}}{\Delta} g_{i} h_{j} f_{p} & -\frac{D_{56}}{\Delta} g_{i} h_{j} f_{p} & 0 \\ \hline 0 & g_{i} h_{j} f_{q} & -g_{i} h_{j}^{*} f_{p} & -\frac{D_{56}}{\Delta} g_{i} h_{j} f_{p} & \frac{D_{55}}{\Delta} g_{i} h_{j} f_{p} & 0 \\ \hline-\frac{D_{13}}{D_{33}} g_{i}^{\prime} h_{j} f_{p} & -\frac{D_{34}}{D_{33}} g_{i}^{\prime} h_{j} f_{p} & & & & \\ -\frac{D_{34}}{D_{33}} g_{i} h_{j}^{*} f_{p} & -\frac{D_{23}}{D_{33}} g_{i} h_{j}^{*} f_{p} & & 0 & 0 & \frac{1}{D_{33}} g_{i} h_{j} f_{p}\end{array}\right]$

$i, j, q, p$ and $n$ are same as described in Eq. (3.14). Furthermore,

$$
g_{i}^{\prime}=\frac{\partial g_{i}}{\partial x} \text { and } h_{j}^{*}=\frac{\partial h_{j}}{\partial y}
$$

The total potential energy $\Pi$ of the layer can be obtained from

$$
\Pi=\frac{1}{2} \int_{V}\{\in\}^{T}\{\sigma\} d V-\int_{V}\{q\}^{T}\left\{p_{b}\right\} d V-\int_{\Sigma}\{q\}^{T}\left\{p_{t}\right\} d s
$$

where $\left\{p_{b}\right\}$ is the body force vector per unit volume and $\left\{p_{t}\right\}$ is the traction load vector acting on any surface of the composite plate. Here $\Sigma$ is a surface of the element subjected to traction forces.

The strain vector $\{\in\}$ and the stress vector $\{\sigma\}$ can be expressed as

$$
\begin{gathered}
\{\in\}=[B]\{q\} \\
\{\sigma\}=[D][B]\{q\}
\end{gathered}
$$

where

$$
[B]=[R][N]
$$




$$
[R]=\left[\begin{array}{cccccc}
\frac{\partial}{\partial x} & 0 & 0 & \frac{\partial}{\partial y} & \frac{\partial}{\partial z} & 0 \\
0 & \frac{\partial}{\partial y} & 0 & \frac{\partial}{\partial x} & 0 & \frac{\partial}{\partial z} \\
0 & 0 & \frac{\partial}{\partial z} & 0 & \frac{\partial}{\partial x} & \frac{\partial}{\partial y}
\end{array}\right]^{T}
$$

Further,

$$
[B]=\left[\begin{array}{llllll}
\underline{B}_{1} & \underline{B}_{2} & \ldots & \underline{B}_{n} & \ldots & \underline{B}_{18}
\end{array}\right]
$$

\begin{tabular}{|c|c|c|c|c|c|c|}
\hline \multirow{2}{*}{\multicolumn{2}{|c|}{$g_{i}^{\prime} h_{j} f_{q}$}} & 0 & $-g_{i}^{\prime \prime} h_{j} f_{p}$ & $\frac{D_{66}}{\Delta} g_{i}^{\prime} h_{j} f_{p}$ & $-\frac{D_{56}}{\Delta} g_{i}^{\prime} h_{j} f_{p}$ & 0 \\
\hline & & $g_{i} h_{j}^{*} f_{q}$ & $-g_{i} h_{j}^{* *} f_{p}$ & $-\frac{D_{56}}{\Delta} g_{i} h_{j}^{*} f_{p}$ & $\frac{D_{55}}{\Delta} g_{i} h_{j}^{*} f_{p}$ & 0 \\
\hline \multirow{4}{*}[\underline{B}_{n}]{$=$} & $\begin{array}{l}-\frac{D_{13}}{D_{33}} g_{i}^{\prime} h_{j} \widehat{f}_{p} \\
-\frac{D_{34}}{D_{33}} g_{i} h_{j}^{*} \widehat{f}_{p}\end{array}$ & $\begin{array}{l}-\frac{D_{34}}{D_{33}} g_{i}^{\prime} h_{j} \widehat{f}_{p} \\
-\frac{D_{23}}{D_{33}} g_{i} h_{j}^{*} \hat{f}_{p}\end{array}$ & $g_{i} h_{j} \widehat{f}_{q}$ & 0 & 0 & $\frac{1}{D_{33}} g_{i} h_{j} \hat{f}_{p}$ \\
\hline & $g_{i} h_{j}^{*} f_{q}$ & $g_{i}^{\prime} h_{j} f_{q}$ & $-2 g_{i}^{\prime} h_{j}^{*} f_{q}$ & $\begin{array}{l}\frac{D_{66}}{\Delta} g_{i} h_{j}^{*} f_{p} \\
-\frac{D_{56}}{\Delta} g_{i}^{\prime} h_{j} f_{p}\end{array}$ & $\begin{array}{l}-\frac{D_{56}}{\Delta} g_{i} h_{j}^{*} f_{p} \\
+\frac{D_{55}}{\Delta} g_{i}^{\prime} h_{j} f_{p}\end{array}$ & 0 \\
\hline & $\begin{array}{l}g_{i} h_{j} \widehat{f}_{q} \\
-\frac{D_{13}}{D_{33}} g_{i}^{\prime \prime} h_{j} \widehat{f}_{p} \\
-\frac{D_{34}}{D_{33}} g_{i}^{\prime} h_{j}^{*} \widehat{f}_{p}\end{array}$ & $\begin{array}{l}-\frac{D_{34}}{D_{33}} g_{i}^{\prime \prime} h_{j} \widehat{f}_{p} \\
-\frac{D_{23}}{D_{33}} g_{i}^{\prime} h_{j}^{*} \widehat{f}_{p}\end{array}$ & $\begin{array}{l}-g_{i}^{\prime} h_{j} \widehat{f}_{p} \\
+g_{i}^{\prime} h_{j} f_{q}\end{array}$ & $\frac{D_{66}}{\Delta} g_{i} h_{j} \widehat{f}_{p}$ & $-\frac{D_{56}}{\Delta} g_{i} h_{j} \widehat{f}_{p}$ & $\frac{1}{D_{33}} g_{i}^{\prime} h_{j} f_{p}$ \\
\hline & $\begin{array}{l}-\frac{D_{13}}{D_{33}} g_{i}^{\prime} h_{j}^{*} f_{p} \\
-\frac{D_{34}}{D_{33}} g_{i} h_{j}^{* *} f_{p}\end{array}$ & $\begin{array}{l}g_{i} h_{j} \hat{f}_{q} \\
-\frac{D_{34}}{D_{33}} g_{i}^{\prime} h_{j}^{*} f_{p} \\
-\frac{D_{23}}{D_{33}} g_{i} h_{j}^{* *} f_{p}\end{array}$ & $\begin{array}{l}-g_{i} h_{j}^{*} \widehat{f}_{p} \\
+g_{i} h_{j}^{*} f_{q}\end{array}$ & $-\frac{D_{56}}{\Delta} g_{i} h_{j} \hat{f}_{p}$ & $\frac{D_{55}}{\Delta} g_{i} h_{j} \widehat{f}_{p}$ & $\frac{1}{D_{33}} g_{i} h_{j}^{*} f_{p}$ \\
\hline
\end{tabular}

where

Here $\quad g_{i}^{\prime \prime}=\frac{\partial^{2} g_{i}}{\partial x^{2}} ; \quad h_{j}^{* *}=\frac{\partial^{2} h_{j}}{\partial y^{2}} ; \quad \hat{f}_{q}=\frac{\partial f_{q}}{\partial z} ;$ and $\quad \hat{f}_{p}=\frac{\partial f_{p}}{\partial z}$ 
Minimization of the total potential energy functional, Eq. (3.17), yields the element property matrix $[K]^{e}$ and the element influence vector $\{f\}^{e}$ as

$$
\begin{aligned}
& {[K]^{e}=\int_{-L_{X}}^{L_{X}} \int_{-L_{Y}}^{L_{Y}} \int_{-L_{Z}}^{L_{Z}}[B]^{T}[D][B] d x d y d z} \\
& {[f]^{e}=\int_{-L_{X}}^{L_{X}} \int_{-L_{Y}}^{L_{Y}} \int_{-L_{Z}}^{L_{Z}}[N]^{T}\left\{p_{b}\right\} d x d y d z+\iint_{\Sigma}[N]^{T}\left\{p_{t}\right\} d s}
\end{aligned}
$$

The global equation can be obtained in the following form after assembly:

$$
[K]\{Q\}=\{F\}
$$

where $[K],\{Q\}$, and $\{F\}$ are respectively, the global property matrix, the global DOFs vector, and the global influence vector. They can be defined as

$$
[K]=\sum_{e}[K]_{e} ; \quad\{Q\}=\sum_{e}\{q\} ;\{F\}=\sum_{e} p_{b}+\sum_{e} p_{t}
$$

\subsubsection{Displacement FE Model}

A new model with 18-node 3D mixed FE as shown in Figure 3.1(b) has been developed. In this case, the transverse stress quantities $\left(\tau_{x z}, \tau_{y z}\right.$ and $\sigma_{z}$ where $z$ is the thickness direction) are not invoked as nodal DOFs. Continuity of displacement fields $u(x, y, z)$, $v(x, y, z)$ and $w(x, y, z)$ has been enforced through the thickness direction only. Also, it is considered a linear variation of the displacement fields along the plane of the plate and the transverse direction. The displacement fields are expressed as

$u_{k}(x, y, z)=\sum_{i=1}^{3} \sum_{j=1}^{3} g_{i} h_{j} a_{0 i j k}+z \sum_{i=1}^{3} \sum_{j=1}^{3} g_{i} h_{j} a_{1 i j k}$

where $k=1,2,3$ 


\subsubsection{Constitutive Equations}

Each layer in the composite has been considered to be in a 3D state of stress so that the constitutive relation for a typical $i^{\text {th }}$ layer with reference to the material coordinate axes $(1,2,3)$ can be shown to be,

$$
\left\{\begin{array}{l}
\sigma_{1} \\
\sigma_{2} \\
\sigma_{3}
\end{array}\right\}^{i}=\left[\begin{array}{ccc}
C_{11} & C_{12} & C_{13} \\
& C_{22} & C_{23} \\
S y m & & C_{33}
\end{array}\right]^{i}\left\{\begin{array}{c}
\epsilon_{1} \\
\epsilon_{2} \\
\epsilon_{3}
\end{array}\right\}^{i}
$$

where $\left(\sigma_{1}, \sigma_{2}, \sigma_{3}\right)$ are the stresses and $\left(\epsilon_{1}, \epsilon_{2}, \epsilon_{3}\right)$ are the linear strain components referred to the layer coordinates $(1,2,3)$ and $C_{m n}$ 's $(m, n=1, \ldots, 3)$ are the elastic constants of the $i^{\text {th }}$ layer.

The stress-strain relations for the $i^{\text {th }}$ layer is the same as in Eq. (3.6a) in the global coordinates $X, Y, Z$ with the exception that in this case

$$
\{\sigma\}=\left[\begin{array}{lll}
\sigma_{x} & \sigma_{y} & \sigma_{z}
\end{array}\right]^{T}
$$

and

$$
\{\in\}=\left[\in_{x} \quad \in_{y} \quad \in_{z}\right]^{T}
$$

\subsubsection{FE Formulation}

The displacement fields $u(x, y, z), v(x, y, z)$ and $w(x, y, z)$ expressed in Eq. (3.29), can now be further expressed in terms of nodal variables as

$u_{k}(x, y, z)=\sum_{n=1}^{18} g_{i} h_{j}\left(f_{q} u_{k n}\right)$

where ' $n$ ' is the node number in the 3D element, shown in the Figure 3.1(b). $u_{k n}(k=1$, $2,3$ and $n=1,2, \ldots, 18)$ are the nodal displacement variables. 
Here, $i=1,2,3$ for the nodes with $\xi=-1, \xi=0$ and $\xi=1$, respectively.

$j=1,2,3$ for the nodes with $\delta=-1, \delta=0$ and $\delta=1$, respectively.

$q=1,2$ for the nodes with $\eta=-1$ and $\eta=1$, respectively.

$f_{1}=\frac{1}{2}(1-\eta) ; f_{2}=\frac{1}{2}(1+\eta)$

The displacement fields $u(x, y, z), v(x, y, z)$ and $w(x, y, z)$ in terms of the nodal DOFs are:

$$
\{u\}=[N]\{q\}
$$

where

$$
\begin{gathered}
\{u\}=\left[\begin{array}{llll}
u & v & w
\end{array}\right]^{T} \\
{[N]=\left[\begin{array}{llllll}
\underline{N}_{1} & \underline{N}_{2} & \cdots & \underline{N}_{n} & \cdots & \underline{N}_{18}
\end{array}\right]} \\
\{q\}=\left[\begin{array}{llllll}
\underline{q}_{1}^{T} & \underline{q}_{2}^{T} & \cdots & \underline{q}_{n}^{T} & \cdots & \underline{q}_{18}^{T}
\end{array}\right]^{T} \\
\left\{q_{n}\right\}=\left[\begin{array}{llll}
u_{n} & v_{n} & w_{n}
\end{array}\right]^{T}
\end{gathered}
$$

and

$$
\left[\begin{array}{c}
N_{n} \\
-{ }_{n}
\end{array}\right]=\left[\begin{array}{c:c:c}
g_{i} h_{j} f_{q} & 0 & 0 \\
\hdashline 0 & g_{i} h_{j} f_{q} & 0 \\
\hdashline 0 & 0 & g_{i} h_{j} f_{q}
\end{array}\right]
$$




\subsubsection{Transitional FE Model}

This new variation of 18-node 3D mixed FE model shown in Figure 3.1(b) has been developed by invoking the displacement and the transverse stress quantities as upper surface nodal DOFs and only displacement as lower surface nodal DOFs. This model is developed to serve as a connector between stress-displacement continuity element and displacement continuity element. The displacement fields are expressed as

$u_{k}(x, y, z)=\sum_{i=1}^{3} \sum_{j=1}^{3} g_{i} h_{j} a_{0 i j k}+z \sum_{i=1}^{3} \sum_{j=1}^{3} g_{i} h_{j} a_{1 i j k}+z^{2} \sum_{i=1}^{3} \sum_{j=1}^{3} g_{i} h_{j} a_{2 i j k}$

where $k=1,2,3$.

\subsubsection{Constitutive Equations}

The constitutive relation for a typical $i^{\text {th }}$ layer with reference to the material coordinate axes $(1,2,3)$ is same as used in the first model (Eq. 3.5, 3.6a, 3.6b,3.6c, and 3.6d).

\subsubsection{FE Formulation}

For the upper surface nodes, the transverse stresses can be obtained from the constitutive Eq. (3.6a) and strain-displacement relations Eq. (3.7). The displacement fields $u(x, y, z)$, $v(x, y, z)$ and $w(x, y, z)$ expressed in Eqs. (3.35) can be represented by the Eqs. (3.15a), respectively.

In this case, however, $n$ is the node number in the $3 \mathrm{D}$ element, shown in the Figure 3.1(b). $u_{k n}(k=1,2,3$ and $n=1,2, \ldots, 18)$ are the nodal displacement variables in both 
lower and upper surfaces whereas $\hat{u}_{k n}$ contains the nodal transverse stress variables in upper surface only.

Here, $i=1,2,3$ for the nodes with $\xi=-1, \xi=0$ and $\xi=1$, respectively.

$j=1,2,3$ for the nodes with $\delta=-1, \delta=0$ and $\delta=1$, respectively.

$q=1,2$ and $p=3$ for the nodes with $\eta=-1$ and $\eta=1$, respectively.

$f_{1}=\frac{1}{4}\left(1-2 \eta+\eta^{2}\right)$

$f_{2}=\frac{1}{4}\left(3+2 \eta-\eta^{2}\right)$

$f_{3}=\frac{h}{2}\left(-1+\eta^{2}\right)$

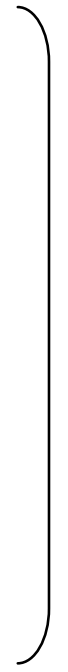

Finally, the displacement fields $u(x, y, z), v(x, y, z)$ and $w(x, y, z)$ in terms of the nodal DOFs are:

$$
\{u\}=[N]\{q\}
$$

where

$$
\{u\}=\left[\begin{array}{lll}
u & v & w
\end{array}\right]^{T}
$$

$$
[N]=\left[\begin{array}{llllll}
\underline{N}_{1} & \underline{N}_{2} & \ldots & \underline{N}_{n} & \ldots & \underline{N}_{18}
\end{array}\right]
$$

$$
\{q\}=\left[\begin{array}{llllll}
q_{1}^{T} & \sim_{\sim}^{T} & \ldots & \sim_{\sim}^{T} & \ldots & q_{\sim}^{T}
\end{array}\right]^{T}
$$

$$
\begin{aligned}
\left\{q_{n}\right\} & =\left[\begin{array}{lll}
u_{n} & v_{n} & w_{n}
\end{array}\right]^{T} \\
{\left[\underline{N}_{n}\right.} & =\left[\begin{array}{c:c:c}
g_{i} h_{j} f_{q} & 0 & 0 \\
\hline 0 & g_{i} h_{j} f_{q} & 0 \\
\hdashline 0 & 0 & g_{i} h_{j} f_{q}
\end{array}\right]
\end{aligned}
$$

where $n=m \ldots m+2, m=1,7,13$ 
and

$$
\left\{q_{n}\right\}=\left[\begin{array}{llllll}
u_{n} & v_{n} & w_{n} & \left(\tau_{x z}\right)_{n} & \left(\tau_{y z}\right)_{n} & \left(\sigma_{z}\right)_{n}
\end{array}\right]^{T}
$$

$\left[\underline{N}_{n}\right]=\left[\begin{array}{l|l|l|l|l|l} & & & & \\ g_{i} h_{j} f_{q} & 0 & -g_{i}^{\prime} h_{j} f_{p} & \frac{D_{66}}{\Delta} g_{i} h_{j} f_{p} & -\frac{D_{56}}{\Delta} g_{i} h_{j} f_{p} & 0 \\ \hdashline 0 & g_{i} h_{j} f_{q} & -g_{i} h_{j}^{*} f_{p} & -\frac{D_{56}}{\Delta} g_{i} h_{j} f_{p} & \frac{D_{55}}{\Delta} g_{i} h_{j} f_{p} & 0 \\ \hdashline-\frac{D_{13}}{D_{33}} g_{i}^{\prime} h_{j} f_{p} & -\frac{D_{34}}{D_{33}} g_{i}^{\prime} h_{j} f_{p} & g_{i} h_{j} f_{q} & 0 & & \\ -\frac{D_{34}}{D_{33}} g_{i} h_{j}^{*} f_{p} & -\frac{D_{23}}{D_{33}} g_{i} h_{j}^{*} f_{p} & & & 1 \\ & & & \\ D_{33} g_{i} h_{j} f_{p}\end{array}\right]$

where, $n=m+3 \ldots m+5, m=1,7,13$

and $i, j, q, p$ are same as described in Eq. (3.14). Furthermore, $g_{i}^{\prime}=\frac{\partial g_{i}}{\partial x}$ and $h_{j}^{*}=\frac{\partial h_{j}}{\partial y}$

\subsection{Conclusions}

This chapter presented three 18-node 3D FE models for analysis of composite beam and plate. The first model considering both stress and displacement continuity already proved a good working to analysis laminated plate. The rest two new models are able to consider only displacement continuity and a mixer of both models i.e. one side only displacement and other side both displacement and stress continuity. In chapter five, the verification of these models will be presented in the case of analysis composite beams and plates. For 
simplicity, in the following, the first model will be called the mixed FE model, the second model will be called the displacement model, the third model will be called the transitional model, and the analysis using all three models will be referred to as the combined model. 


\section{Chapter IV}

\section{Material Constitutive Relations}

\subsection{Introduction}

In order to obtain accurate analysis, proper material models are needed. This chapter presents the concrete, reinforcing steel and FRP material models that are used in this study.

\subsection{Concrete}

\subsubsection{Compressive behavior}

For compression, widely accepted Saenz's (1964) uniaxial stress-strain relationship is used in this analysis. It has the following form:

$$
\sigma=\frac{E_{c} \varepsilon}{1+R_{3} \frac{\varepsilon}{\varepsilon_{0}}-R_{2}\left(\frac{\varepsilon}{\varepsilon_{0}}\right)^{2}+R_{1}\left(\frac{\varepsilon}{\varepsilon_{0}}\right)^{3}}
$$

where

$$
\begin{aligned}
& R_{1}=\frac{R_{E}\left(R_{f}-1\right)}{\left(R_{e}-1\right)^{2}}-\frac{1}{R_{e}} \\
& R_{2}=2 R_{1}-1 \\
& R_{3}=R_{1}+R_{E}-2
\end{aligned}
$$


Modular ratio $R_{E}=\frac{E_{C}}{E_{0}}$

Stress ratio $R_{f}=\frac{f_{C}^{\prime}}{f_{f}}$

Strain ratio $R_{e}=\frac{\varepsilon_{f}}{\varepsilon_{0}}$

Secant modulus $E_{0}=\frac{f_{C}^{\prime}}{\varepsilon_{0}}$

$E_{c}=$ Initial tangent modulus

$\sigma=$ Stress in concrete

$\varepsilon=$ Strain in concrete

$f_{c}^{\prime}=$ Characteristic compressive stress of concrete

$f_{f}=$ Stress in the concrete at the maximum strain

$\varepsilon_{0}=$ Strain in the concrete at the maximum stress $f_{c}^{\prime}$

$\varepsilon_{f}=$ Strain in the concrete at the compressive failure

The tangent modulus, $E_{t}$, corresponding to the specified strain can be found by taking derivatives of the Eq. (4.1) with respect to strain component. This leads to

$$
E_{t}=\frac{d \sigma}{d \varepsilon}=\frac{E_{C}\left[1+R_{2}\left(\frac{\varepsilon}{\varepsilon_{0}}\right)^{2}-2 R_{1}\left(\frac{\varepsilon}{\varepsilon_{0}}\right)^{3}\right]}{\left[1+R_{3} \frac{\varepsilon}{\varepsilon_{0}}-R_{2}\left(\frac{\varepsilon}{\varepsilon_{0}}\right)^{2}+R_{1}\left(\frac{\varepsilon}{\varepsilon_{0}}\right)^{3}\right]^{2}}
$$


Beyond the peak stress point in the strain-softening region, with further straining, the compressive stress begins to decrease and the equivalent uniaxial tangent modulus becomes negative. In order to prevent the numerical difficulties associated with a negative tangent modulus, once the ultimate yield stress $f_{c}^{\prime}$ has been reached, $E_{t}$ is set to zero and the concrete behaves like perfectly plastic material (Figure 4.1). This plastic response is allowed to propagate through a limited strain $\Delta \varepsilon$, at which time the unbalanced stress is released. This process proceeds in a stepwise fashion.

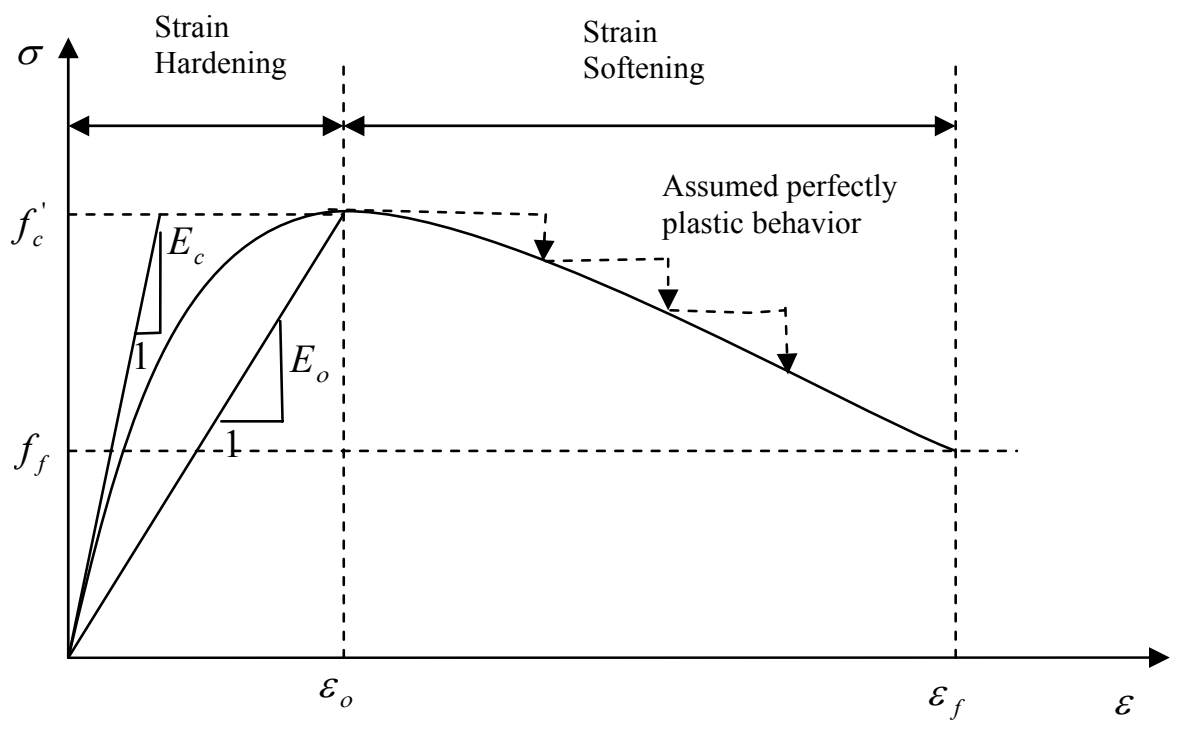

Figure 4.1: Uniaxial Stress-strain Curve for Concrete

Tangent modulus $E_{p i}(i=1,2,3)$, along the three principle directions can be calculated from the Eq. (4.2) with the help of the three principal strains from the last load step. Then the $3 \mathrm{D}$ stress and strain can be computed from the following incremental stress-strain relations along the principal direction:

$$
\{\Delta \sigma\}=[C]\{\Delta \varepsilon\}
$$


where $\{\sigma\}$ and $\{\varepsilon\}$ are stress and strain vectors along the principal directions respectively. The symmetric constitutive matrix $[C]$ is:

$$
[C]=\frac{1}{(1-v)(1-2 v)}\left[\begin{array}{cccccc}
(1-v) E_{P 1} & v E_{12} & v E_{13} & 0 & 0 & 0 \\
v E_{12} & (1-v) E_{P 2} & v E_{23} & 0 & 0 & 0 \\
v E_{13} & v E_{23} & (1-v) E_{P 3} & 0 & 0 & 0 \\
0 & 0 & 0 & \frac{(1-2 v) E_{12}}{2} & 0 & 0 \\
0 & 0 & 0 & 0 & \frac{(1-2 v) E_{13}}{2} & 0 \\
0 & 0 & 0 & 0 & 0 & \frac{(1-2 v) E_{23}}{2}
\end{array}\right]
$$

where

$$
E_{i j}=\frac{\left|\sigma_{p i}\right| E_{p i}+\left|\sigma_{p j}\right| E_{p j}}{\left|\sigma_{p i}\right|+\left|\sigma_{p j}\right|}, i=1,2 ; j=2,3 ; i \neq j
$$

This constitutive matrix along the principal direction can be transformed to the global direction by applying conventional coordinate transformation.

\subsubsection{Tensile behavior}

Until the crack, initial tangent modulus $E_{c}$ is used to find the maximum positive (tensile) stress. After the cracking in the concrete takes place, a smeared model is used to represent the discontinuous macro crack behavior. This cracked concrete can still carry some tensile stress perpendicular to the crack, which is termed tension stiffening. In this study, a simple descending line is used to model this tension stiffening phenomenon as shown in Figure 4.2. The default value of the strain $\varepsilon^{*}$ at which the tension stiffening stress reduced to zero is $\varepsilon^{*}=0.001$. In figure $4.2, E_{c}$ and $E_{t}$ are the modulus of elasticity 
of tensile concrete between zero to fracture strain and fracture strain to $\varepsilon^{*}$ respectively. $f_{t}^{\prime}$ is the maximum stress at fracture of concrete, which has corresponding strain $\varepsilon_{t}$.

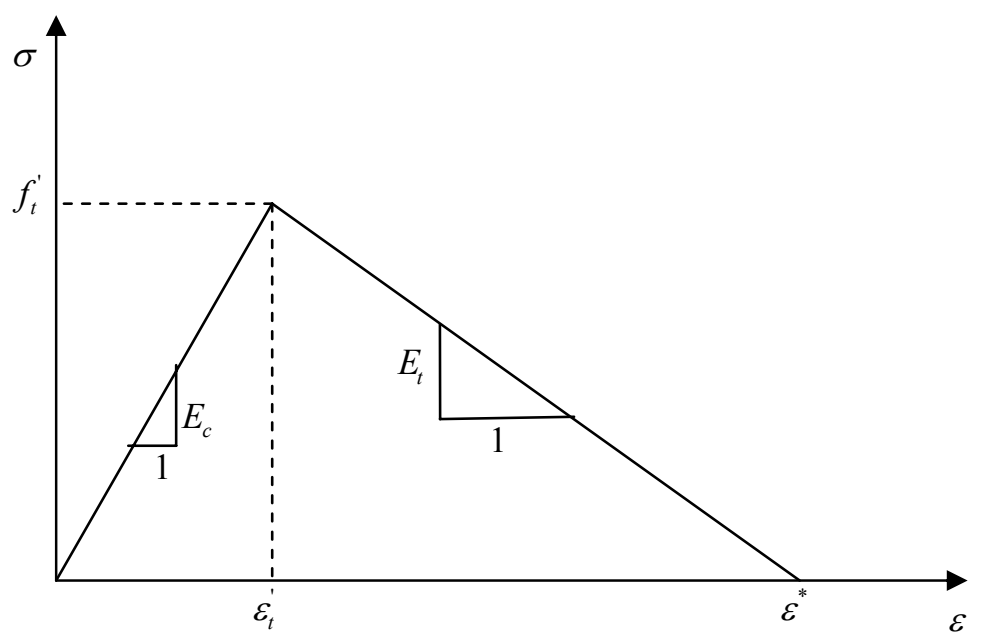

Figure 4.2: Tension Stiffening Model

\subsubsection{Modeling of Crack}

In the concrete, when the tensile stress in the principle direction exceeds the tensile strength, $\sigma_{f}$, of concrete, the tensile failure would occur (Desai et al. 2002). Due to this crack at an integration point, we need to modify the constitutive matrix. After the crack forms, both normal and shear stiffness are reduced. For failure in the first principal direction ( $\sigma_{p 1}$ exceeds $\sigma_{f}$ ), the modified constitutive matrix $[C]$ is: 


$$
[C]=\left[\begin{array}{cccccc}
E_{0} \eta & 0 & 0 & 0 & 0 & 0 \\
0 & \frac{E_{P 2}}{1-v^{2}} & \frac{v E_{23}}{1-v^{2}} & 0 & 0 & 0 \\
0 & \frac{v E_{32}}{1-v^{2}} & \frac{E_{P 3}}{1-v^{2}} & 0 & 0 & 0 \\
0 & 0 & 0 & \frac{E_{0} \eta_{S}}{2(1+v)} & 0 & 0 \\
0 & 0 & 0 & 0 & \frac{E_{0} \eta_{S}}{2(1+v)} & 0 \\
0 & 0 & 0 & 0 & 0 & \frac{E_{23}}{2(1+v)}
\end{array}\right]
$$

The constant $\eta$ in Eq. (4.5) is the stiffness normal to the tensile failure plane reduction factor, and $\eta_{S}$ is the shear stiffness in the tensile failure plane reduction factor.

Further modification is applied to constitutive matrix for the tensile failure along the second principal directions. The new constitutive matrix $[C]$ is given in Eq. (4.6).

$$
[C]=\left[\begin{array}{cccccc}
E_{0} \eta & 0 & 0 & 0 & 0 & 0 \\
0 & E_{0} \eta & 0 & 0 & 0 & 0 \\
0 & 0 & \frac{E_{P 3}}{1-v^{2}} & 0 & 0 & 0 \\
0 & 0 & 0 & \frac{E_{0} \eta_{S}}{2(1+v)} & 0 & 0 \\
0 & 0 & 0 & 0 & \frac{E_{0} \eta_{S}}{2(1+v)} & 0 \\
0 & 0 & 0 & 0 & 0 & \frac{E_{0} \eta_{S}}{2(1+v)}
\end{array}\right]
$$




\subsection{Steel reinforcing bars}

The stress-strain curve of the reinforcing bar is assumed to be elastic up to the steel yield stress $\left(f_{y}\right)$ followed by linear hardening up to the steel ultimate strength $\left(f_{u}\right)$ as shown in Figure 4.3. The dowel action of the reinforcing steel is neglected and the bond between steel and concrete is assumed to remain perfect.

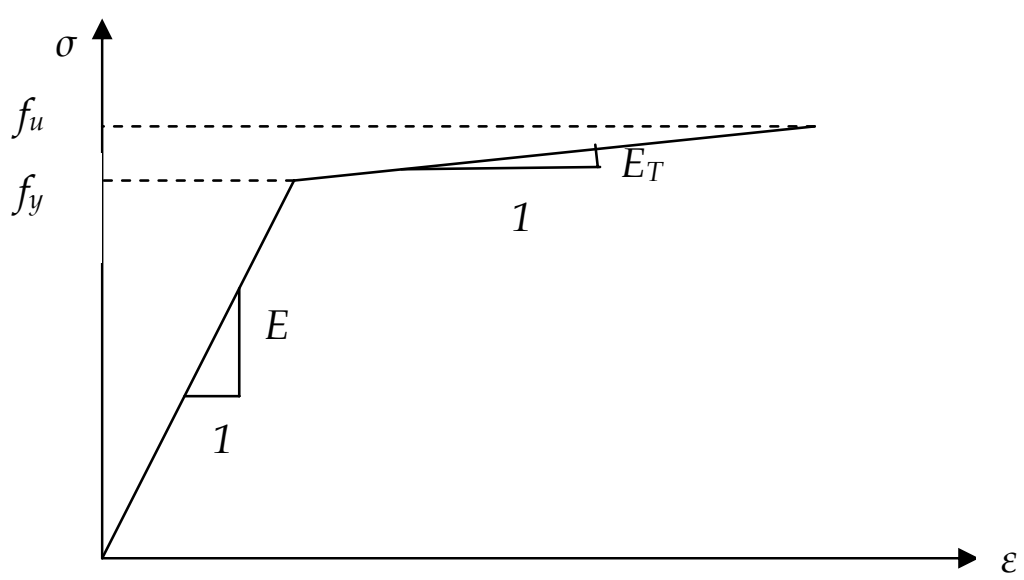

Figure 4.3: Uniaxial stress-strain relation for steel.

Furthermore, the reinforcement has uniaxial stiffness only and is assumed to be smeared throughout the element. Up to the yielding, the nonzero element of $6 \times 6$ constitutive matrix for reinforcement is:

$$
D_{11}^{r}=E_{S}^{r}
$$

where $E_{S}^{r}=$ Young's modulus of reinforcement up to yielding.

When there is yielding, reduced modulus of elasticity $\left(E_{T}^{r}\right)$ for reinforcement is used to formulate the constitutive matrix $\left[D^{r}\right]$ where the nonzero element is 


$$
D_{11}^{r}=E_{T}^{r}
$$

where $E_{T}^{r}=$ Young's modulus of reinforcement after yielding.

For this smeared element, the concrete is considered as a linear element for simplicity. The constitutive matrix $\left[D^{c}\right]$ for isotropic concrete material used in this analysis is:

$$
\left[D^{c}\right]=\frac{E}{(1-v)(1-2 v)}\left[\begin{array}{cccccc}
(1-v) & v & v & 0 & 0 & 0 \\
v & (1-v) & v & 0 & 0 & 0 \\
v & v & (1-v) & 0 & 0 & 0 \\
0 & 0 & 0 & \frac{(1-2 v)}{2} & 0 & 0 \\
0 & 0 & 0 & 0 & \frac{(1-2 v)}{2} & 0 \\
0 & 0 & 0 & 0 & 0 & \frac{(1-2 v)}{2}
\end{array}\right]
$$

where:

$E=$ Young's modulus for concrete, $v=$ Poisson's ratio for concrete.

This smeared element is assumed to be bilinear, consisting of bilinear steel and linear concrete. The constitutive matrix $[D]$ used for this smeared element is defined as:

$[D]=\left(1-V^{R}\right)\left[D^{c}\right]+V^{R}\left[D^{r}\right]$

where:

$V^{R}=$ ratio of the volume of reinforcing material to the total volume of the element, $\left[D^{c}\right]=$ stress-strain matrix for concrete (Eq. 4.9), $\left[D^{r}\right]=$ stress-strain matrix for reinforcement (Eqs. $\left.4.7 \& 4.8\right)$. 


\subsection{Fiber-reinforced plastics (FRP)}

The behavior of FRP materials is linear elastic to failure. Ultimate elongation strains are considerably higher than steel yielding strains. This results in ultimate tensile strengths that are typically between four to nine times the yield stress of steel. Failure is sudden and brittle with no load carrying capacity after failure. Typical stress-strain relation of FRP is shown in Figure 4.4.

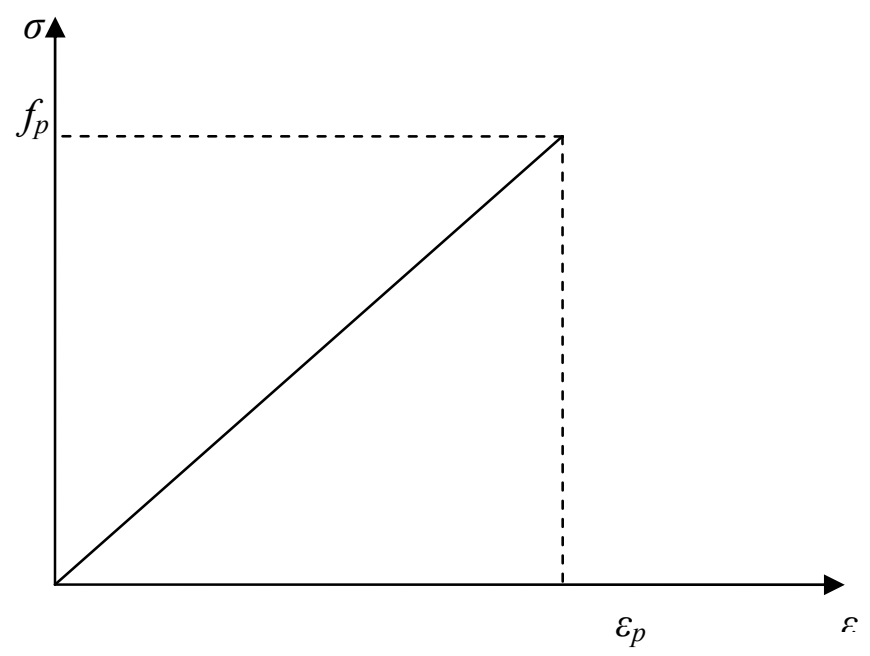

Figure 4.4: Stress-strain Relation of FRP

Mechanical properties of the composites vary to a high degree depending on the orientation of load with respect to the fiber orientation and the fiber to resin volume ratio (Volnyy and Pantelides, 1999). FRP materials exhibit the highest strength when loaded in the direction of the fibers, and have only the strength of the resin when loaded perpendicular to the fibers. Using FRP sheets with the fibers woven orthogonally to produce a fabric that has the same properties in the two directions can offset this effect. 
The constitutive relations for orthotropic FRP materials used in the analysis are:

$$
\left\{\begin{array}{l}
\sigma_{x} \\
\sigma_{y} \\
\sigma_{z} \\
\gamma_{y z} \\
\gamma_{x z} \\
\gamma_{x y}
\end{array}\right\}=\left[\begin{array}{cccccc}
E_{1}\left(\frac{1-v_{23} v_{32}}{\Delta}\right) & E_{1}\left(\frac{v_{21}+v_{31} v_{23}}{\Delta}\right) & E_{1}\left(\frac{v_{31}+v_{21} v_{32}}{\Delta}\right) & 0 & 0 & 0 \\
E_{2}\left(\frac{v_{12}+v_{32} v_{13}}{\Delta}\right) & E_{2}\left(\frac{1-v_{13} v_{31}}{\Delta}\right) & E_{2}\left(\frac{v_{32}+v_{12} v_{31}}{\Delta}\right) & 0 & 0 & 0 \\
E_{3}\left(\frac{v_{13}+v_{12} v_{23}}{\Delta}\right) & E_{3}\left(\frac{v_{23}+v_{21} v_{13}}{\Delta}\right) & E_{3}\left(\frac{1-v_{12} v_{21}}{\Delta}\right) & 0 & 0 & 0 \\
0 & 0 & 0 & G_{23} & 0 & 0 \\
0 & 0 & 0 & 0 & G_{31} & 0 \\
0 & 0 & 0 & 0 & 0 & G_{12}
\end{array}\right]\left\{\begin{array}{l}
\varepsilon_{x} \\
\varepsilon_{y} \\
\varepsilon_{z} \\
\tau_{y z} \\
\tau_{x z} \\
\tau_{x y}
\end{array}\right\}
$$

where

$$
\begin{aligned}
& \Delta=1-v_{12} v_{21}-v_{23} v_{32}-v_{31} v_{13}-2 v_{21} v_{32} v_{13} \\
& \frac{v_{21}}{E_{2}}=\frac{v_{12}}{E_{1}}, \quad \frac{v_{31}}{E_{3}}=\frac{v_{13}}{E_{1}}, \quad \frac{v_{32}}{E_{3}}=\frac{v_{23}}{E_{2}}
\end{aligned}
$$

\subsection{Failure criteria}

\subsubsection{Steel}

Failure criteria for steel are established by using the stress-strain curve as a basis. Principle strains in the elements are compared with the stress-strain curve to determine a value for the tangent modulus. When the principal strain in any steel element exceeds the yield strain, a percentage of initial tangent modulus is used in the elasticity matrix. Similarly, when the principal strain exceeds the strain hardening limit, the structure is assumed to exhibit tension failure. 


\subsubsection{Concrete}

The procedure used to describe the structural behavior of the concrete element is similar to that used for the steel elements. In compression, the concrete stress-strain relations (Figure 4.1) are used to determine the value for the tangent modulus for use in the elasticity matrix. These stress-strain relations defined by Saenz's Eq. (4.1) are presented at the beginning of this chapter. When the principal strain is between zero and the strain at peak stress $\varepsilon_{0}$, Saenz's stress-strain relationship equation (Eq. 4.1) is used to find the modulus of elasticity. The principal strains from the $m^{\text {th }}$ load step is used to determine the tangent modulus for the $(m+1)^{\text {th }}$ load step. When the value of principal strain is between $\varepsilon_{0}$ and the ultimate strain $\varepsilon_{f}$, a very nominal value $(0.001)$ of tangent modulus of elasticity is used. For the principal strain values greater than $\varepsilon_{f}$, it is assumed that the element fails by compression. In tension, up to the rupture strain, the initial modulus of elasticity is used. When the principal strain is greater than rupture strain and less than $\varepsilon^{*}$,

the initial modulus of elasticity is reduced by a factor $\left(1.0 \times 10^{-4}\right)$. For principal strain value greater than $\varepsilon^{*}$, a very nominal value $(0.001)$ of modulus of elasticity is used.

\subsubsection{FRP}

For FRP, the failure criteria were also based on the stress-strain curve. As FRP material is brittle in nature, there is no yielding stage. It behaves elastically to failure. When the principal strain is greater than the ultimate strain, it is assumed tension failure of the elements has taken place. 


\section{Chapter V}

\section{Numerical Results and Discussions}

\subsection{Introduction}

This chapter will present the FE implementation and verification of the proposed element models. It will also present some numerical results for future reference.

\subsection{FE Implementation}

\subsubsection{Introduction}

The theory presented in the previous two chapters is implemented in Fortran to analyze concrete beam strengthened with FRP and composite plate.

The input parameter for this program consists the following:

- Structure parameters

- Element parameters

- Boundary conditions

- Nodal displacements if any

- Concrete properties

- Steel and/or FRP properties

- Initial loads (distributed or point)

The output parameter consists the following: 
- Reprint of input data

- Nodal displacement data

- Initial force distribution among the elements nodes

- Nodal displacements and transverse stresses

- Element stress and displacement.

\subsubsection{Flow Chart}

Figures 5.1 and 5.2 illustrate the flow chart of the main part of the program as well as the implementation of linear and nonlinear analysis of concrete. 


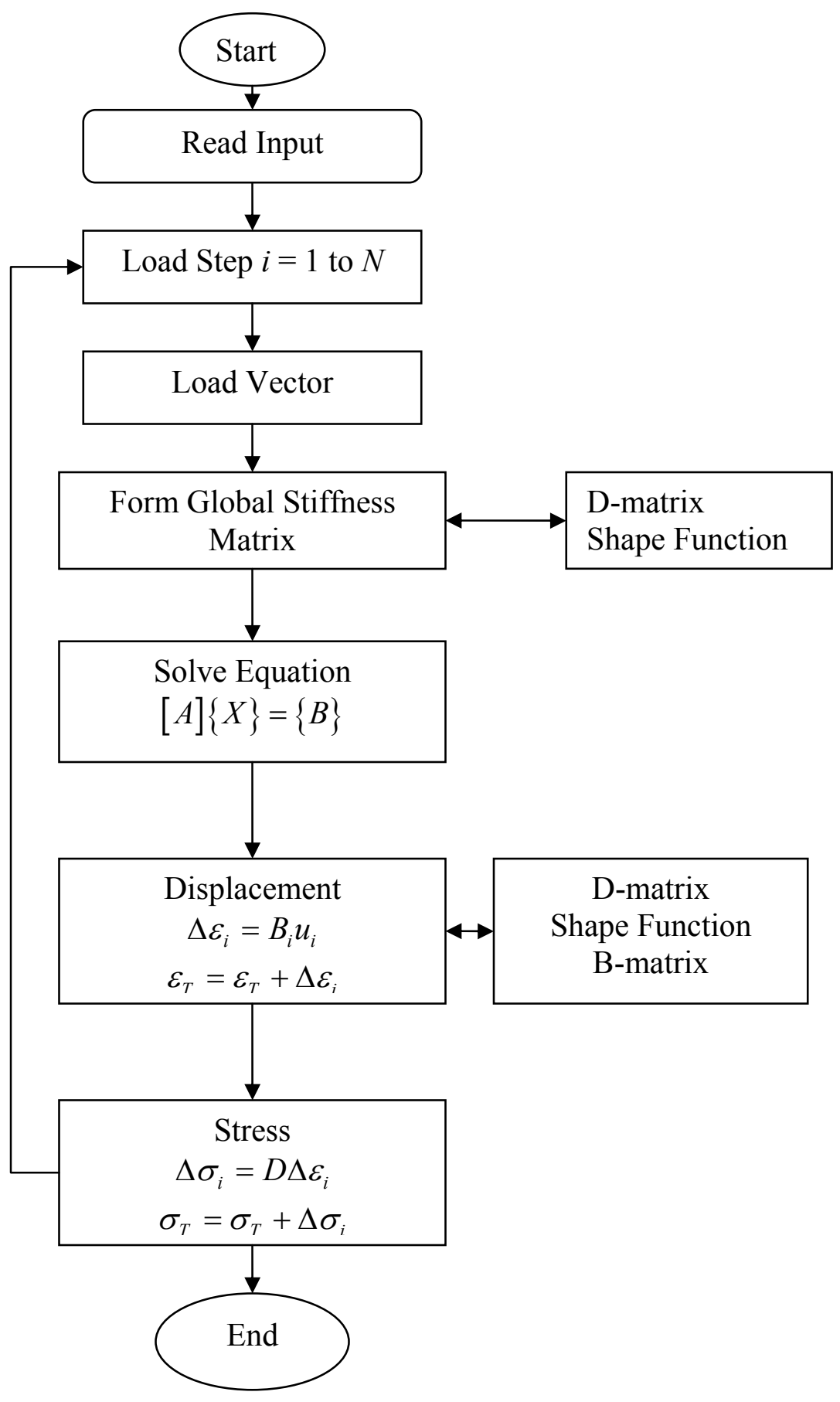

Figure 5.1: Flow chart for incremental displacement and stress calculation 


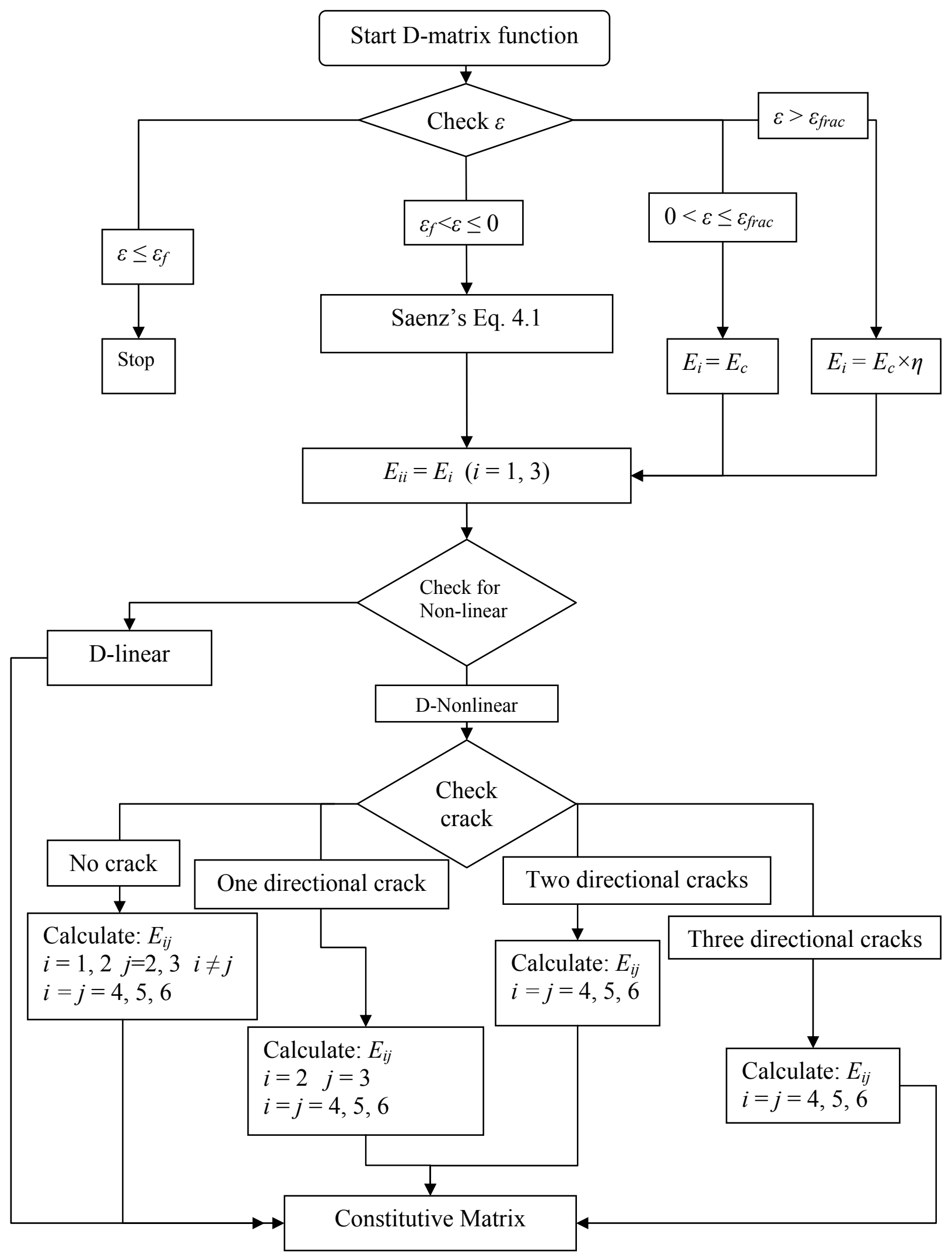

Figure 5.2: Flow chart of concrete constitutive matrix calculation 


\subsection{Validation}

In Chapter 3, we presented three types of FE models: 1) mixed model (both stressesdisplacements as nodal DOFs), 2) transitional model (both stresses- displacements on one surface and only displacements on the other surface as nodal DOFs), and 3) displacement model (only displacements as nodal DOFs). The validity of these models is carried out by the comparison of the results of the analysis of an RC beam strengthened by FRP with an experimental result and the results of the analysis of concrete plate reinforced with external steel sheet with the result from ANSYS (ANSYS Inc. 2004). The material models used in the analysis are as described in Chapter 4.

\subsubsection{Composite beam}

A simply-supported RC beam with an external reinforcement of FRP layers at the bottom experimented by Shahawy et al. (1996) is considered (Figure 5.3) here. The beam is 203 $\mathrm{mm}$ wide, $305 \mathrm{~mm}$ high and $2743 \mathrm{~mm}$ long. The distance between two supports is 2439 $\mathrm{mm}$. Two $13 \mathrm{~mm}$ diameter steel bars are placed in the tension zone at a distance $251 \mathrm{~mm}$ from the top surface and two $3 \mathrm{~mm}$ diameter steel bars are placed in compression zone at $54 \mathrm{~mm}$ from the top surface. Three layers of FRP sheet with their fiber directions oriented in the axial direction of the beam are adhered to the bottom surface of the beam. Each FRP sheet is $0.1702 \mathrm{~mm}$ thick and $203 \mathrm{~mm}$ wide. The beam is subject to four point static load up to failure. 

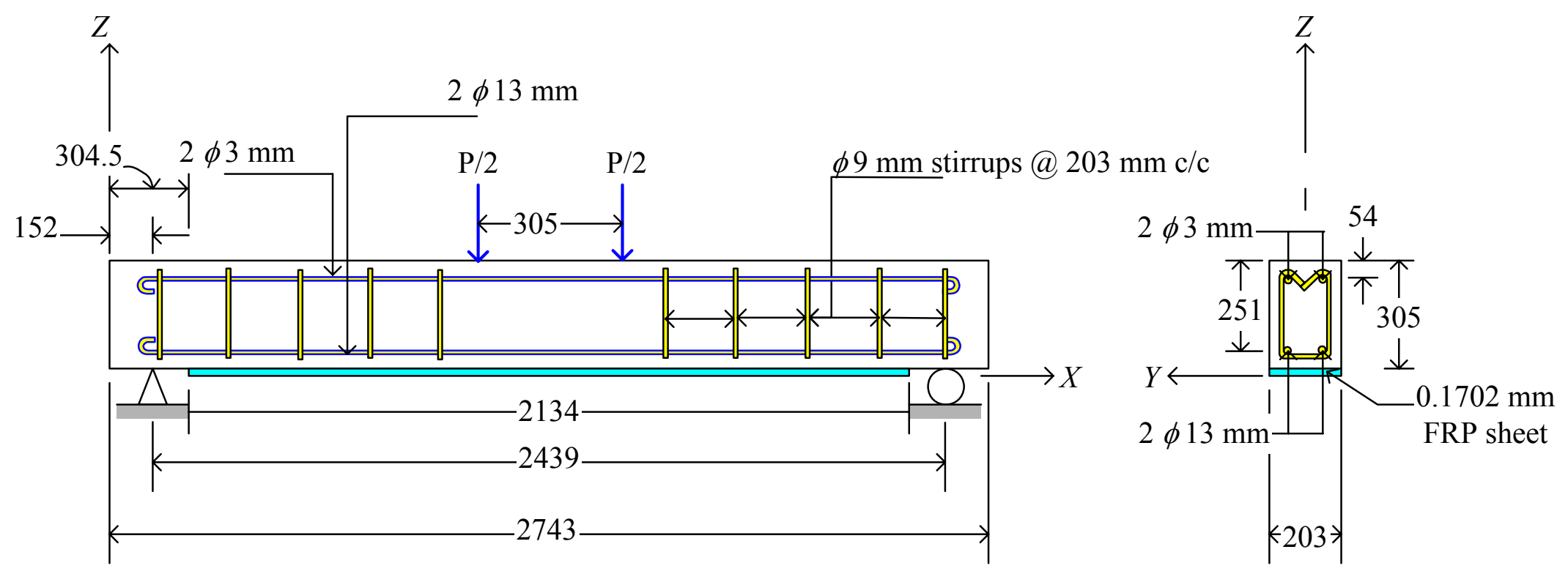

(a)

(b)

Figure 5.3: Geometry of a simply-supported beam under four-point load test (all dimensions are in $\mathrm{mm}$ ) 
The material properties of concrete, reinforcing steel, and FRP reinforcement are, respectively,

$$
\begin{array}{clll}
\varepsilon_{0}=0.0025 & \varepsilon_{f}=0.0035 & f_{c}^{\prime}=41.37 \mathrm{MPa} & f_{f}=10.34 \mathrm{MPa} \\
\sigma_{f}=0.33 \sqrt{f_{c}^{\prime}} \mathrm{MPa} & E_{C}=4700 \sqrt{f_{c}^{\prime}} \mathrm{MPa} & v=0.1 & \eta=1.0 \times 10^{-4} \\
E_{s}=199.9 & \mathrm{GPa} & \\
E_{11}=141.3 \mathrm{GPa} & E_{22}=14.5 \mathrm{GPa} \\
G_{12}=G_{13}=5.86 \mathrm{GPa} & G_{23}=3.52 \mathrm{GPa} \\
v_{12}=0.21 &
\end{array}
$$

Here, $f_{c}^{\prime}, E_{S}, E_{11}$ and $v_{12}$ are given by Shahawy et al. (1996). Remaining properties are considered from Hu et al. (2004).

Due to symmetry in $X$-direction, only half of the beam was analyzed. Symmetric boundary conditions, presented in Table 5.1, were used. In the FE analysis, we meshed the half beam into 176 elements (eight in $X$-direction, one in $Y$-direction and twenty-two in Z-direction). Figure 5.4 shows the FE mesh used in the analysis. The concrete, reinforcement and FRP were modeled as 18-node solid elements. The concrete was considered as nonlinear and smeared crack model was applied. The reinforcement was considered as bi-linear elastic-plastic and uniformly smeared in the corresponding elements. The FRP was analyzed as linear up to failure and assumed to be perfect bonded to the concrete. FRP had a cutoff length of $152.5 \mathrm{~mm}$ from each support. Each top and bottom clear cover was meshed into three layers of $17.86 \mathrm{~mm}$ height. Reinforcement in tension and compression were smeared through out the element of thickness $1.32 \mathrm{~mm}$ and $0.08 \mathrm{~mm}$, respectively. Line load was applied on the top surface by putting concentrated load at three nodes. 
Table 5.1: Boundary condition for RC composite beam

\begin{tabular}{ll}
\hline$X=0$ & $v=w=0$ \\
\hline$X=L / 2^{1}$ & $u=\tau_{y z}=0$ \\
\hline$Y= \pm b / 2^{1}$ (side surface) & $\tau_{x z}=0$ \\
\hline$Z=d / 2^{1}$ (top surface) & $\sigma_{z}=-P(X, Y) ; \tau_{x z}=\tau_{y z}=0$ \\
\hline$Z=-d / 2^{1}$ (bottom surface) & $\sigma_{z}=\tau_{x z}=\tau_{y z}=0$ \\
\hline $1 L$ is the span length, $b$ is the width of the section, and $d$ is the depth of the beam.
\end{tabular}
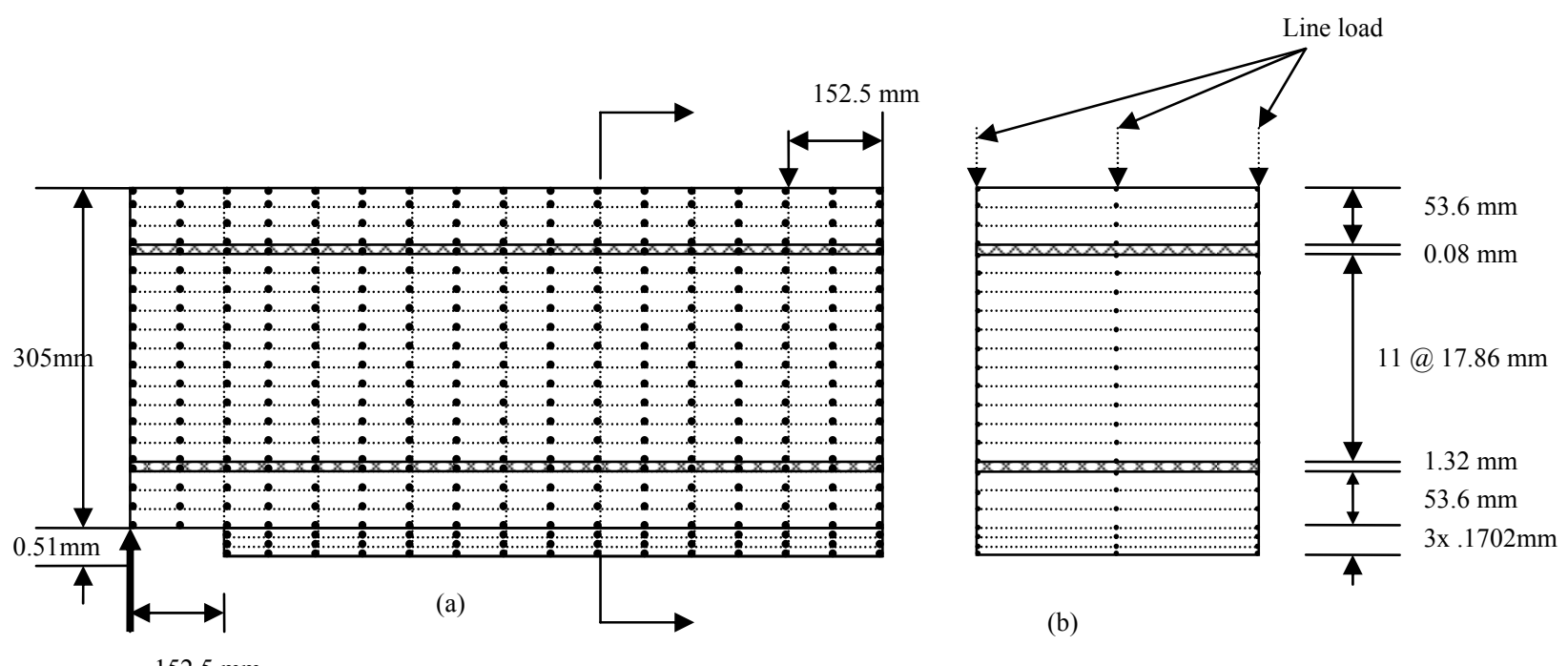

(b)

Figure 5.4: FE mesh used in the result validation 


\subsubsection{Mixed element analysis}

In this analysis, all 176 elements were modeled with modified Ramtekkar et al. (2002) 18-node mixed FE. All nodes have six DOFs- three nodal displacement components in the coordinate axis directions and three nodal transverse stress components. The FE mesh for this analysis is shown in Figure 5.5.

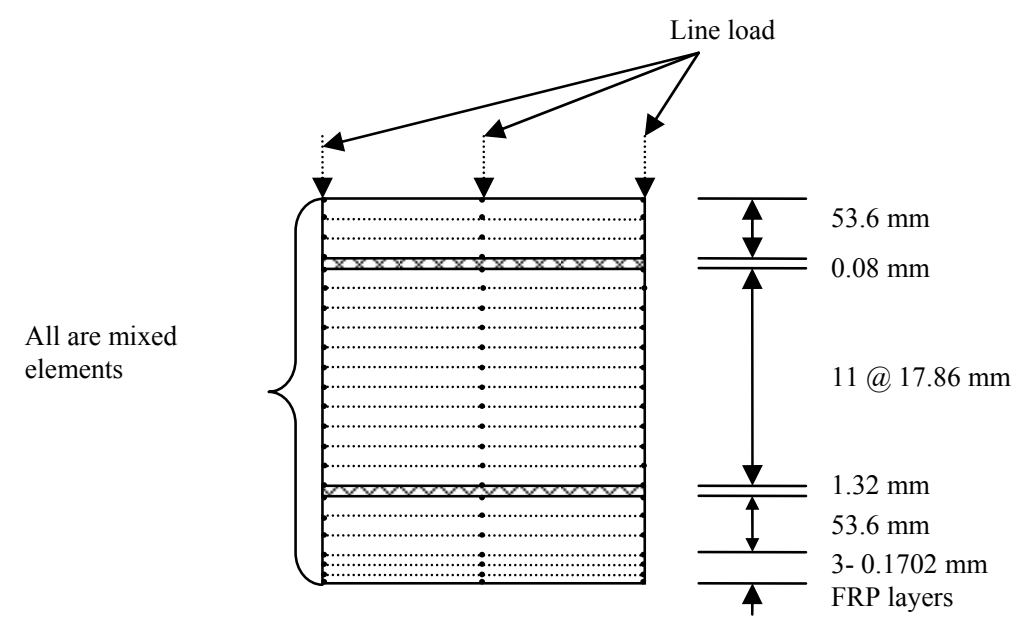

Figure 5.5: FE mesh for mixed analysis

Figure 5.6 shows the load versus mid-span deflection curves of the beam for both numerical and experimental data (Shahawy et al., 1996). The FE analysis predicts the ultimate load to be $55.8 \mathrm{KN}$ which is in a good agreement with the experimental ultimate load of $57 \mathrm{KN}$. The error is $2.1 \%$. The predicted mid-span deflection differs from the experimental result by $6.21 \%$. 


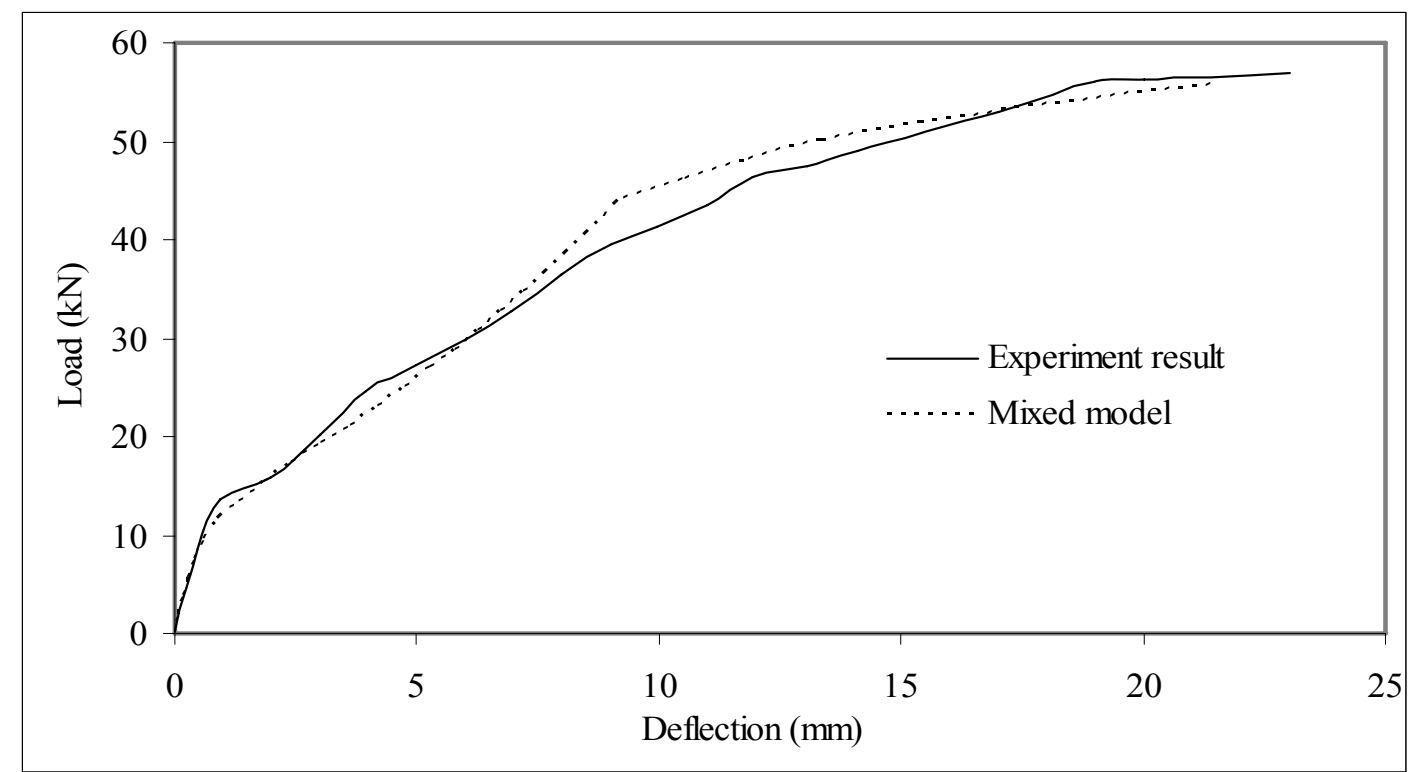

Figure 5.6: Load-deflection curves of RC beams strengthened with three FRP layers analyzed by mixed FE.

\subsubsection{Analysis by using displacement model and combined model:}

First, we analyzed the beam with the displacement model in which every node has three nodal displacement components in the coordinate axis directions as nodal DOFs. Then, we analyzed the beam with the combination of all three models or the combined model. In this combined model, the mixed FE with six DOFs were used for both top and bottom elements. The internal elements are the displacement model and the transitional element models were used between the displacement element and mixed element models. This special arrangement is shown in Figure 5.7. 


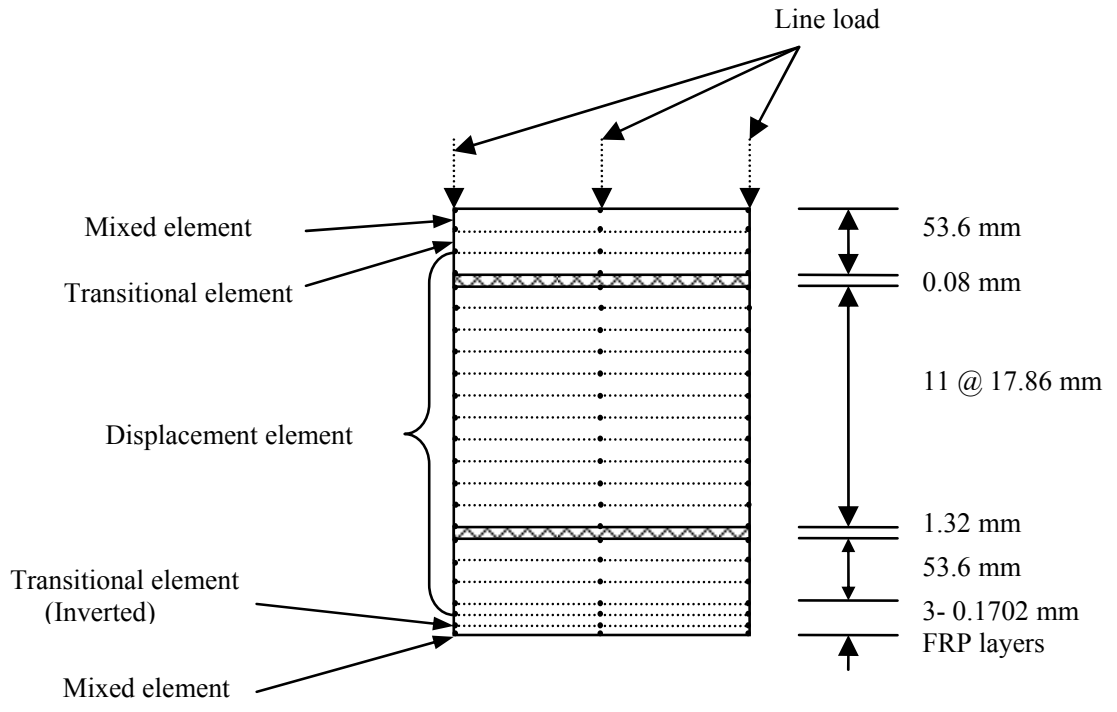

Figure 5.7: FE mesh for displacement and combined element model analysis

The numerical results for both models are presented in Figure 5.8 along with the results from mixed FE analysis and the experiment. The combined model results differ by 12.4 and $13.0 \%$ of the experimental results for the load and the deflection prediction, respectively. The displacement model predicts the load and the deflection to differ by 3.0 and $16.55 \%$ of the experimental results, respectively. Therefore, the mixed model provides a very accurate prediction of the mid-span deflection and the ultimate load, when compared to the results from the experiment. Note that the mixed FE model has six DOFs per node which is computationally very expensive even with the high memory speed. Therefore, we can combine the mixed FE model with the displacement model (three DOFs per node) with of the help of transitional element model (six DOFs on top surface nodes and three DOFs on bottom surface nodes). If the accuracy can be compromised, this combined model should be used. Another benefit of this combined 
model over the displacement model is that the transverse stresses can be prescribed directly at the top and the bottom elements in the combined model. We do not need to integrate the equilibrium equation for transverse stresses.

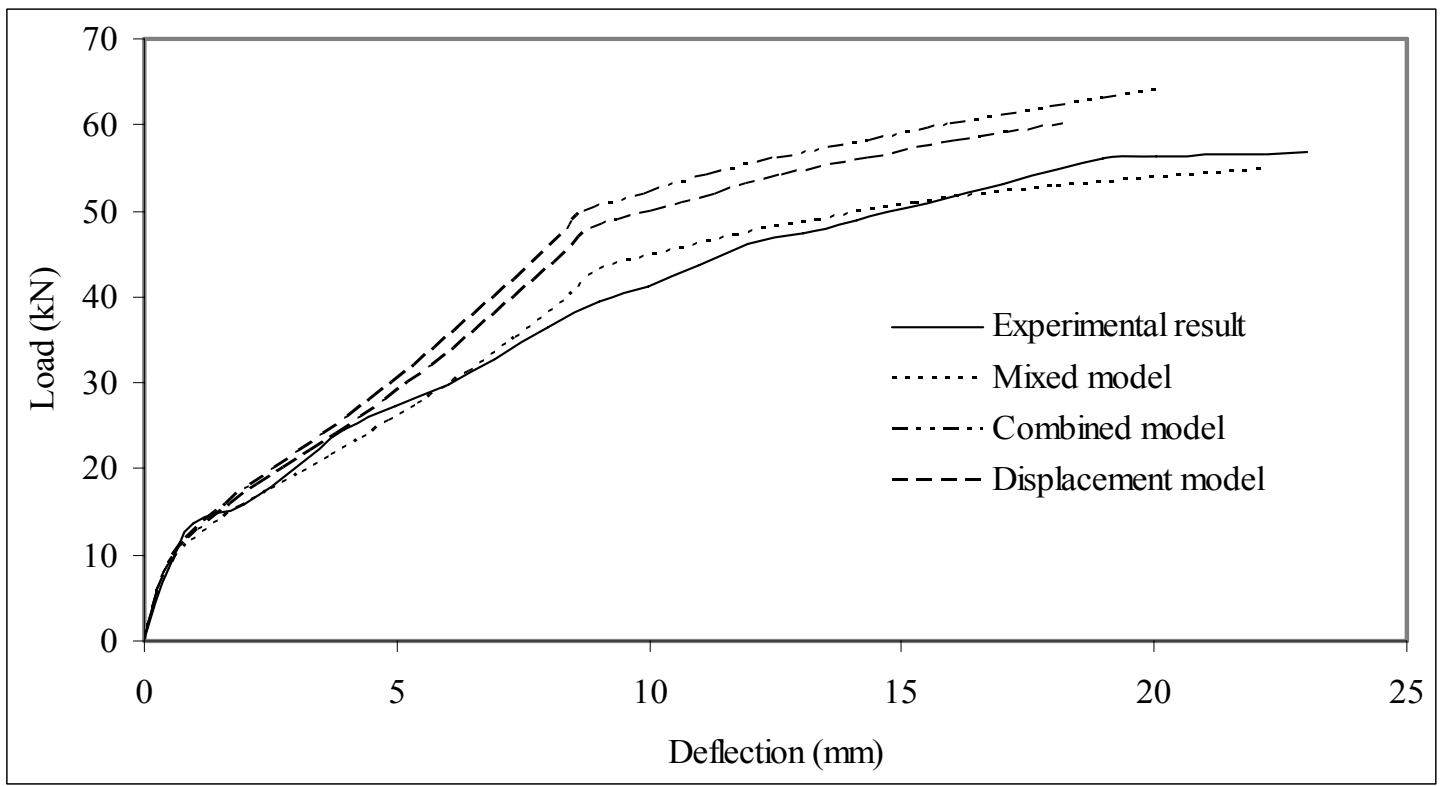

Figure 5.8: Load-deflection curves of RC beams strengthened with three FRP layers analyzing by displacement and combined FE under four-point load.

\subsubsection{Composite plate}

In this section, we considered a rectangular composite concrete plate as shown in Figure 5.9. The size of the plate is $800 \mathrm{~mm}$ wide, $2000 \mathrm{~mm}$ long and $80 \mathrm{~mm}$ thick. A $1.2 \mathrm{~mm}$ thick structural steel sheet, uniformly distributed all over the area at the bottom of the plate is considered. Load was applied through a patch of uniformly distributed load covering the area of $200 \mathrm{~mm} \times 200 \mathrm{~mm}$. The 28 days average compressive and tensile strength of polymer fibre $\mathrm{RC}$ used in the analysis is $34.47 \mathrm{MPa}$ and $3.35 \mathrm{MPa}$, respectively. Because of the bi-axial symmetry, a quarter of the model is used for 
analysis. The quarter model was discretized with four elements in $X$-direction, ten elements in $Y$-direction and five elements in $Z$-direction. The meshing of the model is shown in Figure 5.10.

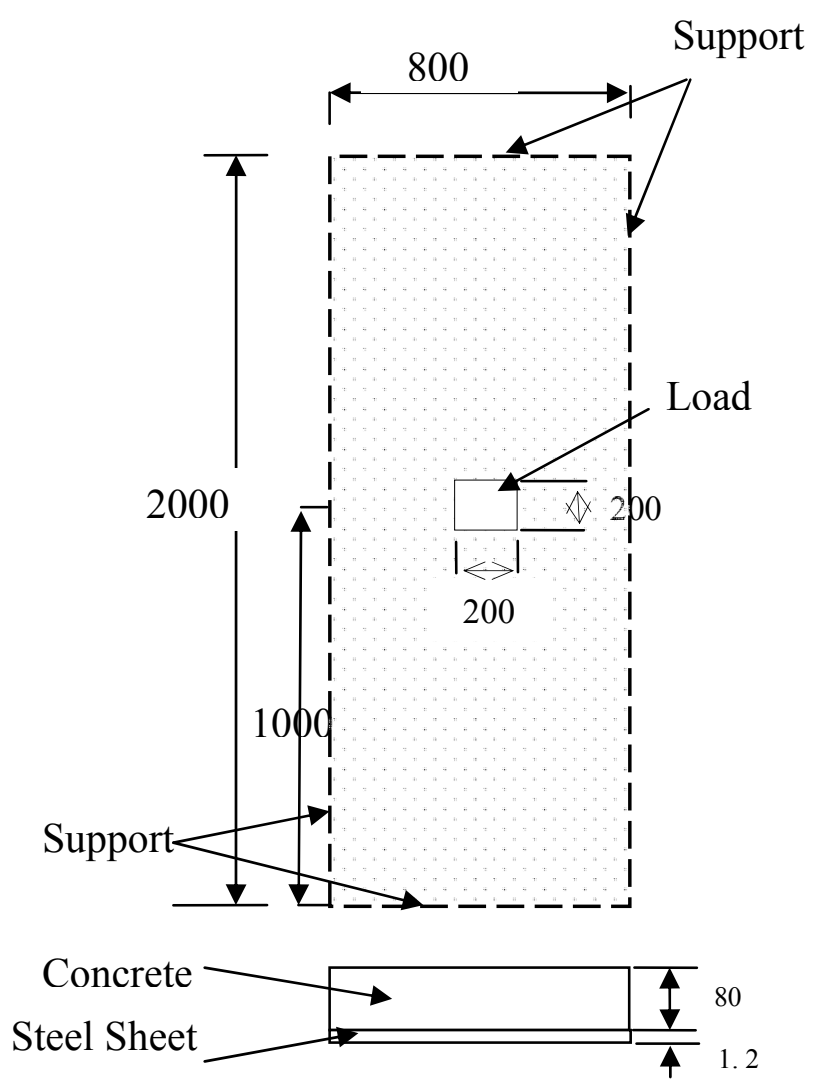

Figure 5.9: Composite plate

The material properties used in the analysis is:

Concrete:

$f_{c}^{\prime}=34.47 \mathrm{MPa}$

$\varepsilon_{0}=0.003$

$\varepsilon_{f}=0.012$

$v=0.1$ 
$E_{c}=27594.24 \mathrm{GPa}$

$f_{f}=8.6175 \mathrm{MPa}$

$\sigma_{f}=3.35 \mathrm{MPa}$

$\eta=1.0 \times 10^{-4}$

Steel:

$E_{s}=200 \mathrm{GPa}$

$v=0.3$

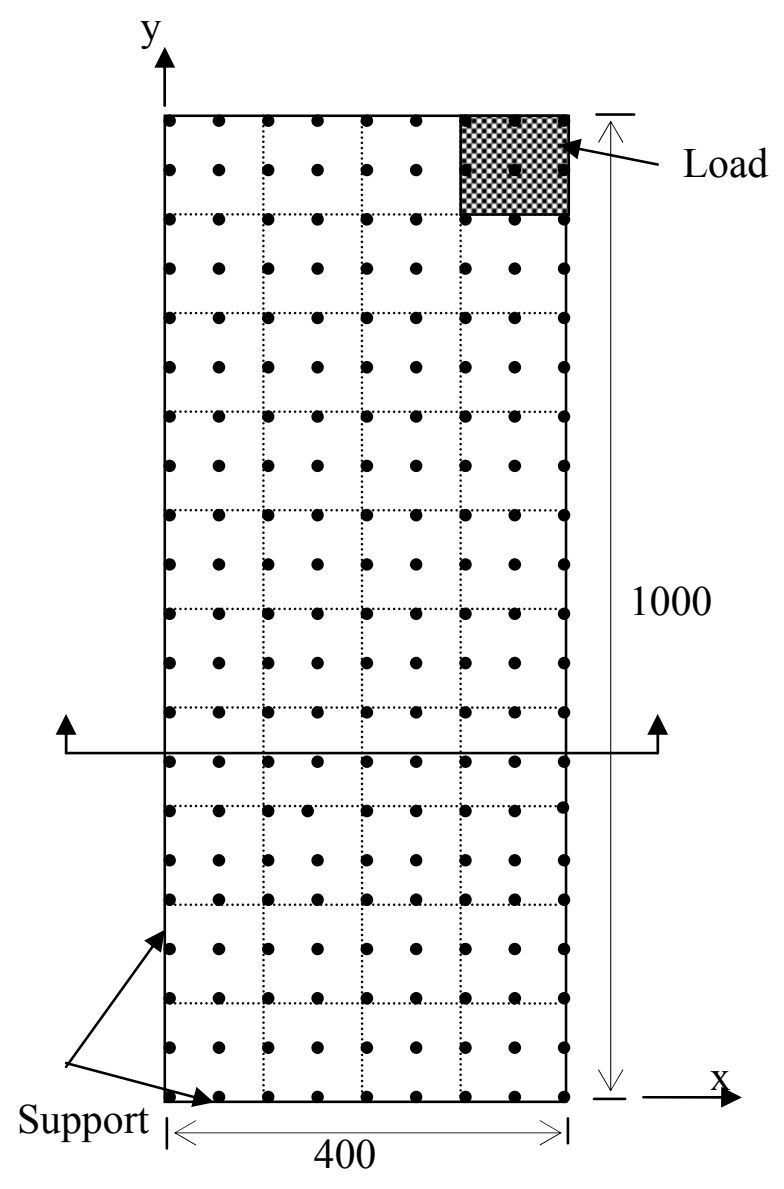

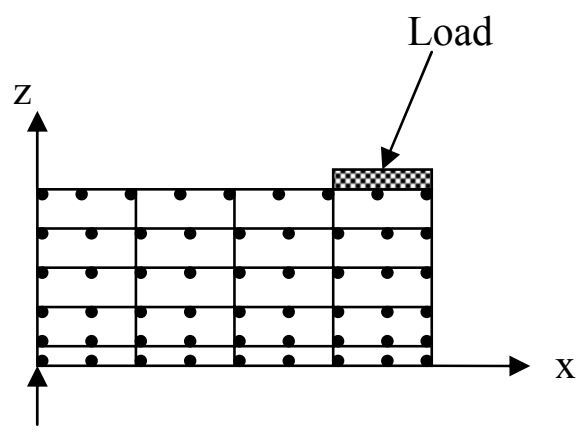

(b)

(a)

Figure 5.10: FE modeling and mesh for composite plate 
Table 5.2: Boundary condition for composite plate

\begin{tabular}{ll}
\hline$X=0$ & $v=w=0$ \\
\hline$X=a / 2^{1}$ & $u=\tau_{y z}=0$ \\
\hline$Y=0$ & $u=w=0$ \\
\hline$Y=b / 2^{1}$ (side surface) & $v=\tau_{x z}=0$ \\
\hline$Z=d / 2^{1}$ (top surface) & $\sigma_{z}=-P(X, Y) ; \tau_{x z}=\tau_{y z}=0$ \\
\hline$Z=-d / 2^{1}$ (bottom surface) & $\sigma_{z}=\tau_{x z}=\tau_{y z}=0$ \\
\hline is the length in the $X$-direction, $b$ is the width in the $Y$-direction, and $d$ is the
\end{tabular}

\subsubsection{Mixed model, Displacement model, and ANSYS Analysis}

Analysis was done by using mixed FE model and displacement element model. As we have considered only five layers in the $Z$-direction, we did not do the analysis by using the combined model. In all analysis, same boundary condition is used as mentioned in Table 5.2. To compare the results, one more analysis was done using commercial FE software- ANSYS v8.1 (ANSYS Inc., 2004). In ANSYS, Solid65 and Solid45 elements were used to model the concrete and steel sheet respectively. Both elements have eight nodes with three DOFs at each node-translation in the nodal $x, y$, and $z$ directions. The Solid65 requires linear isotropic and multilinear isotropic material properties to model the concrete properties. The multilinear isotropic uses the stress-strain curve along with the William and Warnke (1974) failure criteria. The properties used for the failure criteria in 
ANSYS are given in Table 5.3. The steel was modeled as bilinear isotropic material model. Figure 5.11 shows the results of all three analyses. Mixed model and displacement model predict the failure load capacity of $385 \mathrm{kN}$ and $390 \mathrm{kN}$ that is $6.39 \%$ and $7.59 \%$ variation from ANSYS analysis respectively. Their prediction of maximum deflection is varied by $24.44 \%$ and $27.11 \%$ respectively.

Table 5.3: Concrete failure criteria

\begin{tabular}{|l|c|}
\hline \multicolumn{2}{|c|}{ Concrete } \\
\hline ShrCf-Op & 0.7 \\
\hline ShrCf-Cl & 0.9 \\
\hline UnTensSt & 3.35 \\
\hline UnCompSt & -1 \\
\hline BiCompSt & 0 \\
\hline HydroPrs & 0 \\
\hline BiCompSt & 0 \\
\hline UnTensSt & 0 \\
\hline TenCrFac & 1 \\
\hline
\end{tabular}

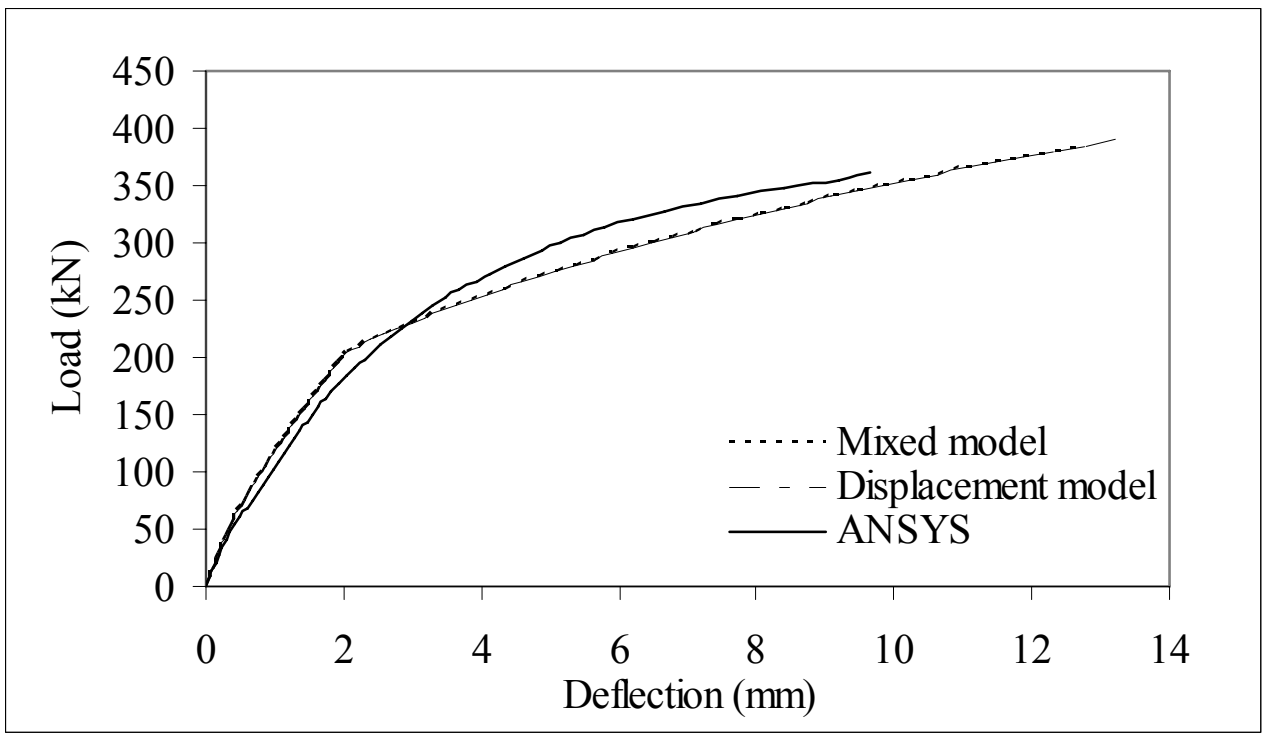

Figure 5.11: Load-deflection curves for analysis of composite plate 


\subsection{Examples}

\subsubsection{Introduction}

In order to demonstrate an applicability of the models on the nonlinear analysis of RC members with FRP materials, this section presents parametric studies for the following parameters for composite beams and plates.

- Number of FRP layers

- Length of FRP layers

- Fibre-orientation of FRP

\subsubsection{Composite beam}

The RC beam strengthened with FRP mentioned in section 5.3.1 is used in this section. The dimension and cross-section of the beam is shown in Figure 5.3. The beam's material properties and boundary conditions used in the analysis are given Eqns. 5.1(a), 5.1(b), 5.1(c) and Table 5.1, respectively. The only variation we make here is the number and length of FRP layers.

\subsubsection{Number of FRP layers}

In this example, the effects of the number of externally reinforced FRP laminas on the nonlinear response of a simply-supported $\mathrm{RC}$ beam are investigated. We have performed eleven sets of analysis starting from a beam without FRP to a beam with ten layers of FRP for each of the three models, i.e. the mixed FE model, the combined model, and the 
displacement model. The result sets are shown in the Figures 5.12, 5.13, and 5.14, respectively. The ultimate load ratio $\left(P_{u} / P_{u 0}\right)$ and the maximum mid-span deflection ratio $\left(\delta_{u} / \delta_{u 0}\right)$ of the beams are presented in Figure 5.15 and Figure 5.16, respectively. Here $P_{u}$ and $P_{u 0}$ are the ultimate load of the beam with and without the FRP reinforcement, respectively, whereas, $\delta_{u}$ and $\delta_{u 0}$ are the maximum mid-span deflection of the beam with and without the FRP reinforcement, respectively.

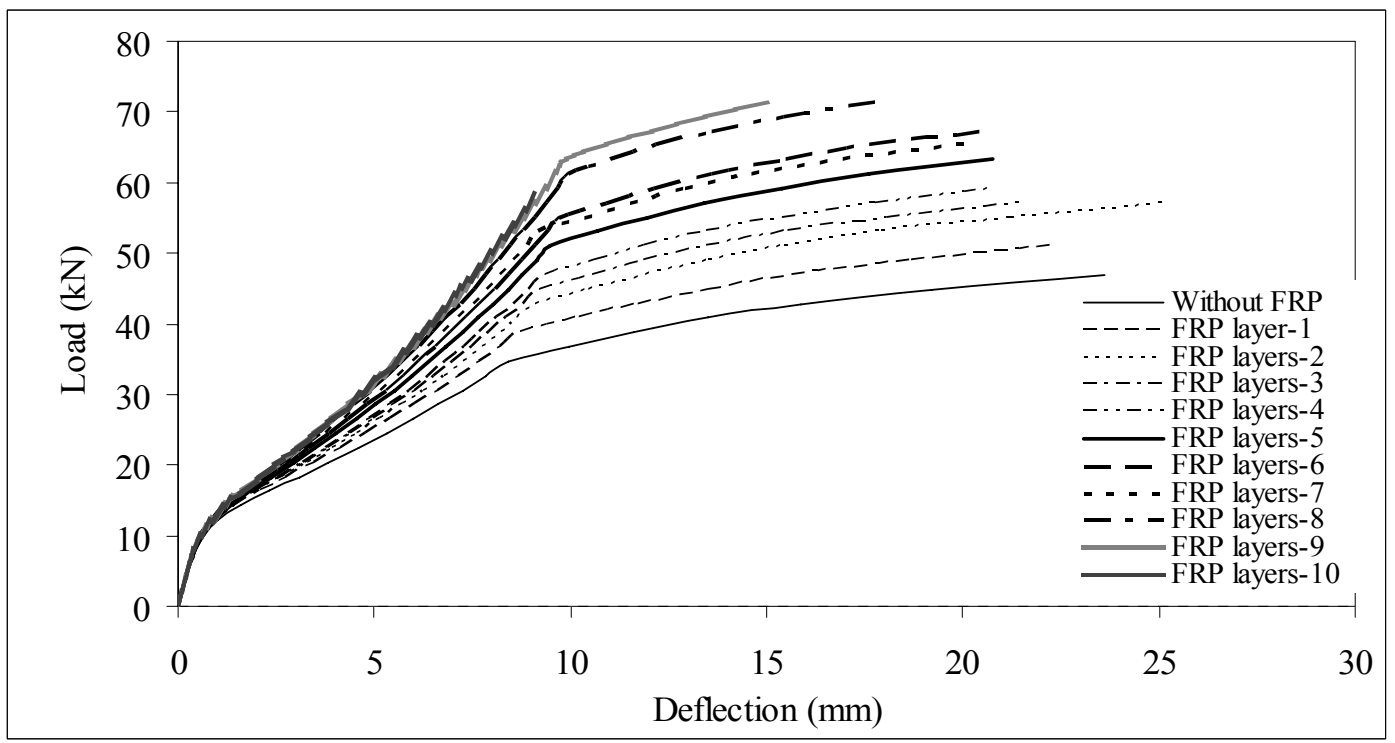

Figure 5.12: Load-deflection curve of RC beams strengthened with variable number of FRP layers by using the mixed FE model. 


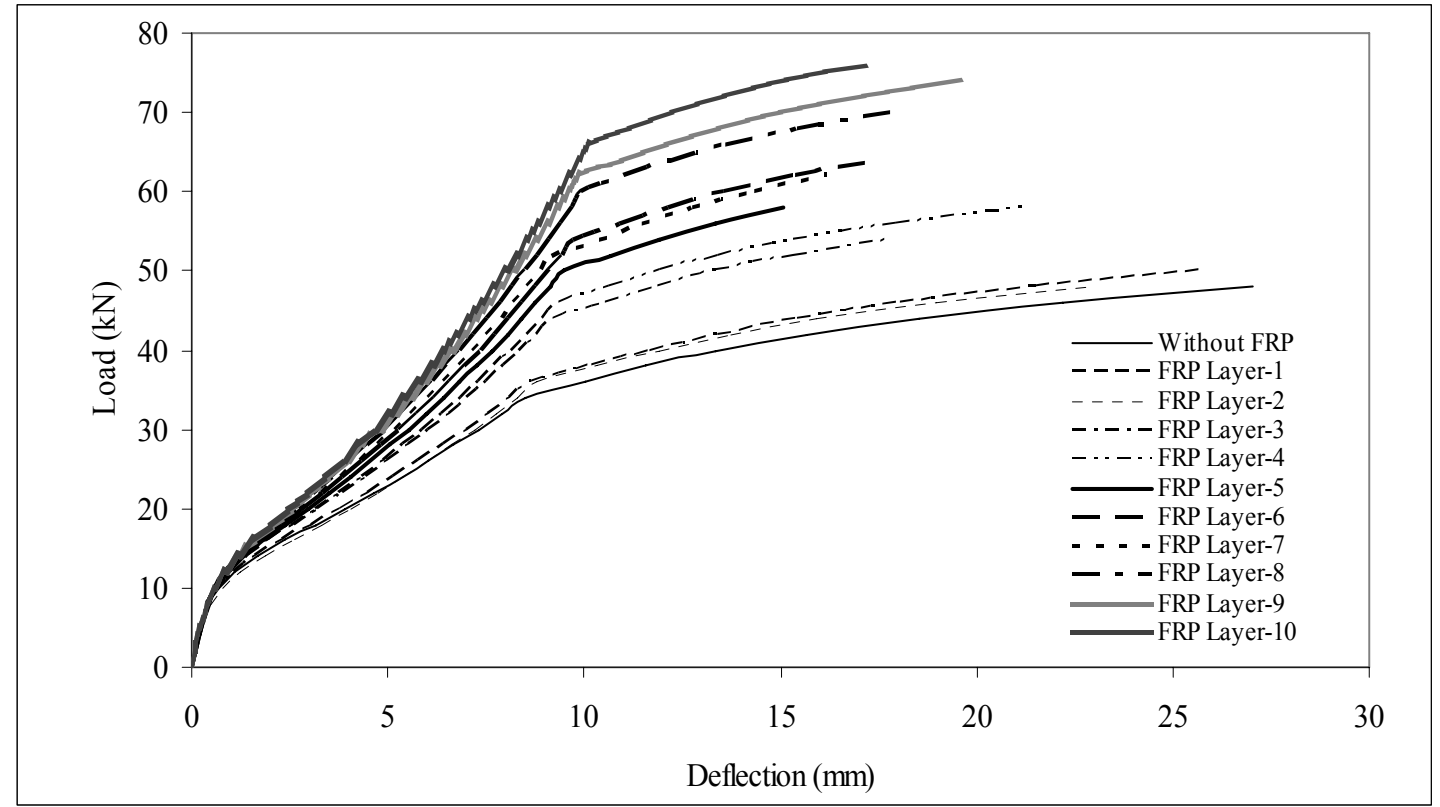

Figure 5.13: Load-deflection curve of RC beams strengthened with variable number of FRP layers by using the combined model.

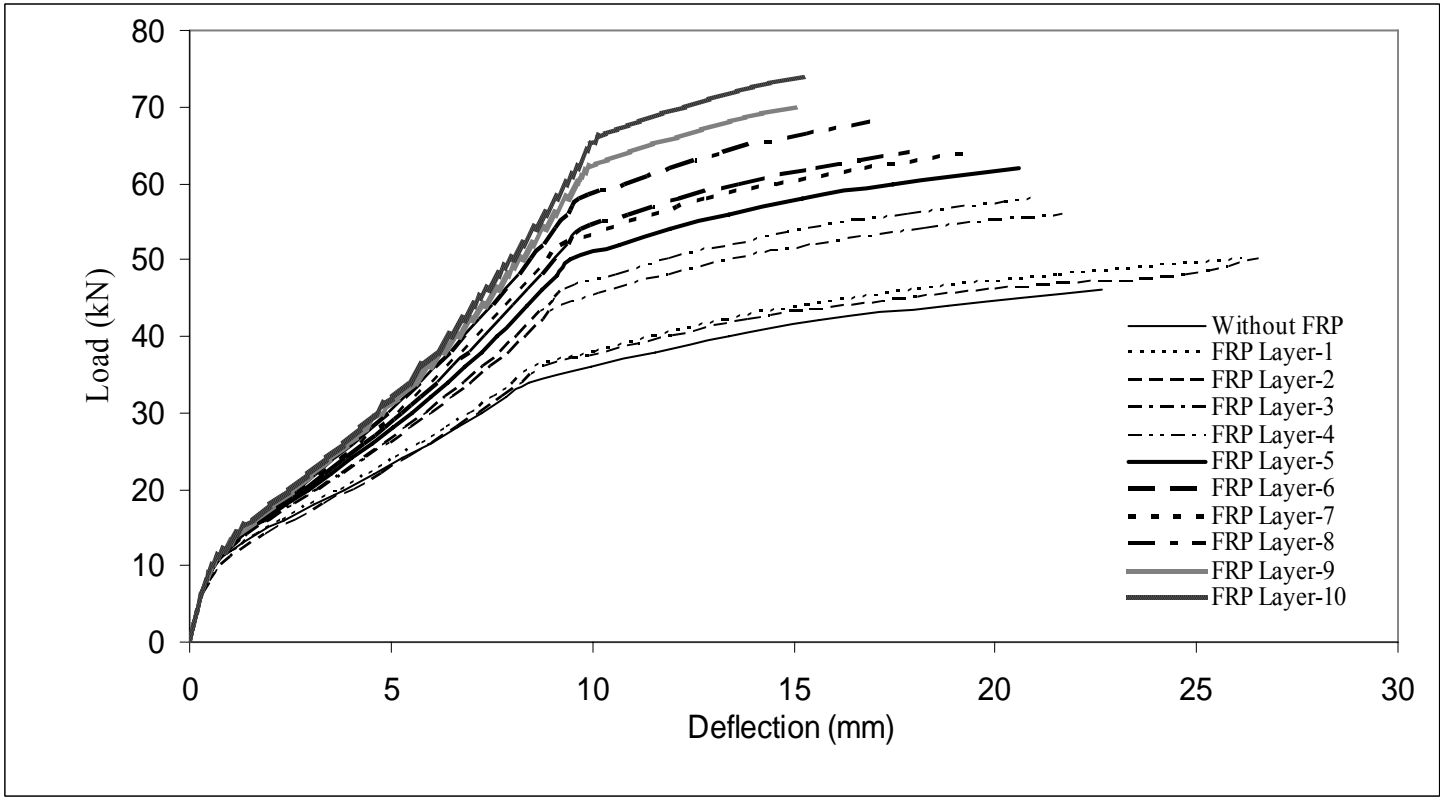

Figure 5.14: Load-deflection curve of RC beams strengthened with variable number of FRP layers by using the displacement model. 
It can be seen that increasing the number of layers of FRP increases the load capacity of the beam and reduces the beam maximum mid-span deflection. The rate increase in the ultimate load is almost constant with the increase in the number of FRP laminas. Slight increase in the maximum mid-span deflection is first noticed when the beam is reinforced with one and two layers of FRP. With more layers of FRP, the maximum mid-span deflection of the beam decreases with the number of the FRP reinforcement. The prediction of the ultimate load capacity of the beams is not significantly affected by the use of different model while the maximum mid-span deflection prediction is. It should be noted hat only up to ten layers of FRP is considered here and that the first-ply failure of the FRP and the delimitation between the laminas are not taken into account in this study.

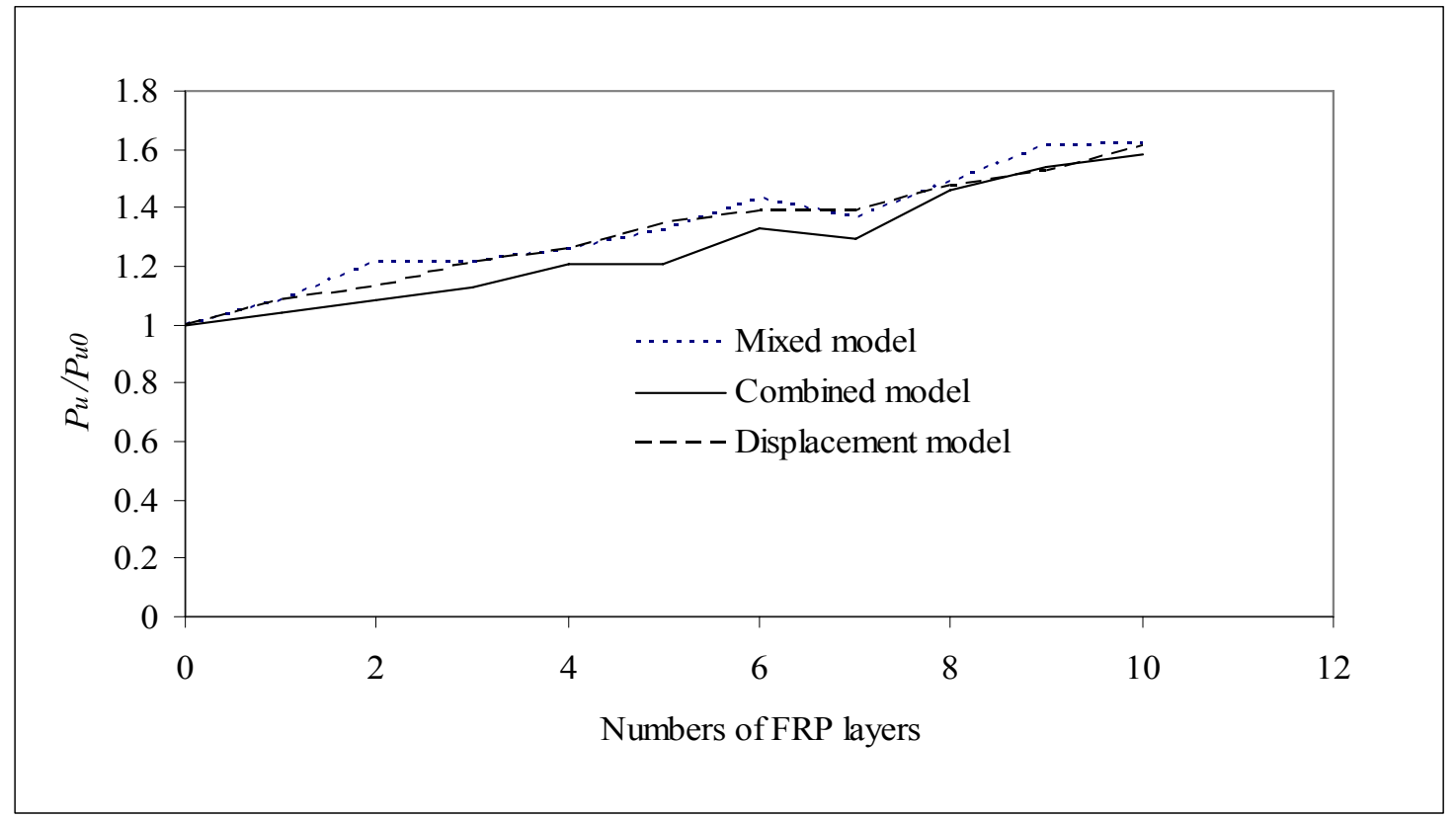

Figure 5.15: Ultimate load ratio versus number of FRP layers for simply supported RC beam with and without FRP layers. 


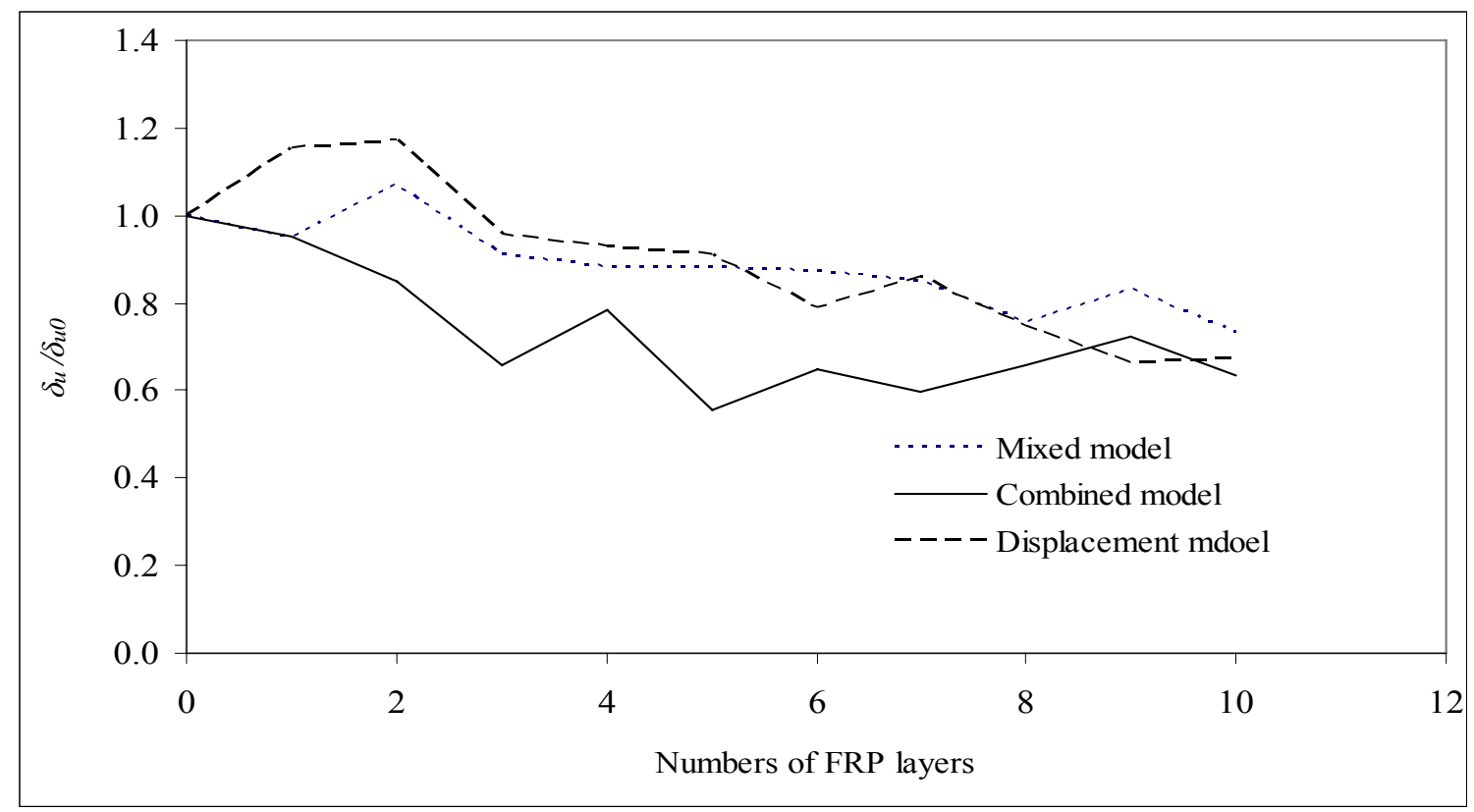

Figure 5.16: Maximum mid span deflection ratio versus number of FRP layers for simply supported RC beam with and without FRP layers.

\subsubsection{Length of FRP layers}

The effects of the externally reinforced FRP lengths on the ultimate load and the maximum mid-span deflection of a simply-supported $\mathrm{RC}$ beam are examined. The beam's geometric and material properties are the same as in previous example. The beam is reinforced with three layers of FRP. The lengths of FRP considered are $0 \%$ (without FRP), $12.5 \%$ (305 mm), 25\% (610 mm), 37.5\% ( $915 \mathrm{~mm}), 50 \%$ (1220 mm), 62.5\% (1524 mm), 75\% (1829 mm), 87.5\% (2135 mm), and 100\% (full length) of the beam length. Figures 5.17, 5.18, and 5.19 illustrate load-deflection curves for the mixed FE model, the combined model, and the displacement model, respectively. It is found that an increase in the length of FRP reinforcement increases the ultimate load of the beam. 


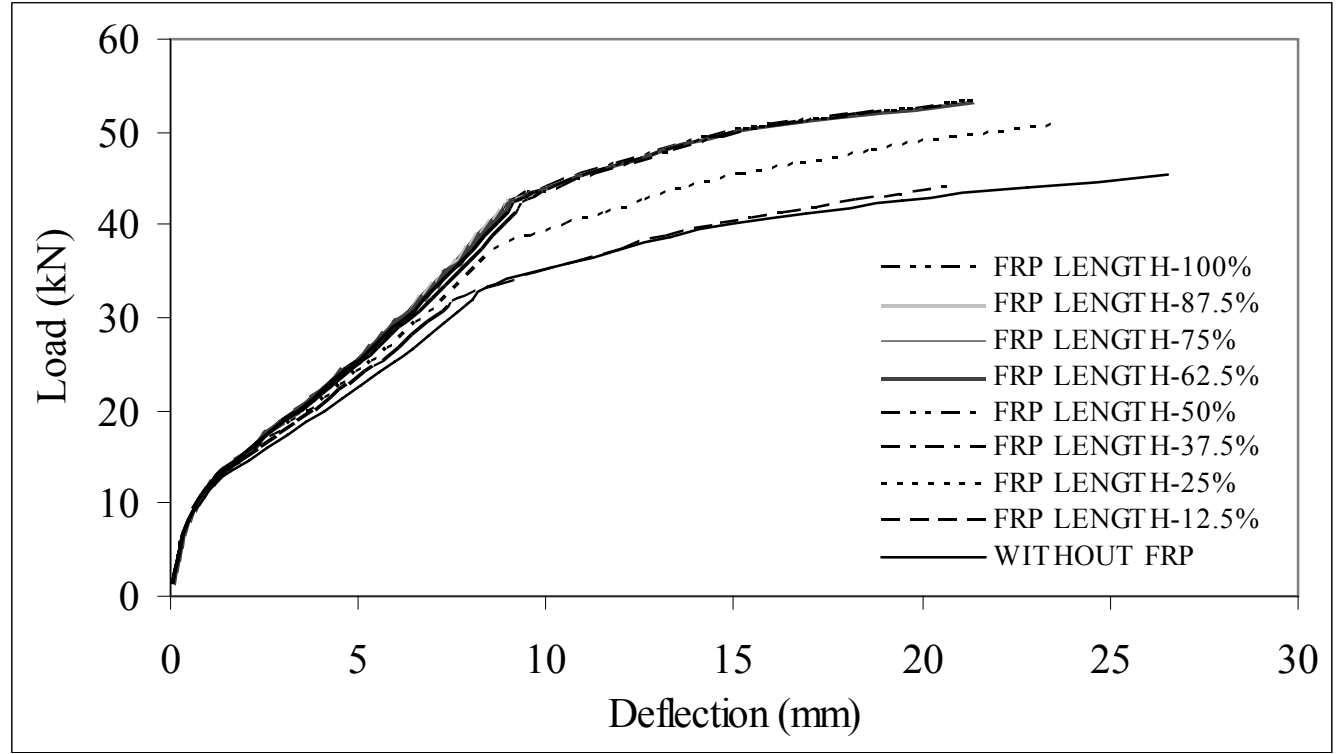

Figure 5.17: Load-deflection curves of a simply-supported beam with varying length of FRP reinforcement by using the mixed FE model

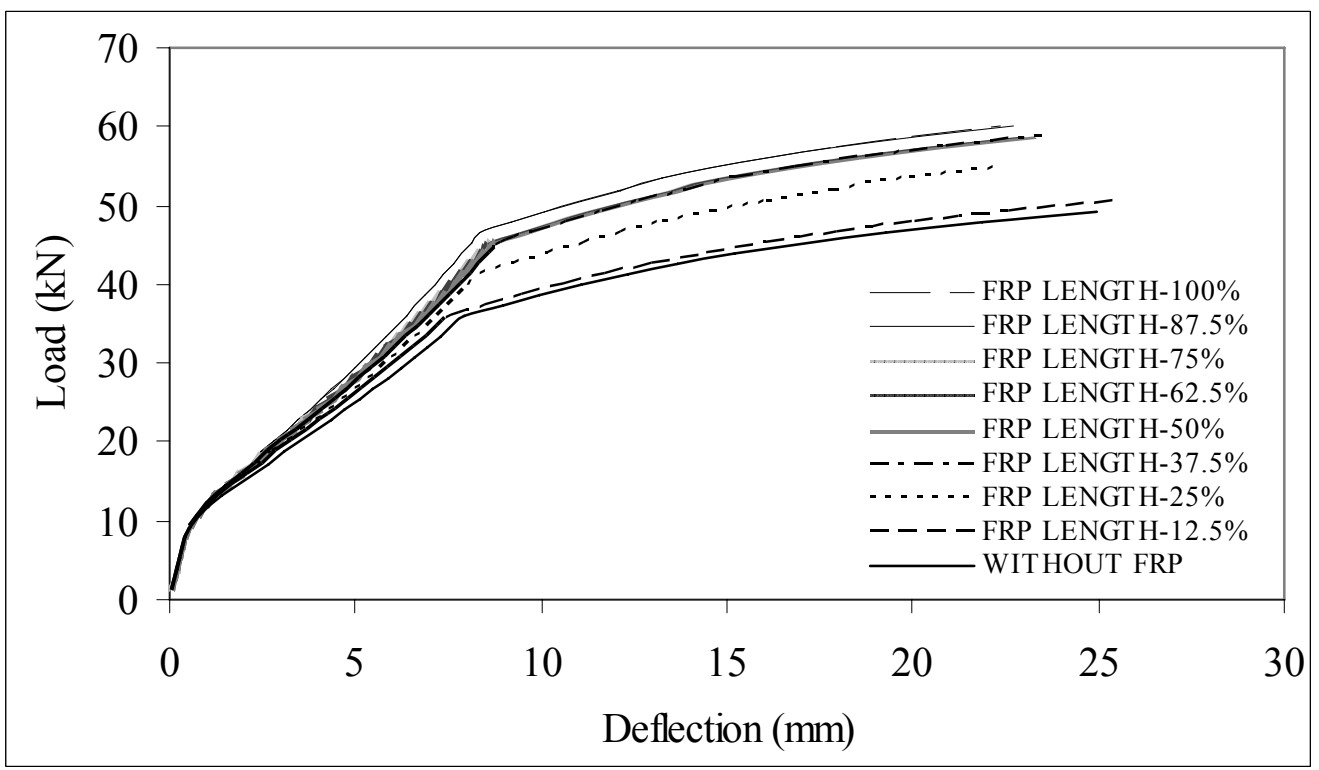

Figure 5.18: Load-deflection curves of a simply-supported beam with varying length of FRP reinforcement by using mixed element model by using the combined model 


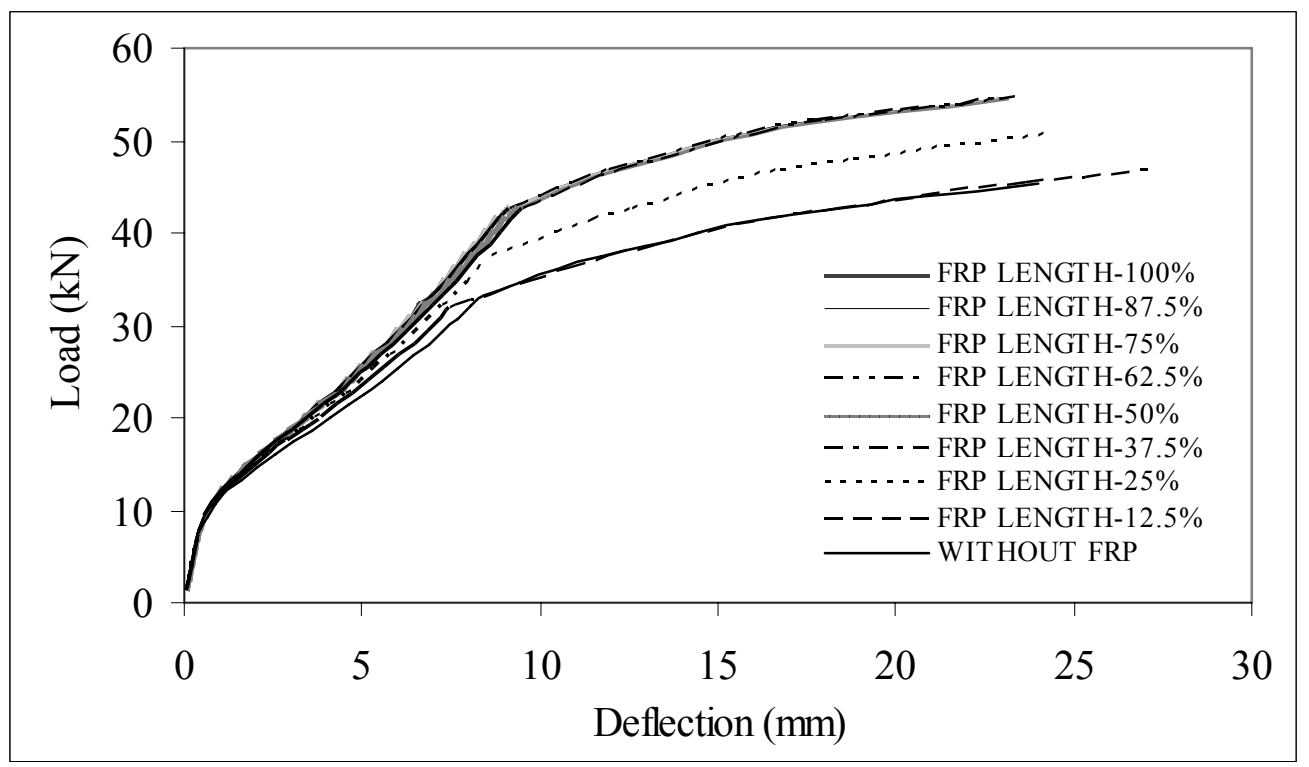

Figure 5.19: Load-deflection curves of a simply-supported beam with varying length of FRP reinforcement by using mixed element model by using the displacement model

The plots of the ultimate load ratio and the maximum mid-span deflection ratio are shown in Figure 5.20 and 5.21, respectively. An increase in the length of the FRP laminas increases the ultimate load of the beam and slightly reduces the maximum mid-span deflection of the beam. The increase in the length of FRP beyond $50 \%$ of the beam length, however, does not significantly contribute to the beam bending capacity nor affects the maximum mid-span deflection. 


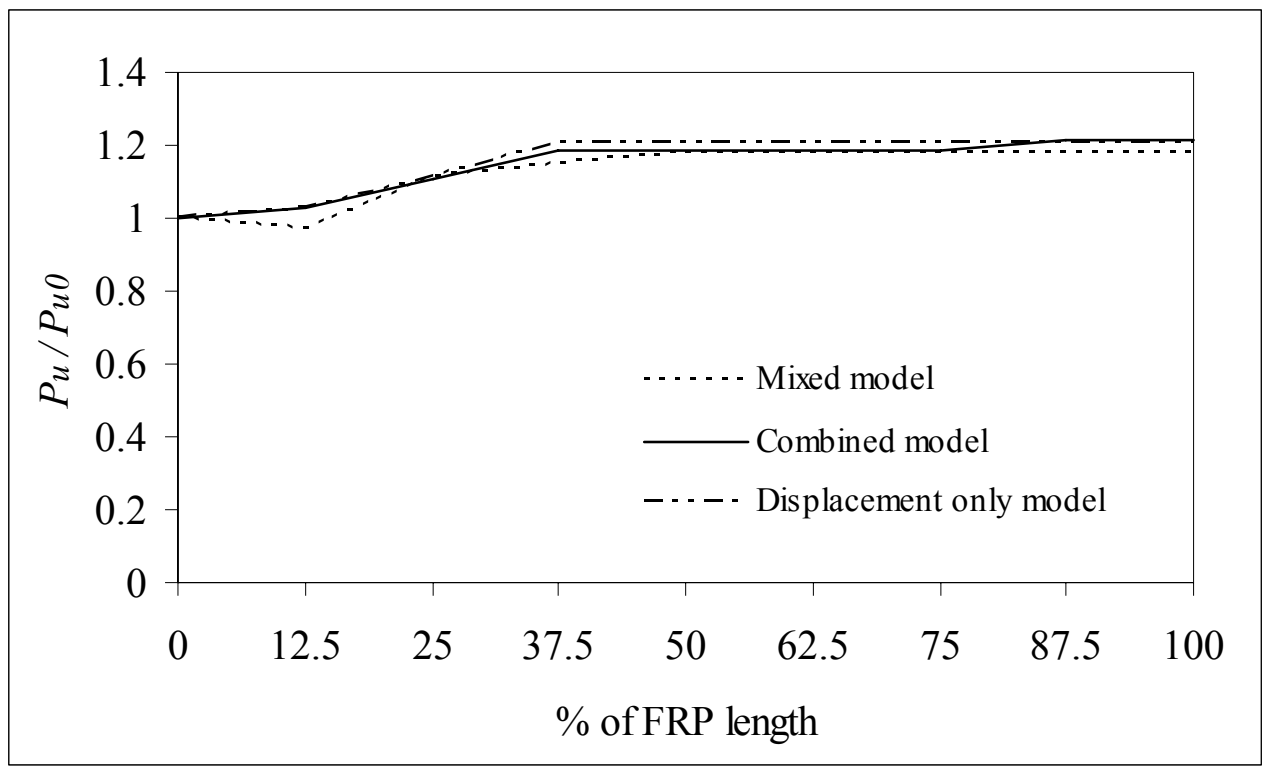

Figure 5.20: Ultimate load ratio versus percent of FRP length for simply supported RC beam.

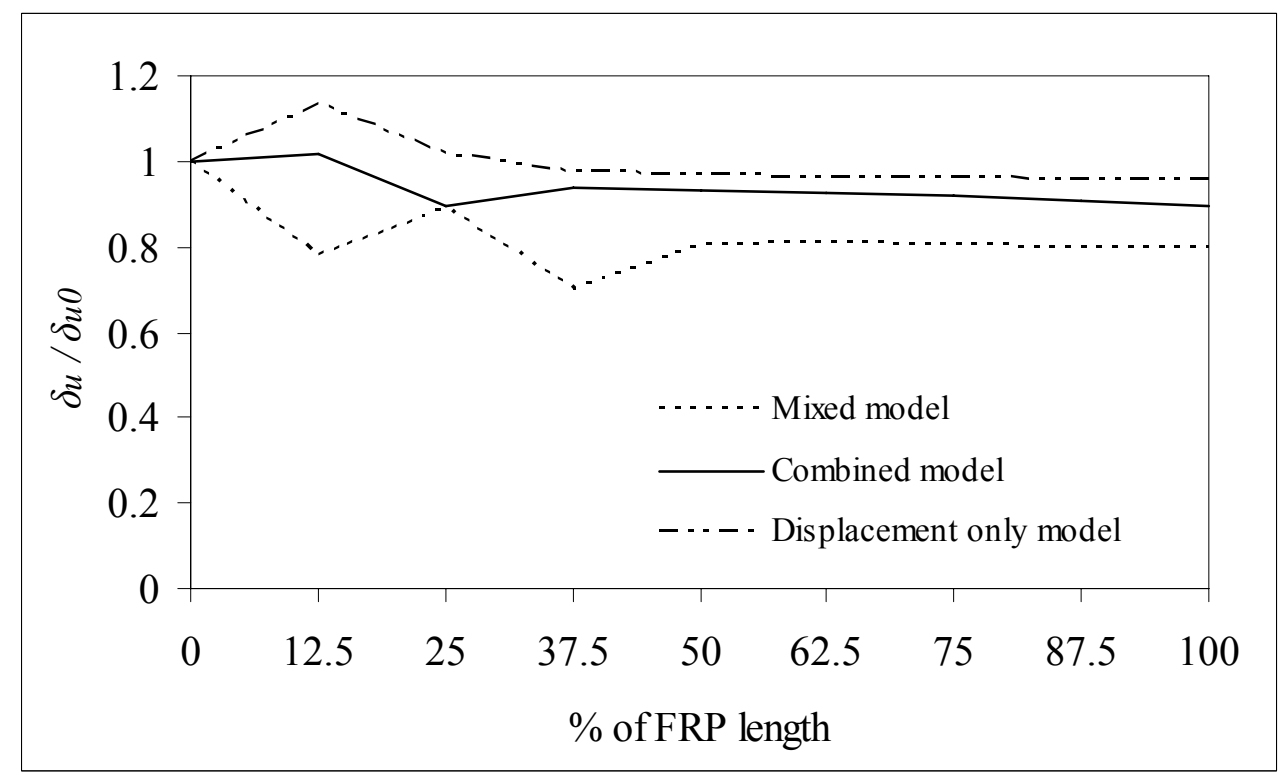

Figure 5.21: Maximum mid span deflection ratio versus percent of FRP length for simply supported RC beam. 


\subsubsection{Composite Plate}

We considered a square concrete plate of size $1000 \mathrm{~mm} \times 1000 \mathrm{~mm} \times 100 \mathrm{~mm}$. A uniformly distributed load was applied on the top surface of the plate. Due to bi-axial symmetry, a quarter plate had been used with ideal support condition (Table 5.2). For meshing, three elements in $X$-direction and three elements in $Y$-direction were considered. In the $Z$-directions, concrete was meshed into six layers and additional layer of mesh was considered for each layer of FRP. The thickness of each FRP layer was $0.1702 \mathrm{~mm}$. The material properties of concrete and of FRP are, respectively

$$
\begin{array}{clll}
\varepsilon_{0}=0.002 & \varepsilon_{f}=0.003 & f_{c}^{\prime}=46.1 \mathrm{MPa} & f_{f}=41.5 \mathrm{MPa} \\
\sigma_{f}=3.9 \mathrm{MPa} \quad E_{c}=43090 \mathrm{MPa} & v=0.1 & \eta=1.0 \times 10^{-4} \\
& & & \\
E_{11}=138 \mathrm{GPa} & E_{22}=14.5 \mathrm{GPa} & v_{12}=0.21 \\
G_{12}=G_{13}=5.86 \mathrm{GPa} & G_{23}=3.52 \mathrm{GPa} &
\end{array}
$$

\subsubsection{Laminating scheme of FRP layers}

Fibre-orientation angle plays an important role in the increase of the plate strength. This is due to FRP having high strength in the fibre direction, and low strength in the direction perpendicular to the fibre. In order to maximize the FRP reinforcement strength, balanced laminate is commonly used. Four-ply $[\beta] /[-\beta] /[\beta] /[-\beta]$ FRP, where the fibreorientation angle $\beta$ is measured from the $X$-axis of the plate, is considered for this example. Each ply is $0.6808 \mathrm{~mm}$ thick. Figures $5.22,5.23$ and 5.24 demonstrate the effects that fibre-orientation angle have on the nonlinear behavior of the concrete plate for mixed FE model, combined model, and displacement model, respectively. 


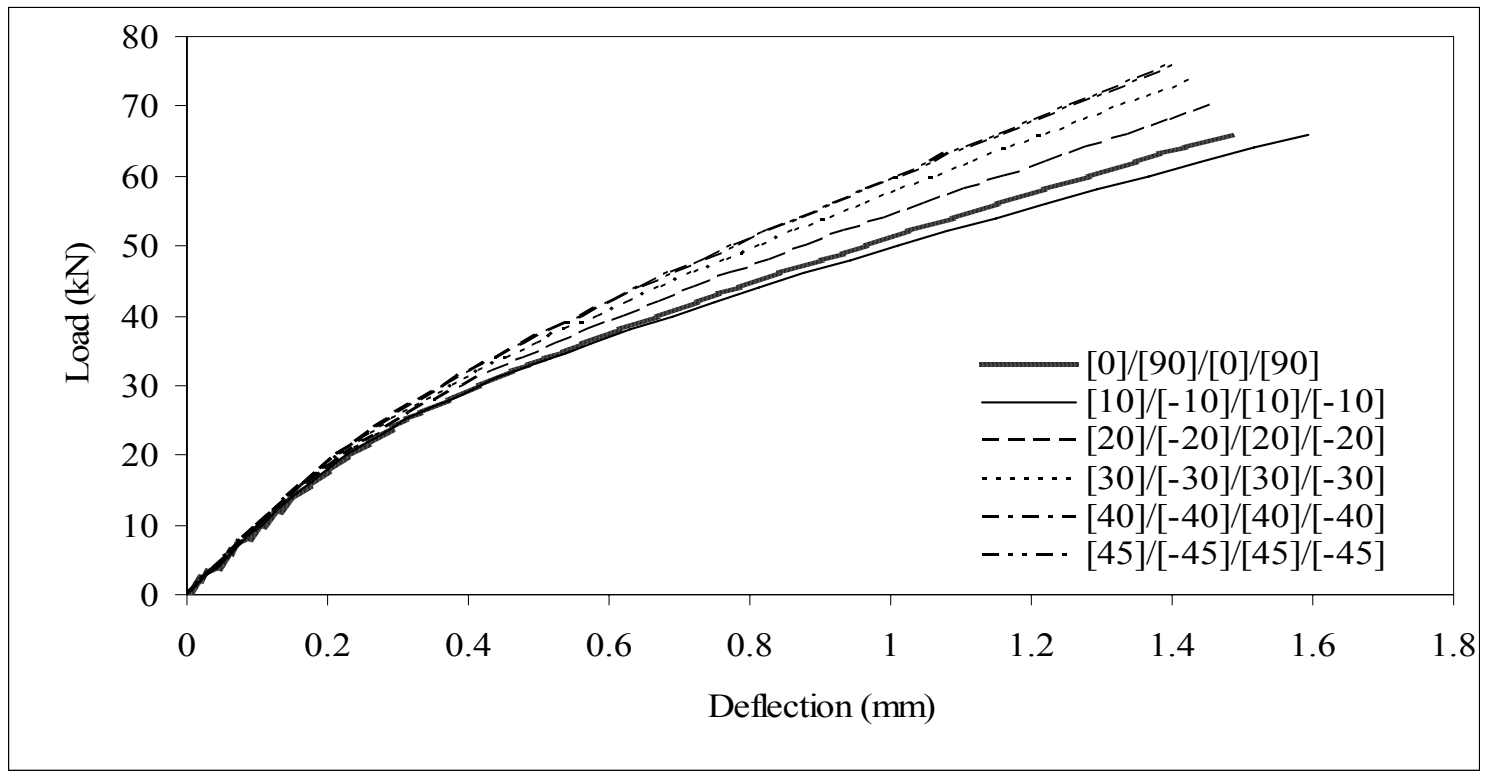

Figure 5.22: Load-deflection curves of a simply-supported plate with four-ply FRP reinforcement having fibre-orientation angle of $[\beta] /[-\beta] /[\beta] /[-\beta]$ by using the mixed FE model.

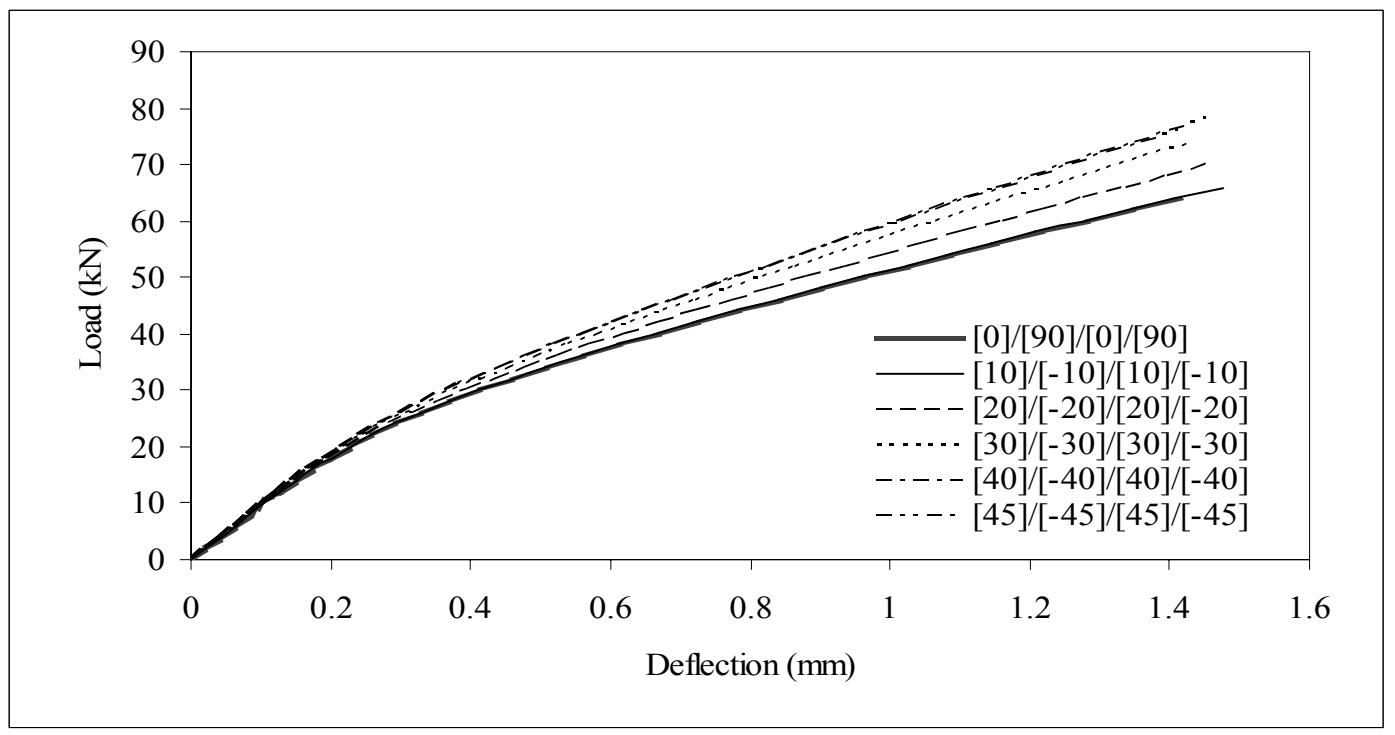

Figure 5.23: Load-deflection curves of a simply-supported plate with four-ply FRP reinforcement having fibre-orientation angle of $[\beta] /[-\beta] /[\beta] /[-\beta]$ by using the combined model. 


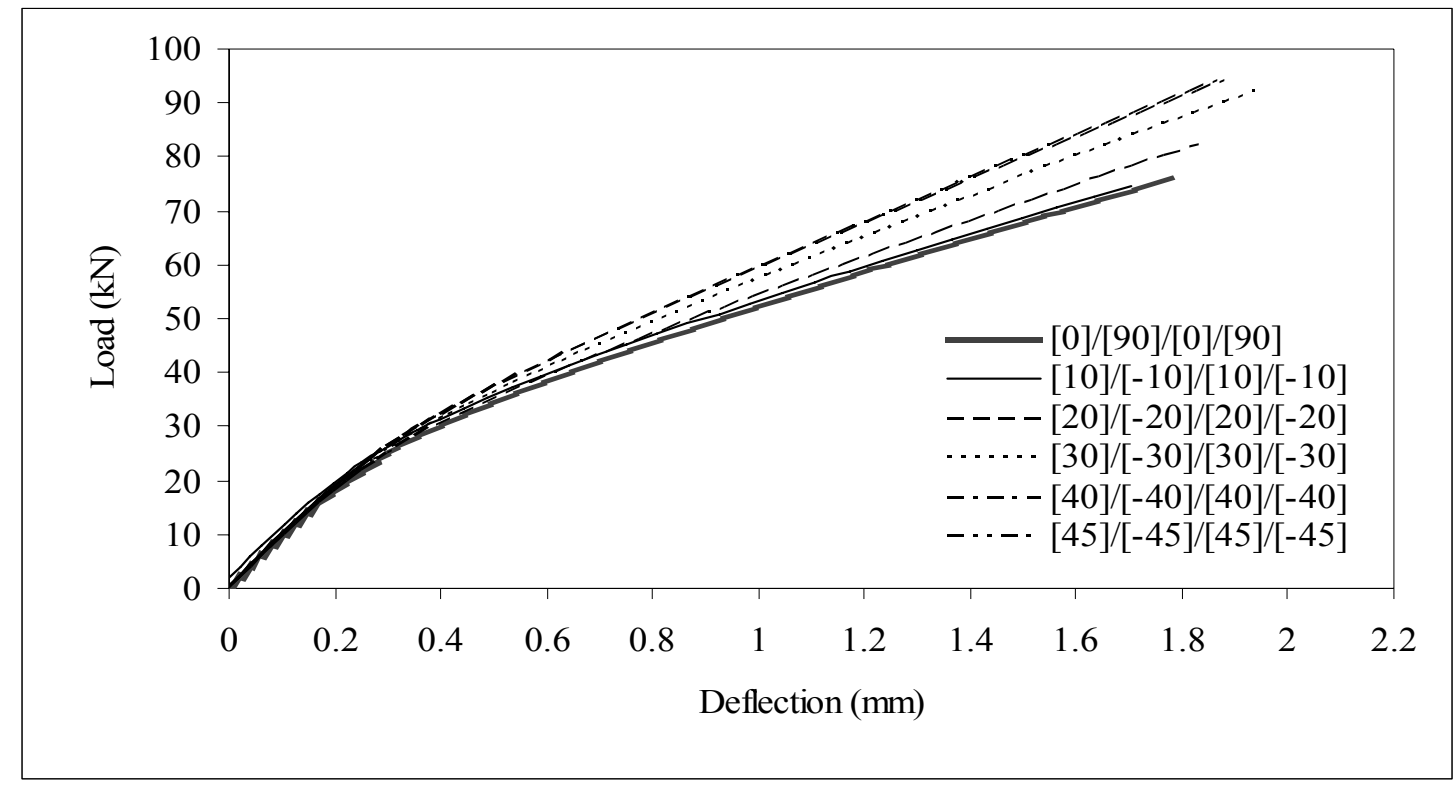

Figure 5.24: Load-deflection curves of a simply-supported plate with four-ply FRP reinforcement having fibre-orientation angle of $[\beta] /[-\beta] /[\beta] /[-\beta]$ by using the displacement element model.

Figures 5.25 and 5.26 demonstrate the effects of fibre-orientation angle on the plate ultimate load capacity ratio and the plate maximum deflection ratio respectively using all three models. Here, $P_{u 0}$ and $\delta_{u 0}$ are the ultimate load capacity and the maximum deflection at the middle of the plate with $[0] /[90] /[0] /[90]$ FRP reinforcement, respectively. The two models: the mixed FE and the combined model, show that an increase in a fibre-orientation angle increases the ultimate load capacity of the plate and, simultaneously, reduces the maximum deflection at the middle of the plate. The displacement model, however, produces questionable results, i.e. the ultimate load capacity and the maximum deflection at the middle of the plate both increase with an increase in the fibre-orientation angle. It should be noted here that due to symmetry in geometry, when $\beta$ is greater than $45^{\circ}$, load-deflection curves of the plate are the same as 
those when $\beta$ is less than $45^{\circ}$. The maximum ultimate load is obtained when the fibreorientation angle reaches $45^{\circ}$. This is expected because of the symmetric property of the problem.

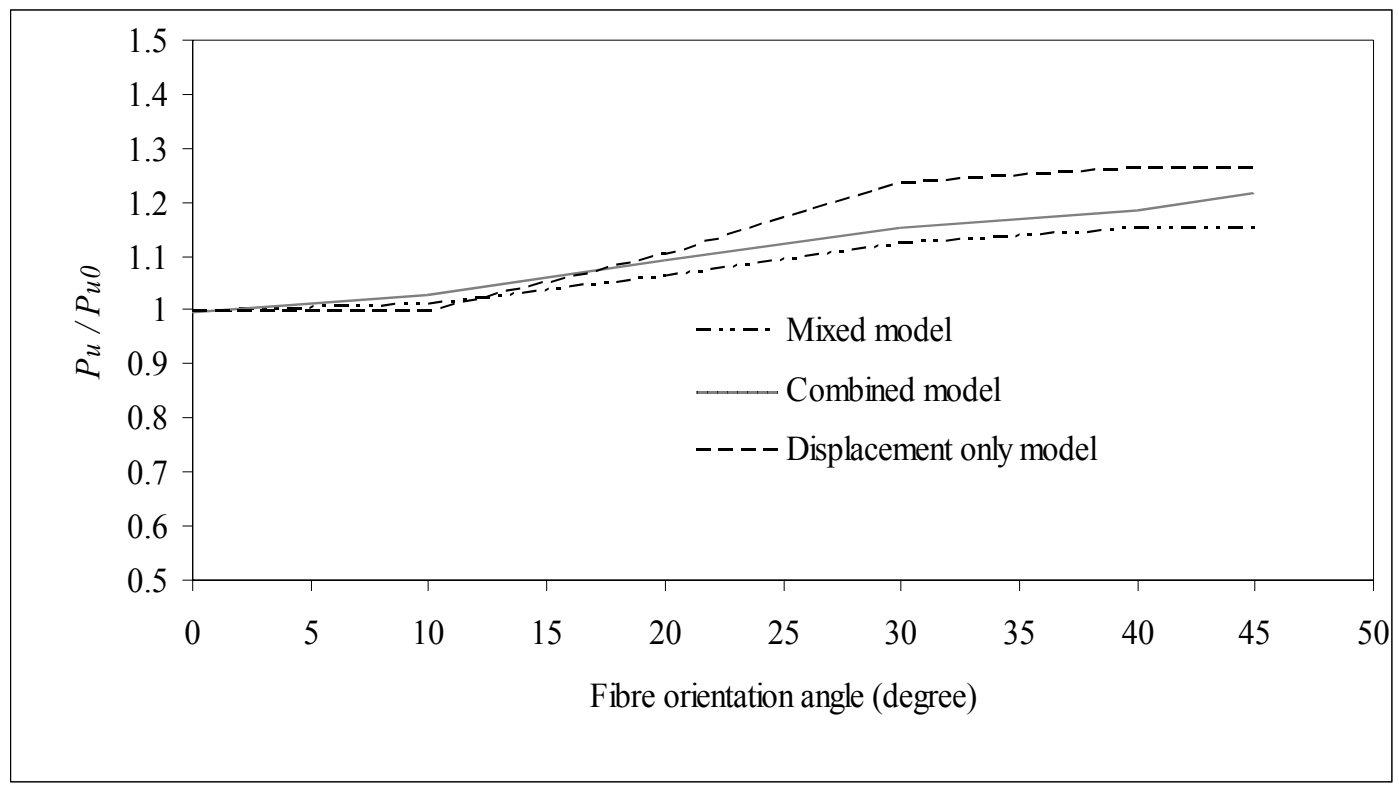

Figure 5.25: Ultimate load ratio of a simply-supported plate with externally reinforced FRP laminates having different fibre-orientation angles of $[\beta] /[-\beta] /[\beta] /[-\beta]$ 


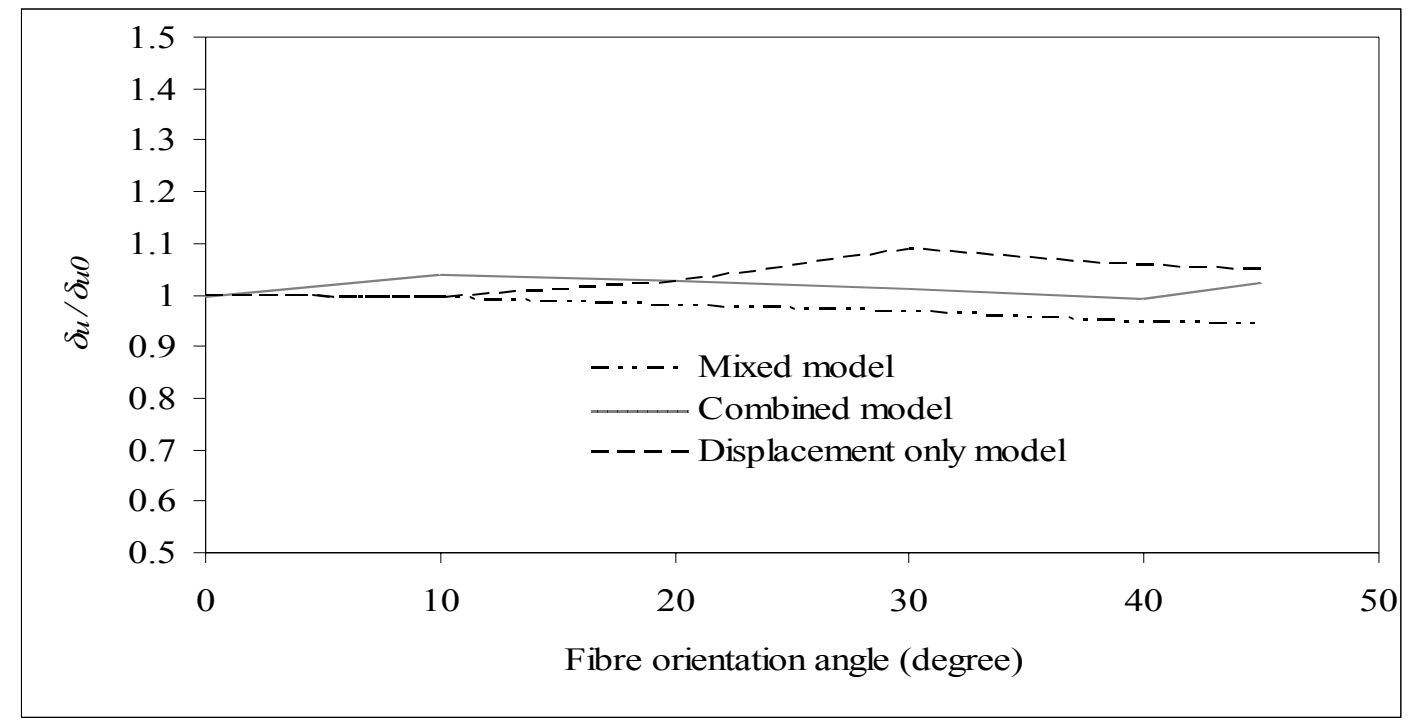

Figure 5.26: Maximum mid span deflection ratio of a simply-supported plate with externally reinforced FRP laminates having different fibre-orientation angles of

$$
[\beta] /[-\beta] /[\beta] /[-\beta]
$$

\subsubsection{Plate aspect ratio}

The effects of the plate aspect ratio $(a / b)$ on the response of an all side simplysupported, FRP reinforced steel-free concrete rectangular plate subjected to a uniformly distributed load are investigated. The plate is reinforced with three FRP layers. Each FRP layer thickness is $0.1702 \mathrm{~mm}$. Two fibre orientations $(0 / 90 / 0$ and $0 / 0 / 0)$ are considered. The ratio of length to width is considered as $a / b=1,1.25,1.67$, and 2.5. Figures 5.27, 5.28, and 5.29 illustrate the plate load-deflection curve predicted by the mixed FE model, the combined model, and the displacement model, respectively. 


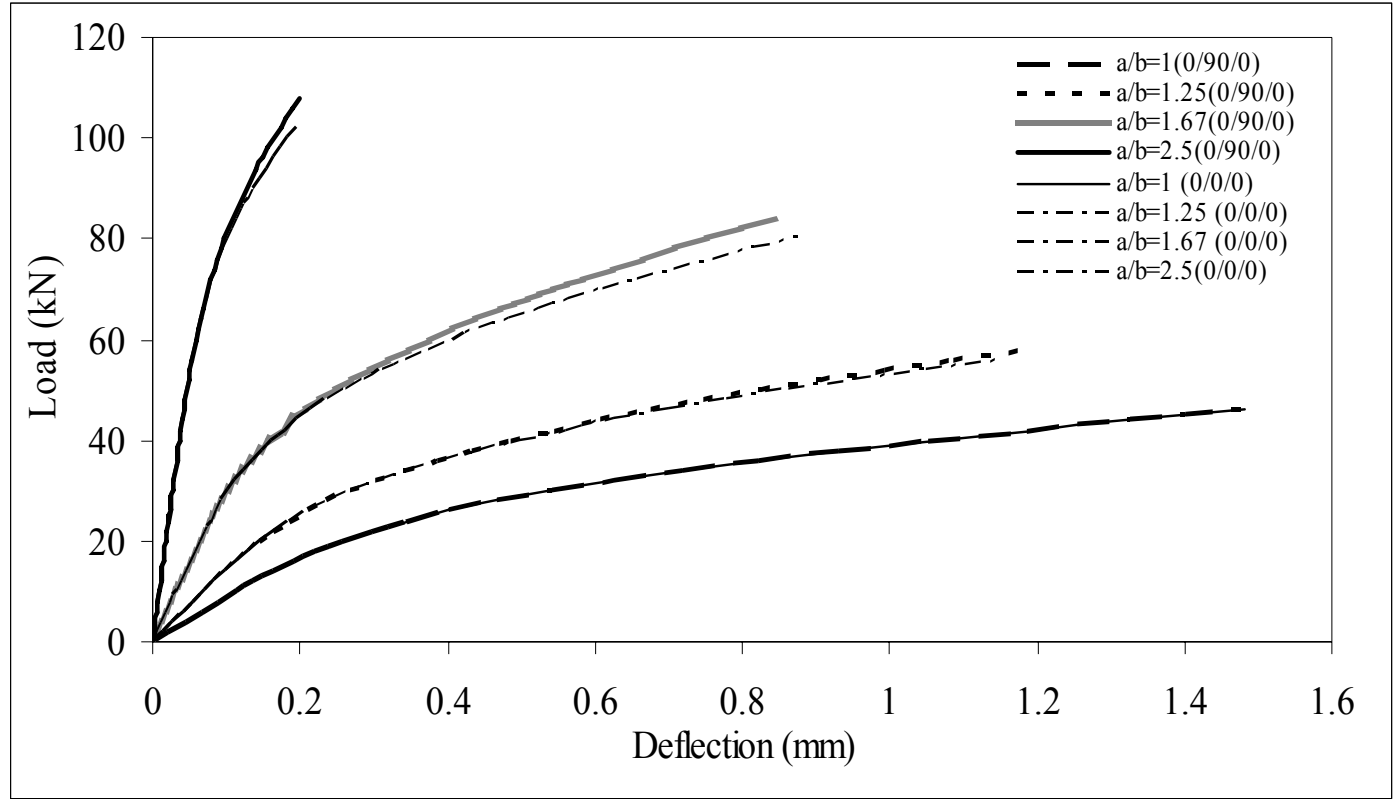

Figure 5.27: Load-deflection curves for concrete plate strengthened with FRP for layers orientation: 0/0/0 and 0/90/0 by using the mixed FE model.

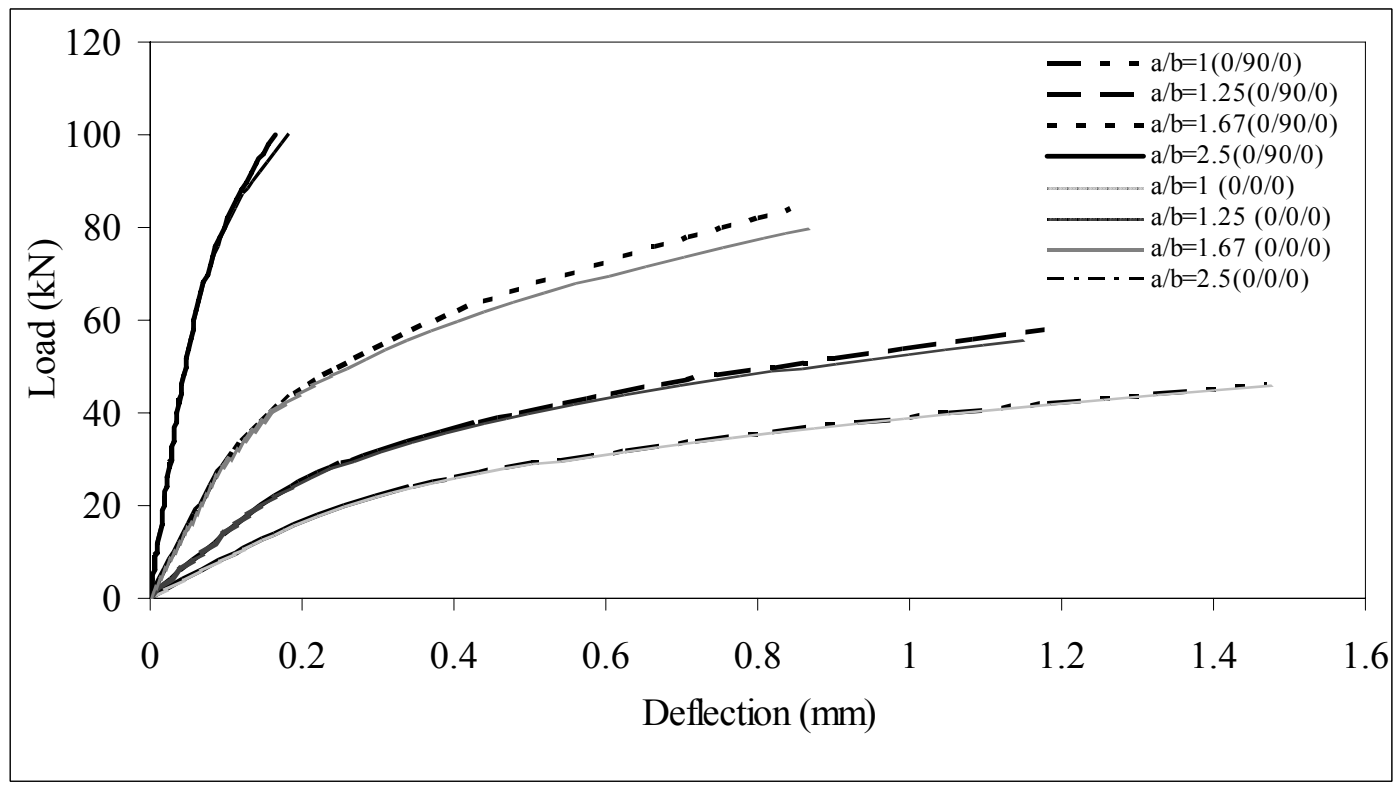

Figure 5.28: Load-deflection curves for concrete plate strengthened with FRP for layers orientation: $0 / 0 / 0$ and $0 / 90 / 0$ by using the combined model. 


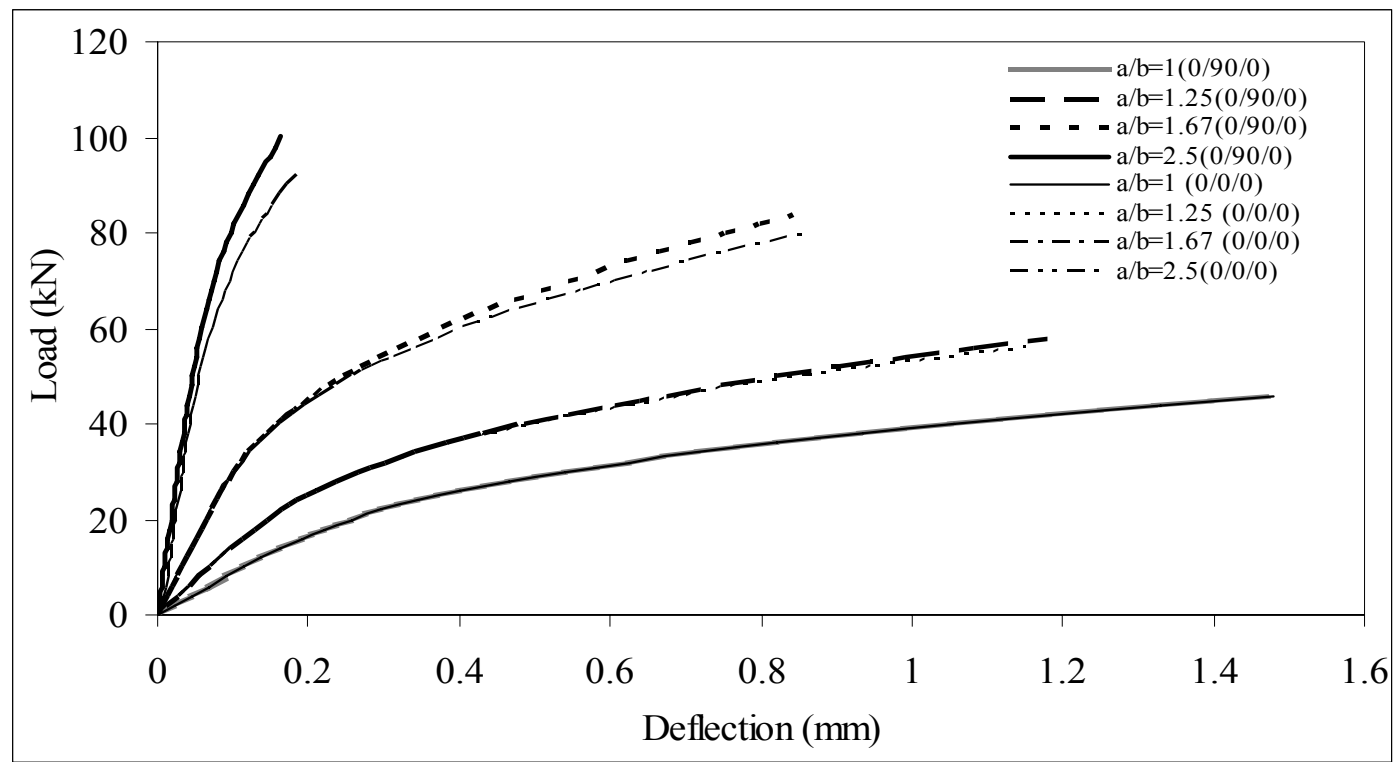

Figure 5.29: Load-deflection curves for concrete plate strengthened with FRP for layers orientation: $0 / 0 / 0$ and $0 / 90 / 0$ by using the displacement model.

Figures 5.30 and 5.31 show the plate ultimate load capacity ratio and the plate maximum deflection ratio calculated using all three models, respectively. The reference ultimate load $P_{u 0}$ and the reference maximum deflection $\delta_{u 0}$ are the values of the plate with $a / b=1$. It is interesting that an increase in the aspect ration increases the plate capacity and decreases the plate maximum deflection. All three models predict the same behaviour and the results are almost identical with the exception of the plate having large aspect ratios where the mixed FE model provides higher prediction of the plate capacity. For two fibre-orientations $(0 / 90 / 0$ and $0 / 0 / 0)$, with $a / b=1$, both results are identical. As $a / b$ increases, $0 / 90 / 0$ orientation shows slightly larger load capacity and less maximum deflection. 


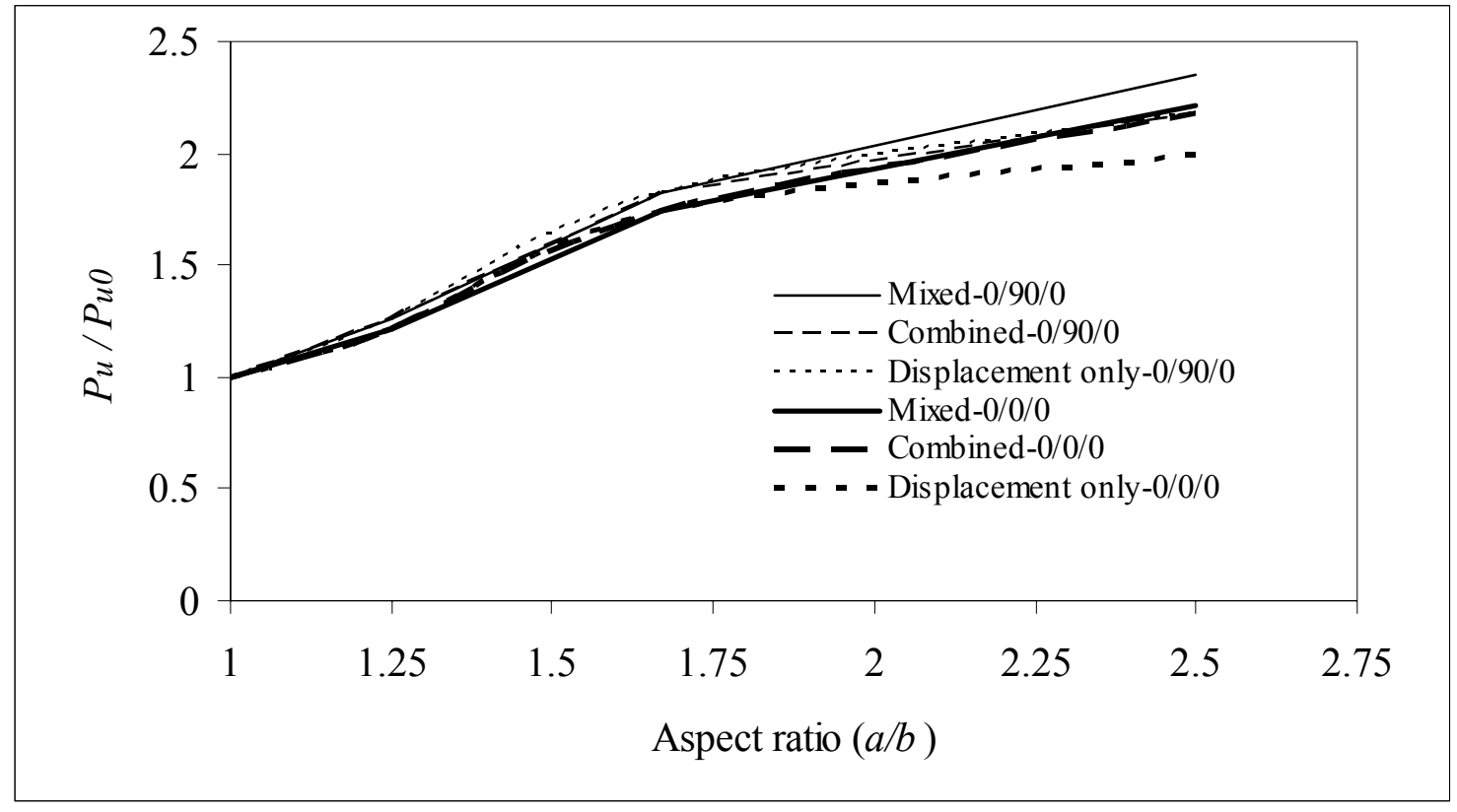

Figure 5.30: Ultimate load ratio versus length-width ratio $(a / b)$ curves for two types of FRP layers orientation $(0 / 90 / 0$ and $0 / 0 / 0)$

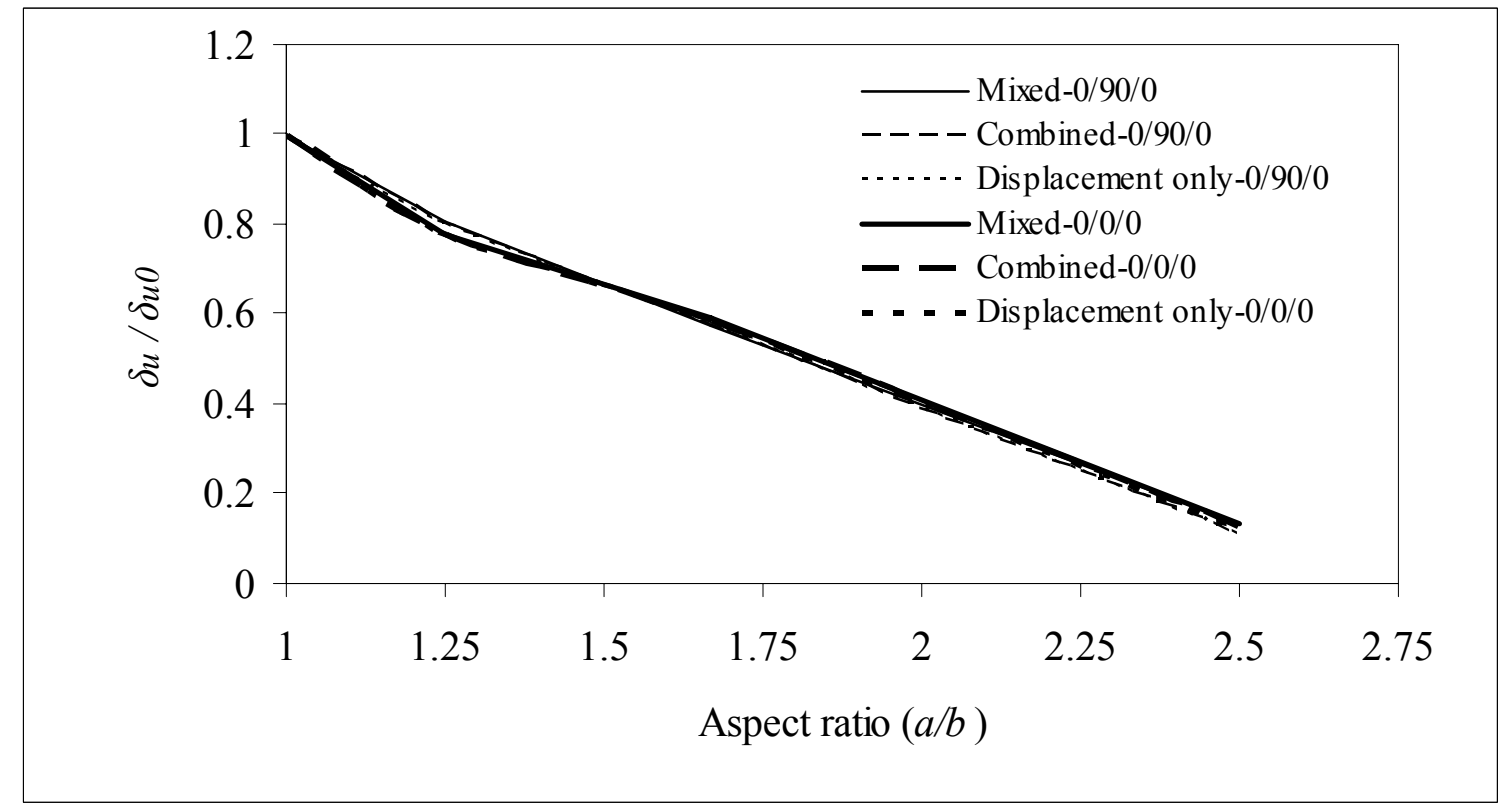

Figure 5.31: Maximum mid span deflection ratio versus length-width ratio $(a / b)$ curves for two types of FRP layers orientation (0/90/0 and 0/0/0) 


\subsubsection{Number of FRP layers}

The effects of the number of externally reinforced FRP laminas on the nonlinear response of a simply-supported concrete plate are investigated. We have performed analysis by considering up to ten layers of FRP for each of the three models, i.e. the mixed FE model, the combined model, and the displacement model. The result sets are shown in the Figures 5.32, 5.33, and 5.34, respectively. The ultimate load ratio $\left(P_{u} / P_{u 0}\right)$ and the maximum mid-span deflection ratio $\left(\delta_{u} / \delta_{u 0}\right)$ of the beams are presented in Figure 5.35. Here $P_{u}$ and $P_{u 0}$ are the ultimate load of the plate with variable number of FRP layers and single layer of FRP reinforcement, respectively, whereas, $\delta_{u}$ and $\delta_{u 0}$ are the maximum mid-span deflection of the plate with variable number of FRP layers and single layer of FRP reinforcement, respectively.

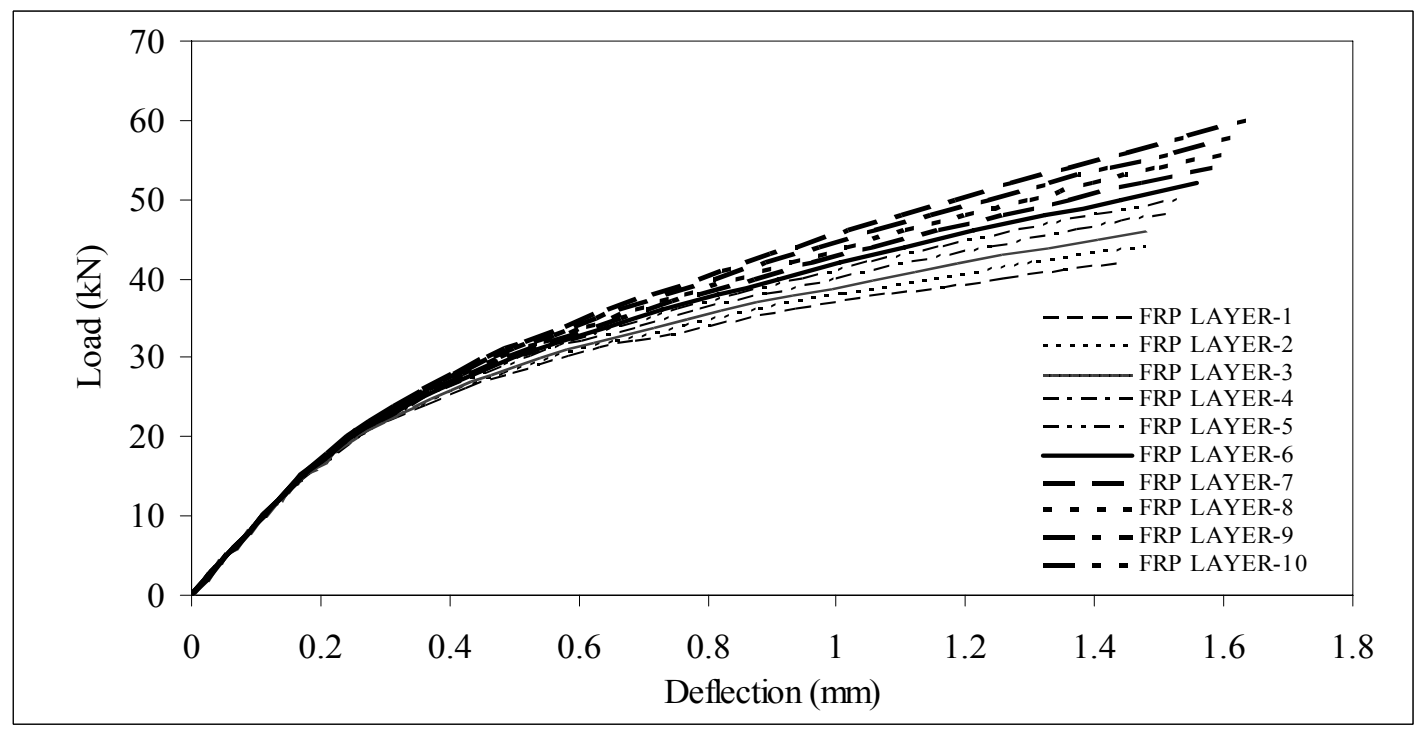

Figure 5.32: Load-deflection curves for concrete plate strengthened with variable number of FRP layers by using the mixed model. 


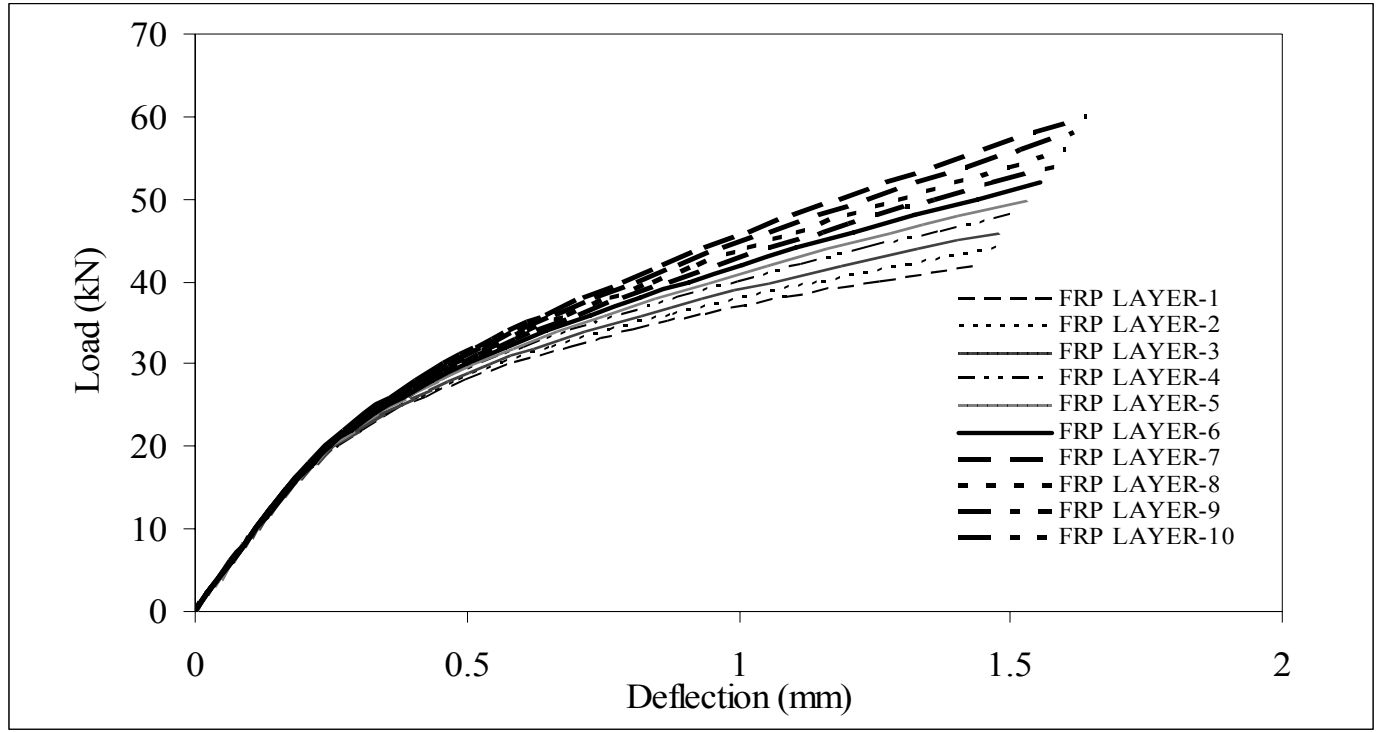

Figure 5.33: Load-deflection curves for concrete plate strengthened with variable number of FRP layers by using the combined model.

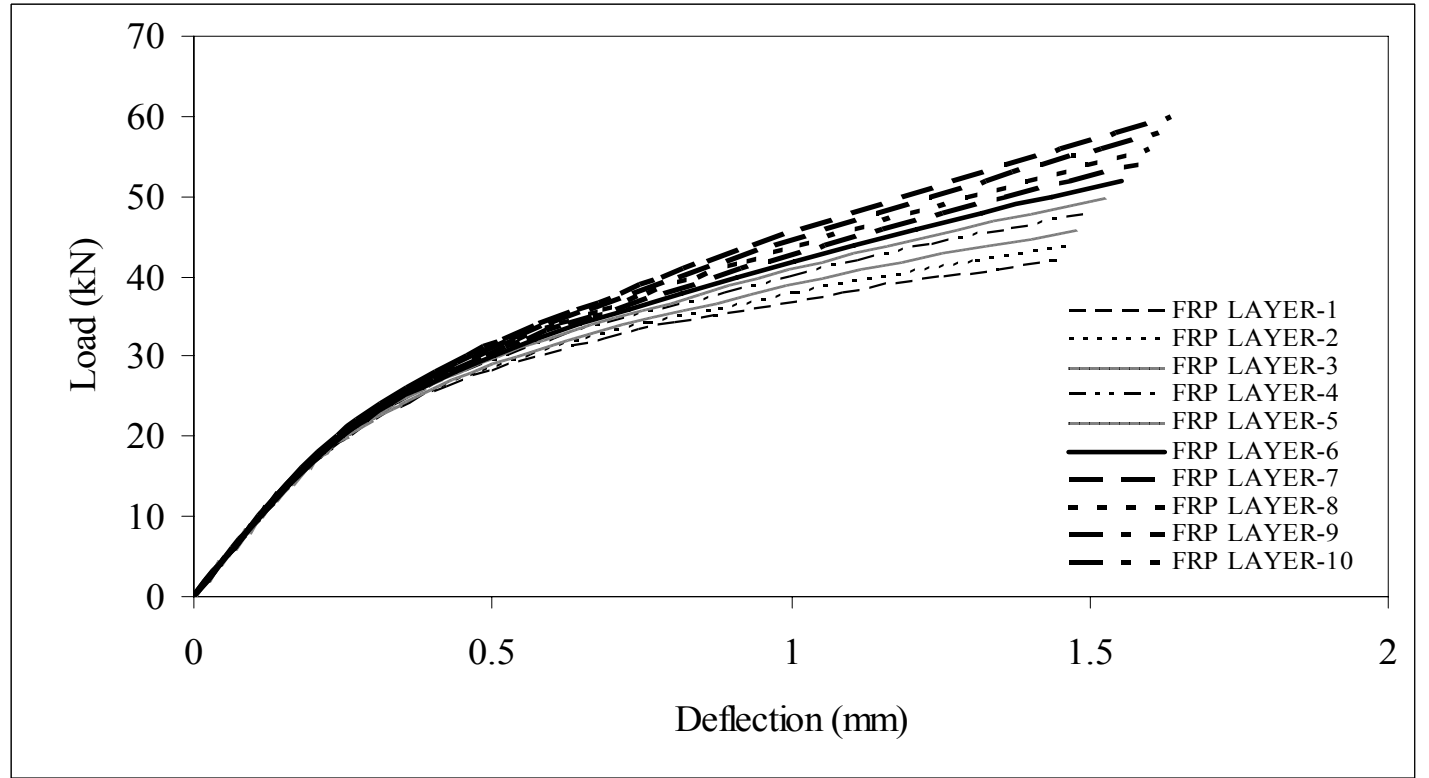

Figure 5.34: Load-deflection curves for concrete plate strengthened with variable number of FRP layers by using the displacement model. 
It can be seen that increasing the number of layers of FRP increases the load capacity of the plate and does not significantly affect the maximum mid-span deflection. The rate increase in the ultimate load is almost constant with the increase in the number of FRP laminas. On the other hand, the maximum mid-span deflection is almost constant with the increasing number of FRP layers. The prediction of both the ultimate load capacity and maximum mid-span deflection of the plate is not affected by the use of different model. It should be noted that only up to ten layers of FRP is considered here and that the first-ply failure of the FRP and the delimitation between the laminas are not taken into account in this study.

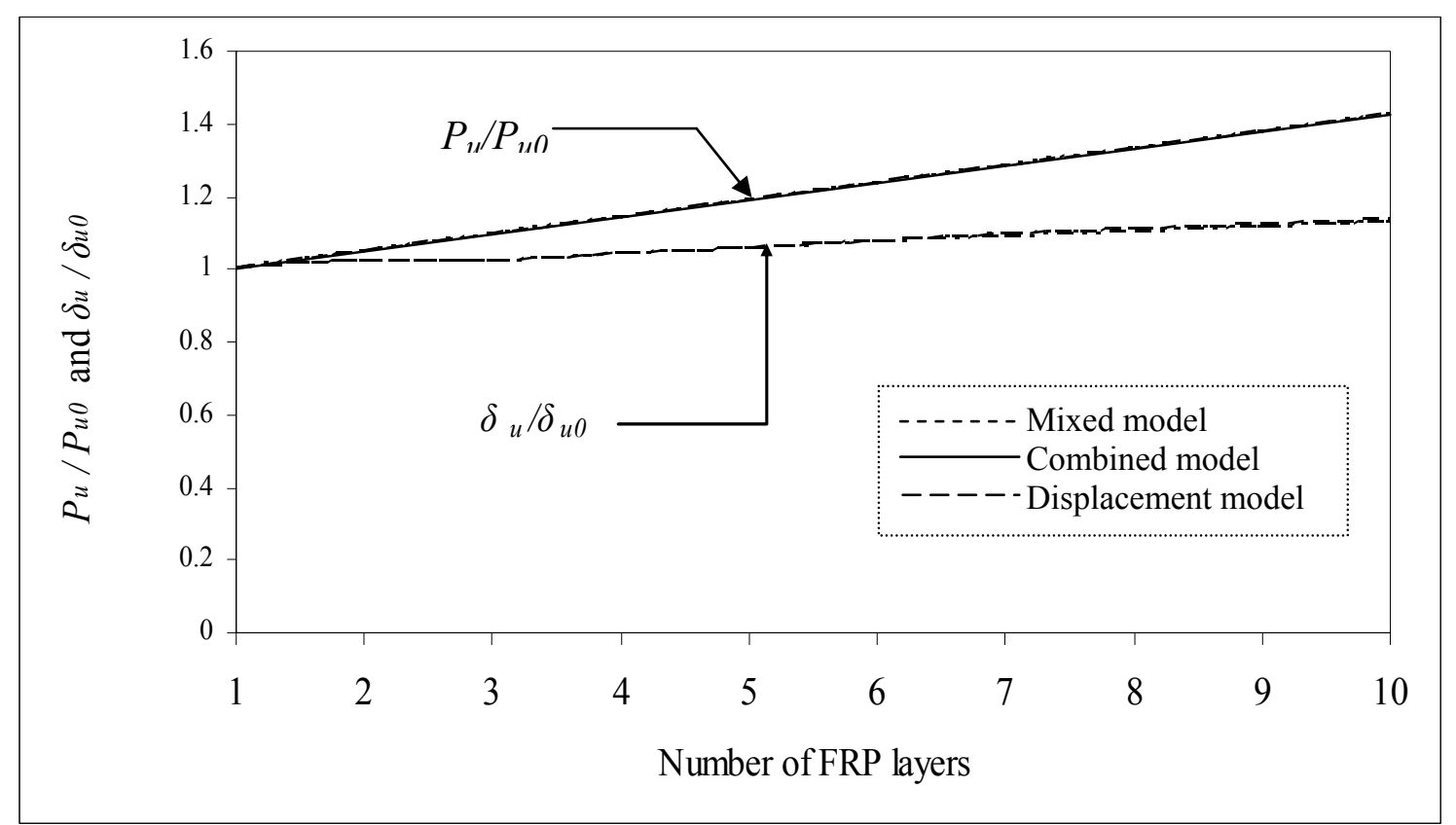

Figure 5.35: Ultimate load ratio and maximum mid span deflection ratio versus number of FRP layers for concrete plate strengthen with FRP 


\section{Chapter VI}

\section{Conclusions}

Three 3D layer-wise 18-node FE models for nonlinear analysis of concrete structures have been introduced. In the first model, three displacement components and three transverse stress components are used while in the second model, only displacement components are used as nodal DOFs. In last model, three displacement components and three transverse stress components are used as nodal DOFs on one surface while only three displacement components are used as nodal DOFs on the opposite surface. All three models incorporate material nonlinearities, smeared crack concept, and smeared reinforcement. The first and third models are based on a mixed FE formulation which approximates displacement components in the form of nodal displacements and nodal stresses using a concept of 3D elasticity theory, a determination of stresses does not require integration. Local-global phenomena are introduced by considering all three models together. In order to reduce the computational time, an element with less DOF is used where the less accurate stress determination is allowed and an element with larger DOF is used where the more accurate stress calculation is required. The developed models are verified by a comparison of numerical and experimental results of RC beams strengthened with FRP and composite concrete plate. From the numerical results, the following conclusions can be made: 
- In composite beam, an increase in the number of layers of FRP increases the load capacity of the beam and reduces the beam maximum mid-span deflection. The prediction of the ultimate load capacity of the beams is not significantly affected by the use of different models while the maximum mid-span deflection prediction is affected for fewer number of FRP layers. With the larger number of FRP layers, all three models show almost similar behavior.

- In composite beam, an increase in the length of FRP beyond $50 \%$ of the beam length, does not significantly contribute to the beam bending capacity nor affects the maximum mid-span deflection.

- In composite plate, an increase in a fibre-orientation angle from X-axis increases the ultimate load capacity of the plate and simultaneously, reduces the maximum deflection at the middle of the plate. The 45/-45/45/-45 fibre-orientation provides the highest ultimate load.

- In composite plate, the load capacity of $0 / 90 / 0$ and $0 / 0 / 0$ FRP reinforcement increases as the length-to-width ratio (or aspect ratio) increases. As the aspect ratio increases, the width of plate decreases in comparison to the length. The plate starts to distribute more loads along the width direction. In the 0/90/0 FRP, the middle layer fiber is oriented along the width direction, hence helps to carry more loads than 0/0/0 FRP reinforcement.

- Increased number of FRP layers increases the load capacity of the plate and does not significantly affect the maximum mid-span deflection. The prediction of both the ultimate load capacity and maximum mid-span deflection of the plate is not affected by the use of different model. 


\section{REFERENCES}

ANSYS Inc., 2004, ANSYS 8.1, Southpointe, 275 Technology Drive, Canonsburg, PA 15317, USA.

Abbas, H.; Gupta, N. K.; and Alam, M., 2004, "Nonlinear response of concrete beams and plates under impact loading”, International Journal of Impact Engineering, V. 30, pp. 1039-1053.

Al-Taan, S. A.; and Ezzadeen, N. A., 1995, "Flexural analysis of reinforced fibrous concrete members using the FE method", Computers \& Structures, V. 56, N. 6, pp. 10651072.

Bhatt, P.; and Kader, M. A., 1998, "Prediction of shear strength of reinforced concrete beams by nonlinear Finite-element analysis", Computers \& Structures, V. 68, pp. 139155.

Cerioni, R.; and Mingardi, L., 1996, "Nonlinear analysis of reinforced concrete foundation plates", Computers \& Structures, V. 61, N. 1, pp. 87-107.

Desai, Y. M.; Mufti, A. A.; and Tadros, G., 2002, "User manual for FEM PUNCH, version 2.0”, ISIS Canada. 
Fanning, P., 2001, "Nonlinear models of reinforced and post-tensioned concrete beams", Electronic Journal of Structural Engineering, V. 2, pp. 111-119

Ferreira , A. J. M.; Camanho, P. P.; Marques, A. T.; and Fernandes, A. A., 2001, "Modeling of concrete beams reinforced with FRP re-bars", Composite Structures, V. 53, pp. 107-116.

Hahn, H. T.; and Tsai, S. W., 1973, "Nonlinear elastic behavior of unidirectional composite laminae", Journal of Composite Materials, V. 7, pp. 102-18.

Hu, H.; Lin, F.; and Jan, Y., 2004, "Nonlinear FE analysis of reinforced concrete beams strengthened by fiber-reinforced plastics", Composite Structures, V. 63, pp. 271-281.

Hu, H. T.; and Schnobrich, W. C., 1990, "Nonlinear analysis of cracked reinforced concrete”, ACI Structural Journal, V. 87, N. 2, pp. 199-207

Jiang, J.; and Mirza, F. A., 1997, "Nonlinear analysis of reinforced concrete slabs by a discrete FE approach", Computers \& Structures, V. 65, N. 4, pp. 585-592.

Kwak, H. G.; and Filippou, F. C., 1997, "Nonlinear FE analysis of R/C structures under monotonic loads", Computers \& Structures, V. 65, N. 1, pp. 1-16. 
Kwak, H. G.; and Kim, S. P., 2002, "Nonlinear analysis of RC beams based on momentcurvature relation", Computers \& Structures, V. 80, pp. 615-628.

Nitereka, C.; and Neale, K. W., 1999,"Analysis of reinforced concrete beams strengthened in flexure with composite laminates", Canadian Journal of Civil Engineering, V. 26, pp. 646-654.

Polak, M. A.; and Vecchio F. J., 1993, "Nonlinear analysis of reinforced concrete shell", Journal of Structural Engineering, V. 119, N. 12, pp. 3439-3462.

Phuvoravan, K.; and Sotelino, D., 2005, "Nonlinear finite-element for reinforced concrete slabs”, Journal of Structural Engineering, V. 131, N. 4, pp. 643-649.

Ramtekkar G. S., Desai Y. M. and Shah A. H., 2002, "Mixed Finite-Element Model for Thick Composite Laminated Plates", Mechanics of Advanced Materials and Structures, V.9, pp.133-156.

Saenz,; and Luis, P., 1964, "Discussion of 'Equation for the stress-strain curve of concrete' by Prakash Desayi and S. Krishnan”, ACI Journal, V. 61, N. 9, pp. 1229-1235.

Shahawy, M. A.; Arockiasamy, M.; Beitelman, T.; and Sowrirajan, 1996, "Reinforced concrete rectangular beams strengthened with CFRP laminates", Composites: Part B, V. 27B, pp. 225-233. 
Supaviriyakit, T.; Pornpongsaroj, P.; and Pimanmas, A., 2004, "Finite-element analysis of FRP-strengthened RC beams", Songkhanakarin Journal of Science Technology, V. 26, N. 4, pp. 497-507.

Tsai, S. W.; and Wu, E. M., 1971, "A general theory of strength for anisotropic materials", Journal of Composite Materials, V. 5, pp. 58-80.

Vecchio, F. J., 1989, "Nonlinear finite-element analysis of reinforced concrete membranes", ACI Structural Journal, V. 86, N. 1, pp. 26-35.

Vecchio, F. J.; Agostino, N.; and Angleakos, B., 1993, "Reinforced concrete slabs subjected to thermal loads", Canadian Journal of Civil Engineering, V. 20, pp. 741-753.

Volnyy, V. A.; and Pantelides, C. P., 1999, "Bond Length of CFRP Composites Attached to Precast Concrete Walls", Journal of Computer for Construction, V.3, N. 4, pp.168-176

Wang, T.; and Hsu, T. T. C., 2001, "Nonlinear finite-element analysis of concrete structures using new constitutive models", Computers \& Structures, V. 79, pp. 2781-2791

Willam, K. J.; and Warnke, E. P., 1974, "Constitutive Model for Triaxial Behaviour of Concrete", Seminar on Concrete Structures Subject to Triaxial Stresses, International Association of Bridge and Structural Engineering Conference, Bergamo, Italy, pp. 174 


\section{APPENDIX}

\section{Input instructions}

1) TITLE (15A4)

Column 1-60 : Title to be printed with the output

2) CONTROL INFORMATION (12I5)

Column variable

01-05 NUMNP : No. of nodes

06-10 NUMEL : No. of elements

11-15 NDF : No. of dof per node

16-20 NDM : No. of dimensions (Default 3 for 3D)

21-25 NUMAT : No. of material sets

26-30 NSN : : No. of Supported nodes

31-35 NPROP : No. of material data

36-40 IDSPLY : : Graphical display (0 for no graphical display)

41-45 ITYPE : Type of analysis (Default to 3 for 3D)

46-50 ILOADSTEP : No. of load steps

51-55 NEQ : No. of equations. (Manually correct after $1^{\text {st }}$ run)

56-60 MBAND $\quad$ : Size of half bandwidth (Manually correct after $2^{\text {nd }}$ run)

3) ELEMENT DATA (I4,4I2,18I4) (One line per elements)

Column

01-04 : Element No. 


$\begin{array}{ll}\text { 05-06 } & : \text { Material set no. } \\ 07-08 & : \text { No. of nodes in the element } \\ 09-10 & : \text { Element model type (1 for combined model, } 2 \\ & \text { for mixed model, } 3 \text { for displacement model) } \\ 11-12 & : \text { Type of material analysis (0 for linear, } 1 \text { for nonlinear) } \\ 13-16 & : 1^{\text {st }} \text { node number of that element } \\ 17-20 & : 2^{\text {nd }} \text { node number of that element } \\ & \text { And up to } 18^{\text {th }} \text { node number for 3-D analysis (i.e. if } \\ & \text { ITYPE=3). For element model type 1, bottom layer of } \\ & \text { transitional elements need to be inverted (interchange top } \\ & \text { and bottom surface nodes). }\end{array}$

\section{4) NODAL DOF LIST}
A) $01-05$
$: 6$ for dof $=6$

B) List of nodes with dof $=6$ (16I5)

: If number of nodes zero, leave the line blank

: If number of nodes are multiple of 16 , put a blank line after this.

C) $01-05 \quad: 3$ for dof $=3$

D) List of nodes with dof $=3$ (16I5)

: If number of nodes zero, leave the line blank

: If number of nodes are multiple of 16 , put a blank line after this. 
4) BOUNDARY CONDITIONS (for individual nodes, not specified means free)

A) No. of sets of BCs

$$
\text { 01-05 : No. of sets of boundary conditions }
$$

B) First set of boundary conditions (6I5)

: 1 for restrained and 0 for free conditions.

: 3 dof/ 6 dof depending on the element model type.

: In transtional element model- top surface nodes-6 dof, bottom surface nodes- 3 dof

: In both stress and displacement continuity model- all 18

nodes are 6 dof

: In displacement continuity model- all 18 nodes are 3 dof

C) List of nodes (16I5)

: List all the nodes that belongs to this BCs set

: If number of nodes are multiple of 16 , put a blank line after this.

... Continue $\mathrm{B}$ and $\mathrm{C}$ for rest of the $\mathrm{BCs}$ sets.

5) NODAL DISPLACEMENT DATA (I5,5X,6E10.0),(one line per node)

Columns

01-05 : Node number

11-20 : Value of $1^{\text {st }}$ dof

21-30 : Value of $2^{\text {nd }}$ dof

$31-40 \quad:$ Value of $3^{\text {rd }}$ dof

41-50 : Value of $4^{\text {th }}$ dof 
$\begin{array}{ll}51-60 & : \text { Value of } 5^{\text {th }} \text { dof } \\ 61-70 & : \text { Value of } 6^{\text {th }} \text { dof }\end{array}$

(for the dof whose value is either 'not known' or 'zero', just leave blank)

(TERMINATED WITH A BLANK LINE) ......................Important

6) CONCRETE PROPERTY (CHARACTERISTIC) DATA (2I5)

Columns

01-05 :Material set number

06-10 :Element type number

Total 14 number of property data to be given for each material set in next two lines. It is to be given in the following format:

$1^{\text {st }}$ line : Young's Modulus, Poisson ratio, , Comp stress, Stress at max strain, Strain at

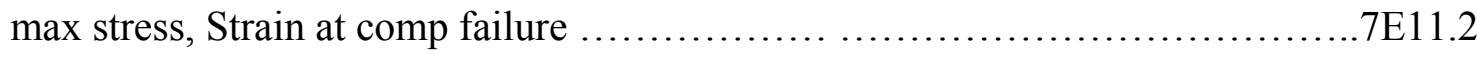

2nd line: Max tensile stress, Normal stiffness reduction factor (1.0*10-4), Density, Thickness, Width \& Length of element, and Angle (anticlockwise) of fiber orientation with the X1-coordinate axis(i.e. Global X-axis) ............................. 11.2

7) MATERIAL PROPERTY (CHARACTERISTIC) DATA (2I5)

Columns

01-05 : Material set number

06-11 : Element type number 
Each material set input line must be followed immediately by the material property data required for that element type. There are total 14 numbers of property data to be given for each material set. It is to be given in the following format:

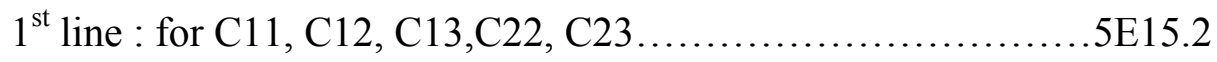

$2^{\text {nd }}$ line: for $\mathrm{C} 33, \mathrm{C} 44, \mathrm{C} 55, \mathrm{C} 66$, Density of the material .........5E15.2

$3^{\text {nd }}$ line: for Thickness, Width \& Length of element, and

Angle (anticlockwise) of fiber orientation with the X1-coordinate

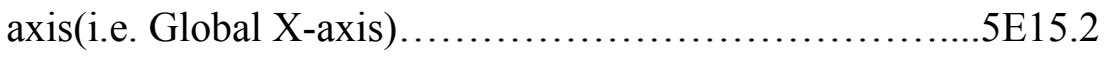

8) NODAL LOAD DATA (I5,5X, 6E10.0), (One line per loaded node)

Columns

01-05 :Node number

11-20 :Force corresponding to $1^{\text {st }}$ dof

21-30 :Force corresponding to $2^{\text {nd }}$ dof

31-40 :Force corresponding to $3^{\text {rd }}$ dof

41-50 :Force corresponding to $4^{\text {th }}$ dof

51-60 :Force corresponding to $5^{\text {th }}$ dof

61-70 :Force corresponding to $6^{\text {th }}$ dof

(TERMINATED WITH A BLANK LINE) .......................Important

9) DISTRIBUTED LOAD DATA, (One line per element)

$(3 \mathrm{I} 5,5 \mathrm{X}, 4 \mathrm{E} 10.2 / 5 \mathrm{E} 10.2)$ 
Columns

01-05 :Element number

06-10 :Surface of the element, which is loaded

(1-F, 2-B, 3-L, 4R, 5-Bot, 6-Top)

11-15 :Direction in which the load is applied (1 for X, 2 for $\mathrm{Y} \& 3$ for Z)

21-30 :Load intensity-1 (P1)

31-40 :Load intensity-2 (P2)

41-50 :Load intensity-3 (P3)

51-60 :Load intensity-4 (P4)

Next line

01-10 :Load intensity-5 (P5)

11-20 :Load intensity-6 (P6)

21-30 :Load intensity-7 (P7)

31-40 :Load intensity-8 (P8)

41-50 :Load intensity-9 (P9)

(TERMINATED WITH A BLANK LINE) .....................Important 


\section{Sample input file}

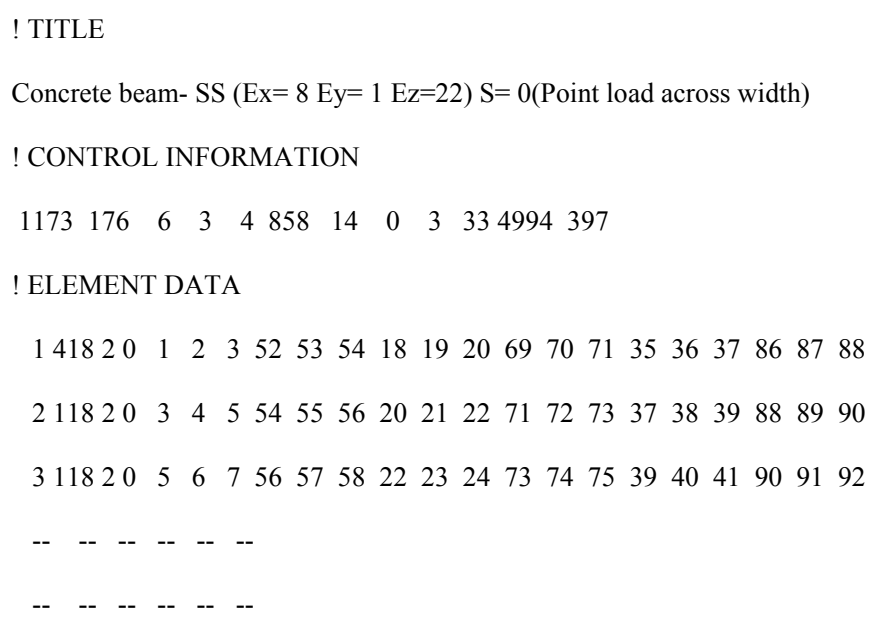


$\begin{array}{llllllllllllllll}157 & 158 & 159 & 160 & 161 & 162 & 163 & 164 & 165 & 166 & 167 & 168 & 169 & 206 & 207 & 208\end{array}$

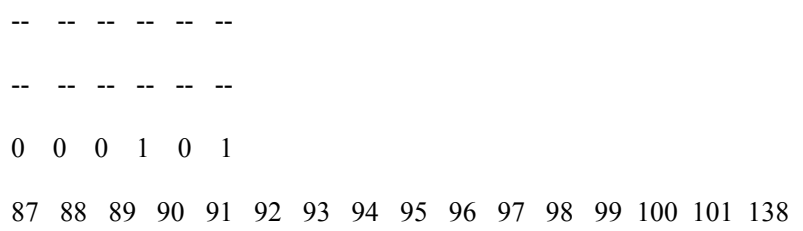


$\begin{array}{llllllllllllllll}86 & 137 & 188 & 239 & 290 & 341 & 392 & 443 & 494 & 545 & 596 & 698 & 749 & 800 & 851 & 902\end{array}$ 953100410551106

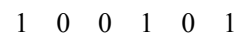

11 $.30230 \mathrm{E}+05.10000 \mathrm{E}+00.00000 \mathrm{E}+00-.4137 \mathrm{E}+02-.10340 \mathrm{E}+2-.2500 \mathrm{E}-02-.3500 \mathrm{E}-02$ $.21200 \mathrm{E}+01.10000 \mathrm{E}-03.10000 \mathrm{E}+01.17858 \mathrm{E}+02.20300 \mathrm{E}+03.15244 \mathrm{E}+03.00000 \mathrm{E}+00$ ! NON- CONCRETE MATERIAL PROPERTIES 


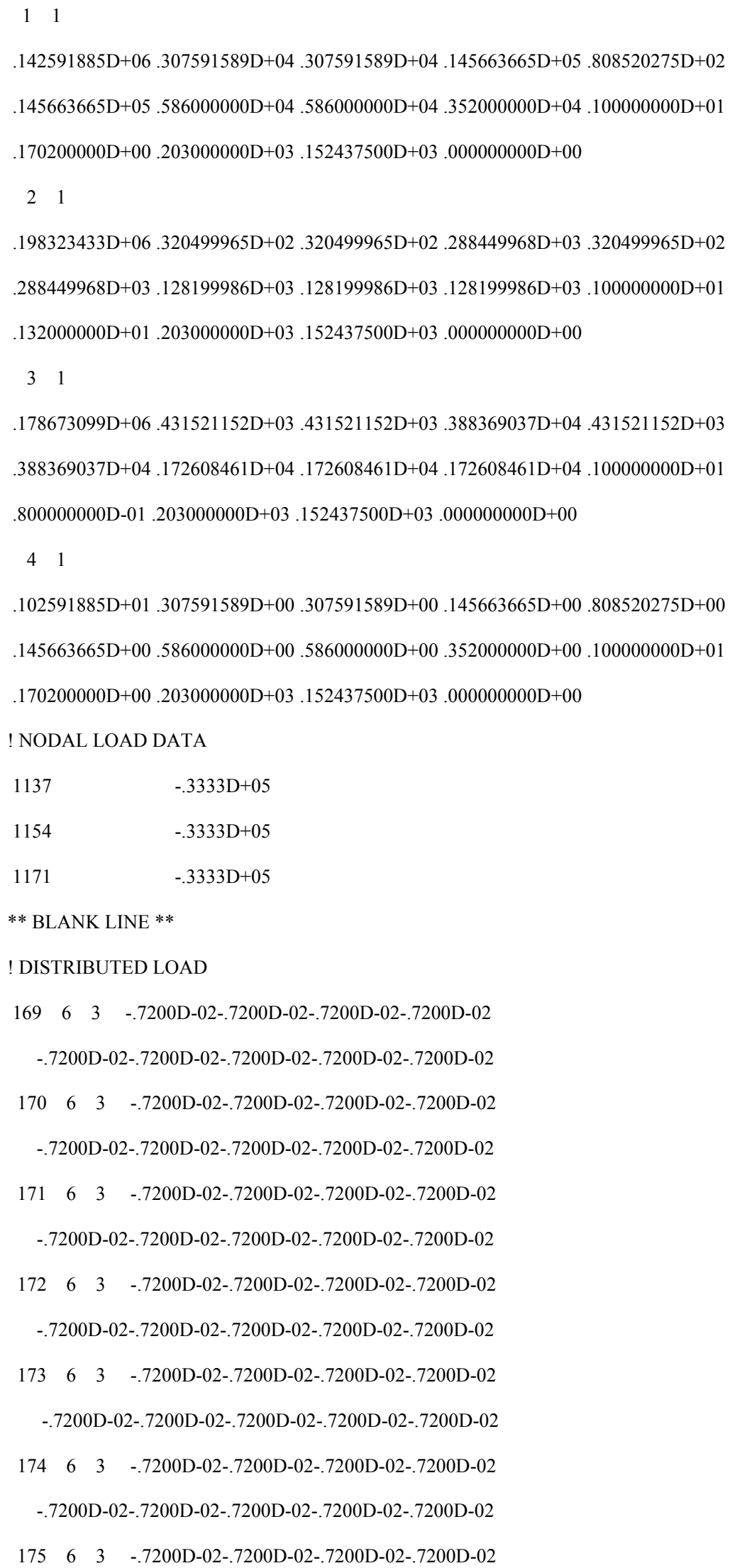


-.7200D-02-.7200D-02-.7200D-02-.7200D-02-.7200D-02

$176 \quad 6 \quad 3 \quad-.7200$ D-02-.7200D-02-.7200D-02-.7200D-02 -.7200D-02-.7200D-02-.7200D-02-.7200D-02-.7200D-02

**BLANK LINE** 


\title{
Sample output file
}

\author{
! HEADER \\ ! GIVEN CONTROL INFORMATION \\ NO. OF NODES ….............................. $=1173$ \\ NO. OF ELEMENTS ........................... $=176$ \\ NO. OF DEGREES OF FREEDOM ..... $=6$ \\ NO. OF DIMENSIONS ....................... $=3$ \\ NO. OF MATERIAL SETS ................... $=4$ \\ NO. OF SUPPORTED NODES ............ $=858$ \\ NO. OF MATERIAL DATA ................. $=14$ \\ GRAPHICAL DISPLAY CODE .......... $=0$ \\ TYPE(3 FOR PLATE)................. $=3$ \\ NO. OF INCREMENTS OF LOAD...... $=95$ \\ NO. OF EQUATION........................... $=4994$ \\ NO. OF HALF BAND WIDTH............ = 397
}

Concrete Beam SS $(\mathrm{Ex}=8 \mathrm{Ey}=1 \mathrm{Ez}=22) \mathrm{S}=0$ (Point load across width)

! GIVEN ELEMENT DATA

ELMT MATERIAL NEL ELTYPE MATYPE NOD-1 NOD-2 NOD-3 NOD-4 NOD-5 NOD-6 NOD-7 NOD-8 NOD-9 NOD10 NOD11 NOD12 NOD13 NOD14 NOD15 NOD16 NOD17 NOD18

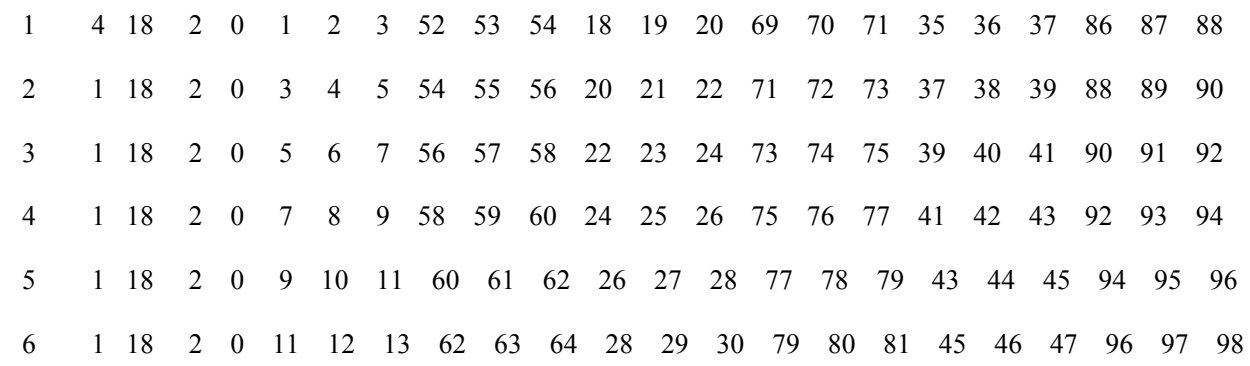

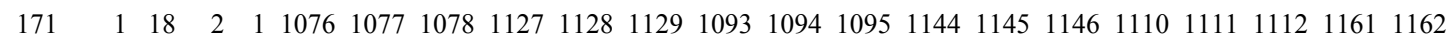
1163 


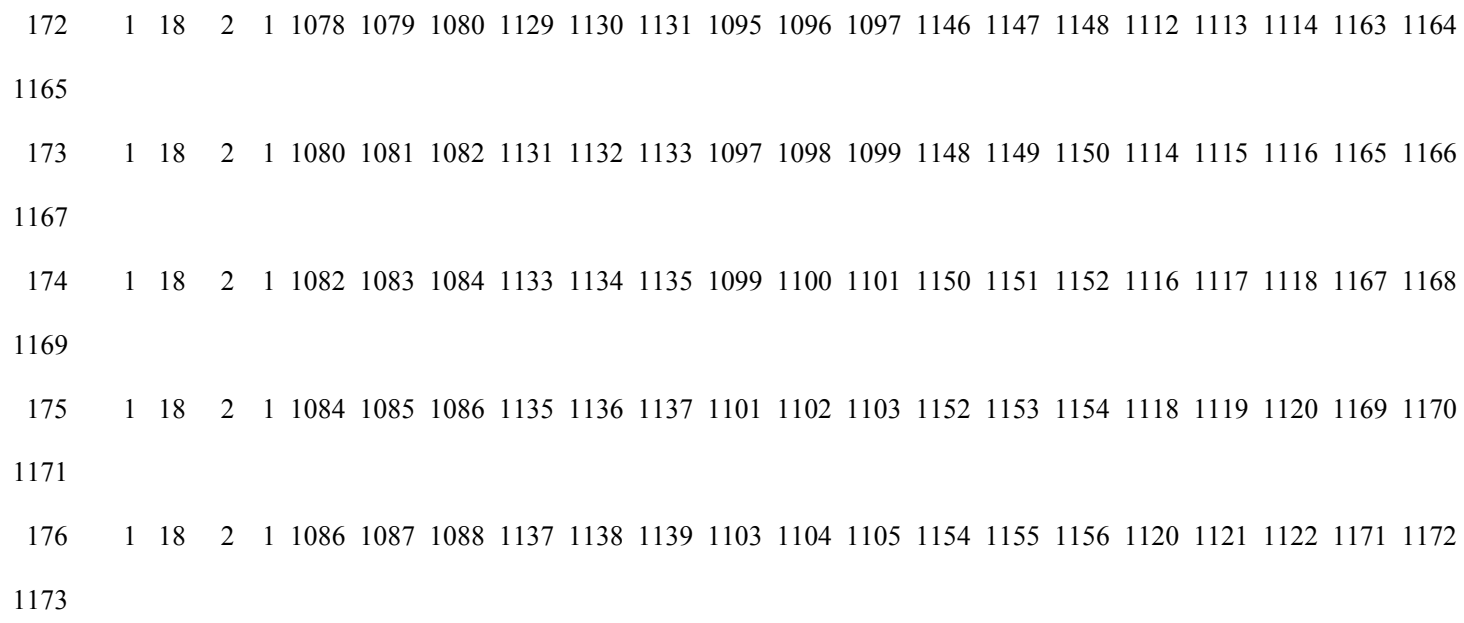




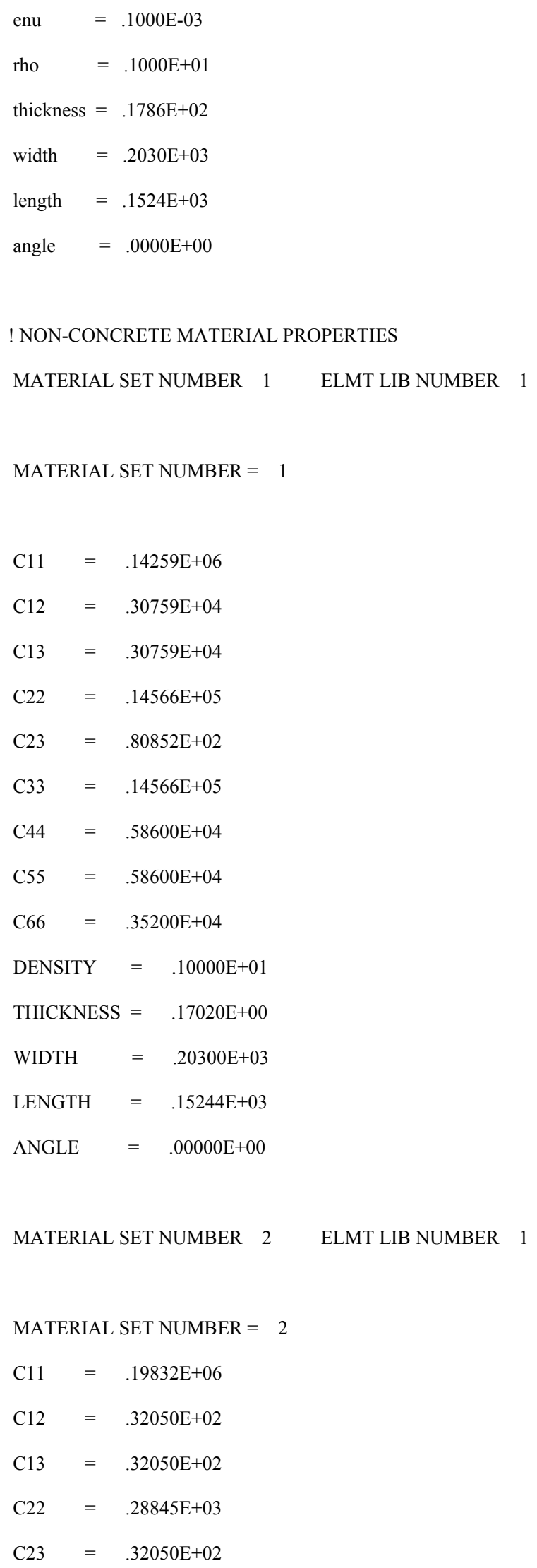




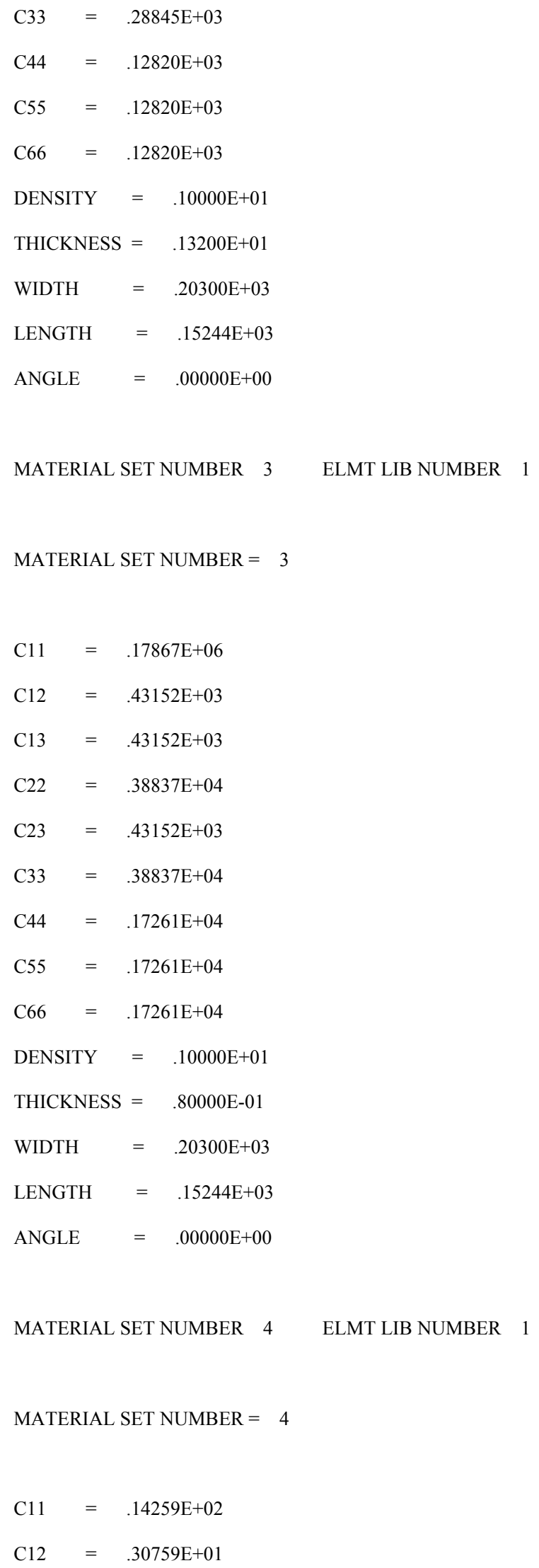




$$
\begin{aligned}
& \mathrm{C} 13=.30759 \mathrm{E}+01 \\
& \mathrm{C} 22=.14566 \mathrm{E}+02 \\
& \mathrm{C} 23=.80852 \mathrm{E}+00 \\
& \mathrm{C} 33=.14566 \mathrm{E}+01 \\
& \mathrm{C} 44=.58600 \mathrm{E}+01 \\
& \mathrm{C} 55=.58600 \mathrm{E}+01 \\
& \mathrm{C} 66=.35200 \mathrm{E}+01 \\
& \text { DENSITY }=.10000 \mathrm{E}+01 \\
& \text { THICKNESS }=.17020 \mathrm{E}+00 \\
& \text { WIDTH }=.20300 \mathrm{E}+03 \\
& \text { LENGTH }=.15244 \mathrm{E}+03 \\
& \text { ANGLE }=.00000 \mathrm{E}+00
\end{aligned}
$$

HALF BAND WIDTH $=397 \quad$ ELMT NUMBER $=103$

! GIVEN NODAL LOAD DATA

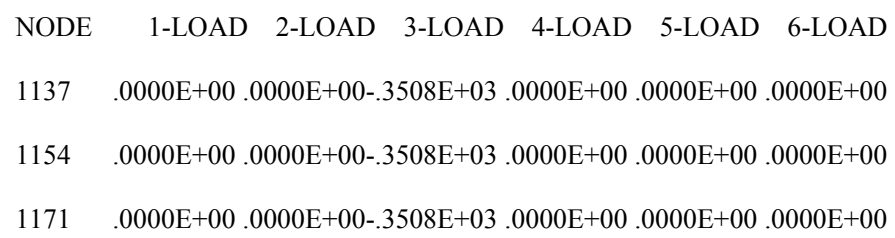

!GIVEN DISTRIBUTED LOAD

ELMT SURFACE DIRECTION $\quad$ LOAD-1 LOAD-2 LOAD-3 $\quad$ LOAD-4 $\quad$ LOAD-5 $\quad$ LOAD-6 $\quad$ LOAD-7 $\quad$ LOAD-8 LOAD-9

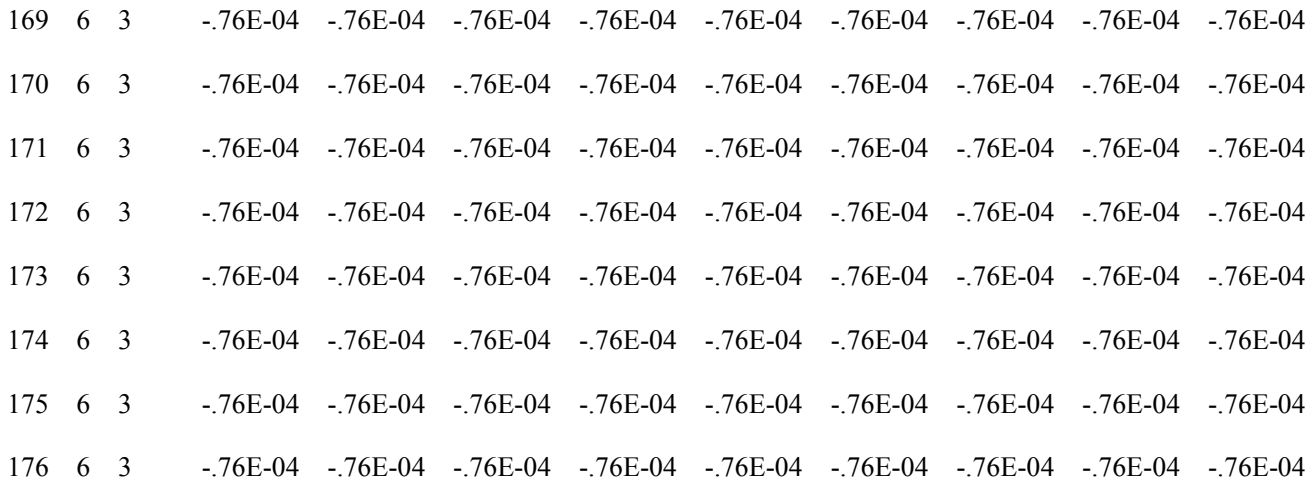


! CALCULATED ELEMENT LOAD VECTOR

! LOAD STEP-1

\begin{tabular}{|c|c|c|c|c|c|c|c|}
\hline \multicolumn{3}{|c|}{ ELEM NODE } & V & W & TOU-XZ & TOU-YZ & SIG-Z \\
\hline 169 & 1 & $.000 \mathrm{E}+00$ & $.000 \mathrm{E}+00$ & $.000 \mathrm{E}+00$ & $.000 \mathrm{E}+00$ & $.000 \mathrm{E}+00$ & $.000 \mathrm{E}+00$ \\
\hline 169 & 2 & $.000 \mathrm{E}+00$ & $.000 \mathrm{E}+00$ & $.000 \mathrm{E}+00$ & $.000 \mathrm{E}+00$ & $.000 \mathrm{E}+00$ & $.000 \mathrm{E}+00$ \\
\hline 169 & 3 & $.000 \mathrm{E}+00$ & $.000 \mathrm{E}+00$ & $.000 \mathrm{E}+00$ & $.000 \mathrm{E}+00$ & $.000 \mathrm{E}+00$ & $.000 \mathrm{E}+00$ \\
\hline 169 & 4 & $.000 \mathrm{E}+00$ & $.000 \mathrm{E}+00$ & $-.651 \mathrm{E}-01$ & $.000 \mathrm{E}+00$ & $.000 \mathrm{E}+00$ & $.000 \mathrm{E}+00$ \\
\hline 169 & 5 & $.000 \mathrm{E}+00$ & $.000 \mathrm{E}+00$ & $-.261 \mathrm{E}+00$ & $.000 \mathrm{E}+00$ & $.000 \mathrm{E}+00$ & $.000 \mathrm{E}+00$ \\
\hline 169 & 6 & $.000 \mathrm{E}+00$ & $.000 \mathrm{E}+00$ & $-.651 \mathrm{E}-01$ & $.000 \mathrm{E}+00$ & $.000 \mathrm{E}+00$ & $.000 \mathrm{E}+00$ \\
\hline 169 & 7 & $.000 \mathrm{E}+00$ & $.000 \mathrm{E}+00$ & $.000 \mathrm{E}+00$ & $.000 \mathrm{E}+00$ & $.000 \mathrm{E}+00$ & $.000 \mathrm{E}+00$ \\
\hline 169 & 8 & $.000 \mathrm{E}+00$ & $.000 \mathrm{E}+00$ & $.000 \mathrm{E}+00$ & $.000 \mathrm{E}+00$ & $.000 \mathrm{E}+00$ & $.000 \mathrm{E}+00$ \\
\hline 169 & 9 & $.000 \mathrm{E}+00$ & $.000 \mathrm{E}+00$ & $.000 \mathrm{E}+00$ & $.000 \mathrm{E}+00$ & $.000 \mathrm{E}+00$ & $.000 \mathrm{E}+00$ \\
\hline 169 & 10 & $.000 \mathrm{E}+00$ & $.000 \mathrm{E}+00$ & $-.261 \mathrm{E}+00$ & $.000 \mathrm{E}+00$ & $.000 \mathrm{E}+00$ & $.000 \mathrm{E}+00$ \\
\hline 169 & 11 & $.000 \mathrm{E}+00$ & $.000 \mathrm{E}+00$ & $-.104 \mathrm{E}+01$ & $.000 \mathrm{E}+00$ & $.000 \mathrm{E}+00$ & $.000 \mathrm{E}+00$ \\
\hline 169 & 12 & $.000 \mathrm{E}+00$ & $.000 \mathrm{E}+00$ & $-.261 \mathrm{E}+00$ & $.000 \mathrm{E}+00$ & $.000 \mathrm{E}+00$ & $.000 \mathrm{E}+00$ \\
\hline 169 & 13 & $.000 \mathrm{E}+00$ & $.000 \mathrm{E}+00$ & $.000 \mathrm{E}+00$ & $.000 \mathrm{E}+00$ & $.000 \mathrm{E}+00$ & $.000 \mathrm{E}+00$ \\
\hline 169 & 14 & $.000 \mathrm{E}+00$ & $.000 \mathrm{E}+00$ & $.000 \mathrm{E}+00$ & $.000 \mathrm{E}+00$ & $.000 \mathrm{E}+00$ & $.000 \mathrm{E}+00$ \\
\hline 169 & 15 & $.000 \mathrm{E}+00$ & $.000 \mathrm{E}+00$ & $.000 \mathrm{E}+00$ & $.000 \mathrm{E}+00$ & $.000 \mathrm{E}+00$ & $.000 \mathrm{E}+00$ \\
\hline 169 & 16 & $.000 \mathrm{E}+00$ & $.000 \mathrm{E}+00$ & $-.651 \mathrm{E}-01$ & $.000 \mathrm{E}+00$ & $.000 \mathrm{E}+00$ & $.000 \mathrm{E}+00$ \\
\hline 169 & 17 & $.000 \mathrm{E}+00$ & $.000 \mathrm{E}+00$ & $-.261 \mathrm{E}+00$ & $.000 \mathrm{E}+00$ & $.000 \mathrm{E}+00$ & $.000 \mathrm{E}+00$ \\
\hline 169 & 18 & $.000 \mathrm{E}+00$ & $.000 \mathrm{E}+00$ & $-.651 \mathrm{E}-01$ & $.000 \mathrm{E}+00$ & $.000 \mathrm{E}+00$ & $.000 \mathrm{E}+00$ \\
\hline NLL & & -2.0403 & $15 / 0947$ & & & & \\
\hline
\end{tabular}

ELEMENT LOAD VECTOR

$\begin{array}{lllllll}\text { ELEM NODE } & \mathrm{U} & \mathrm{V} & \mathrm{W} & \text { TOU-XZ } & \text { TOU-YZ } & \text { SIG-Z }\end{array}$

$\begin{array}{cccccccc}170 & 1 & .000 \mathrm{E}+00 & .000 \mathrm{E}+00 & .000 \mathrm{E}+00 & .000 \mathrm{E}+00 & .000 \mathrm{E}+00 & .000 \mathrm{E}+00\end{array}$

$\begin{array}{llllllll}170 & 2 & .000 \mathrm{E}+00 & .000 \mathrm{E}+00 & .000 \mathrm{E}+00 & .000 \mathrm{E}+00 & .000 \mathrm{E}+00 & .000 \mathrm{E}+00\end{array}$

$\begin{array}{llllllll}170 & 3 & .000 \mathrm{E}+00 & .000 \mathrm{E}+00 & .000 \mathrm{E}+00 & .000 \mathrm{E}+00 & .000 \mathrm{E}+00 & .000 \mathrm{E}+00\end{array}$

$\begin{array}{llllllll}170 & 4 & .000 \mathrm{E}+00 & .000 \mathrm{E}+00 & -.651 \mathrm{E}-01 & .000 \mathrm{E}+00 & .000 \mathrm{E}+00 & .000 \mathrm{E}+00\end{array}$

$\begin{array}{llllllll}170 & 5 & .000 \mathrm{E}+00 & .000 \mathrm{E}+00 & -.261 \mathrm{E}+00 & .000 \mathrm{E}+00 & .000 \mathrm{E}+00 & .000 \mathrm{E}+00\end{array}$ 


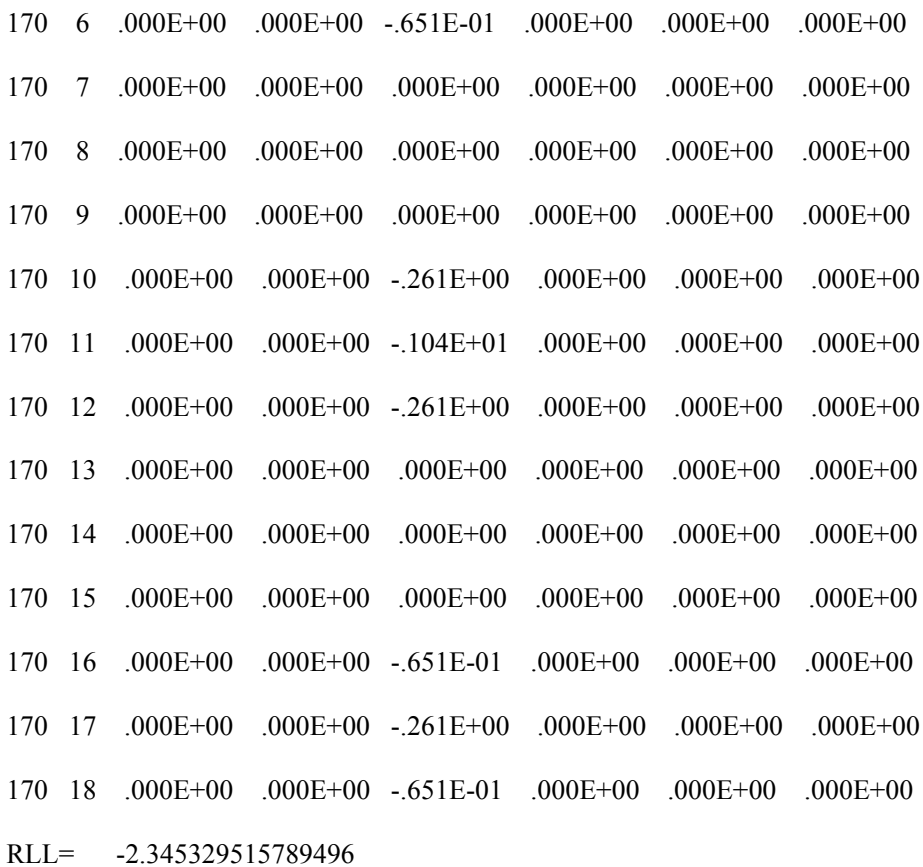




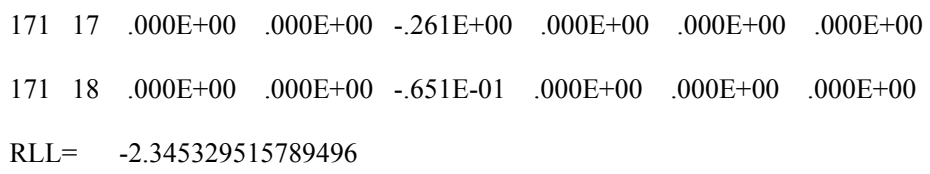




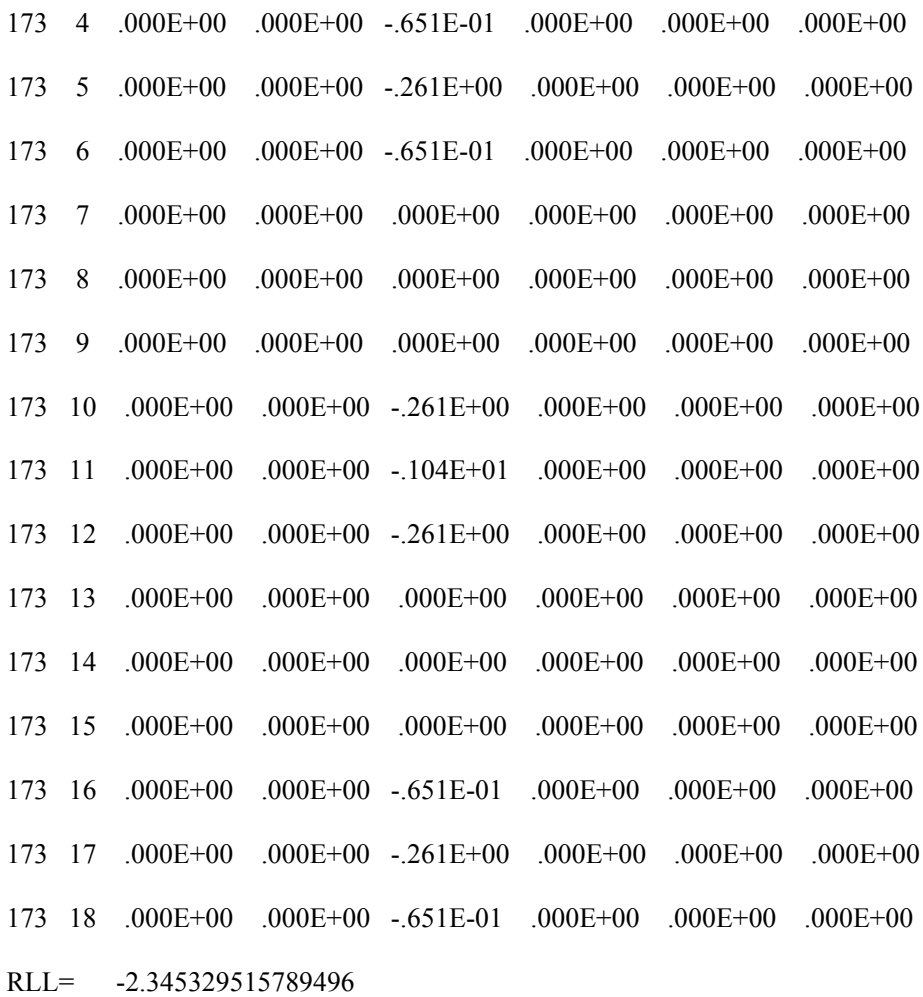




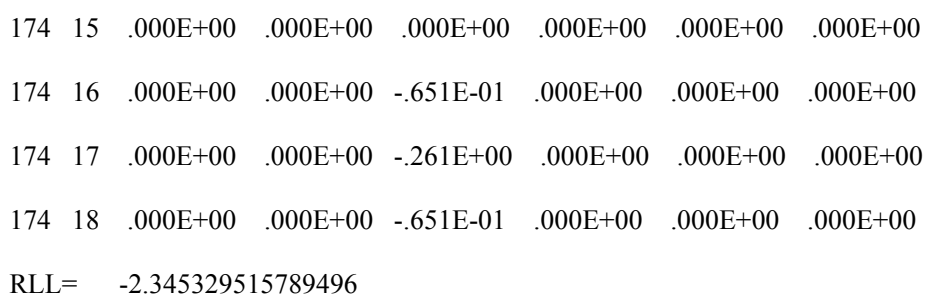




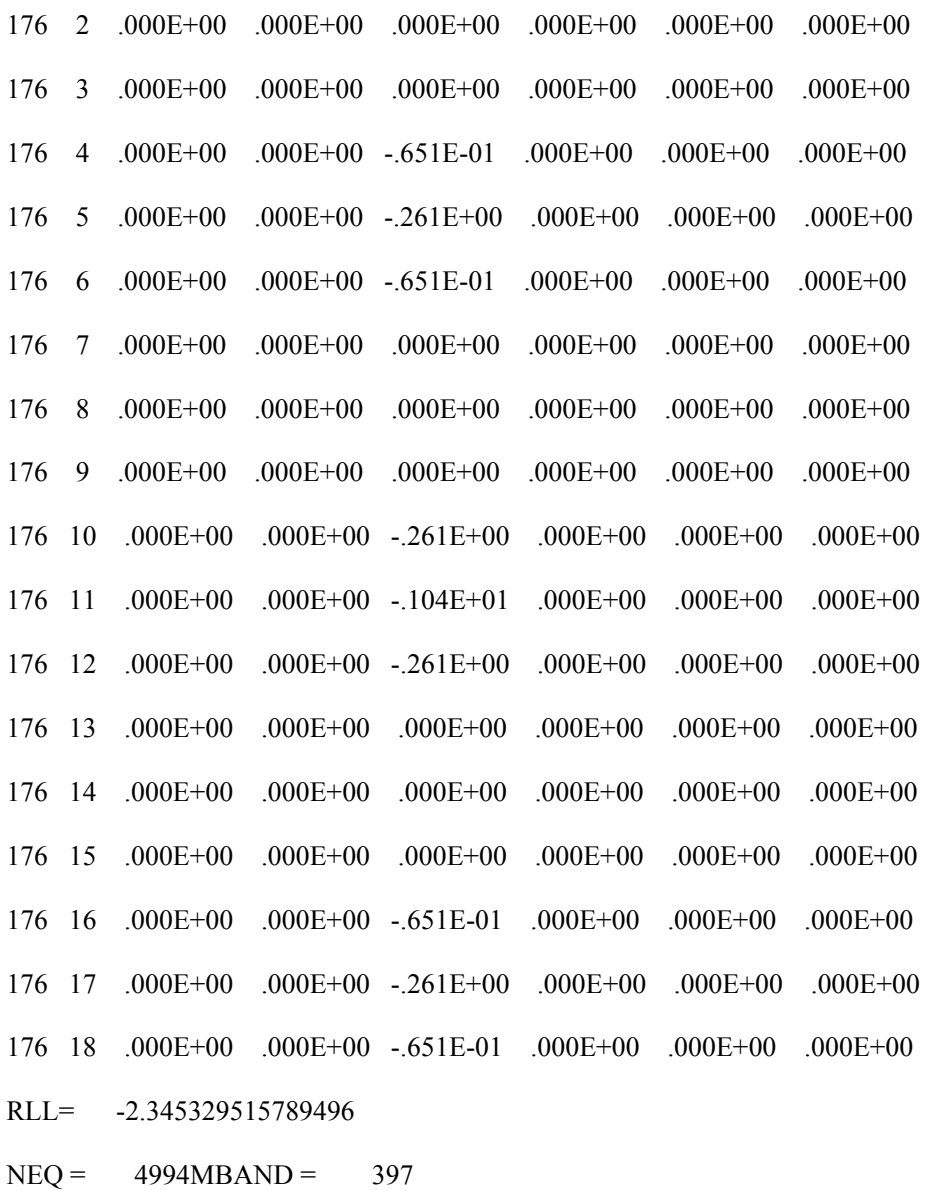




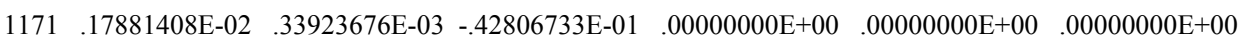

$\begin{array}{lllllll}1172 & 83581817 \mathrm{E}-03 & .15191590 \mathrm{E}-03 & -.42885114 \mathrm{E}-01 & .00000000 \mathrm{E}+00 & .00000000 \mathrm{E}+00 & .00000000 \mathrm{E}+00\end{array}$

$\begin{array}{lllllll}1173 & .00000000 \mathrm{E}+00 & .12950030 \mathrm{E}-03 & -.43123731 \mathrm{E}-01 & .00000000 \mathrm{E}+00 & .00000000 \mathrm{E}+00 & .00000000 \mathrm{E}+00\end{array}$
\end{abstract}

! LOAD STEP- 2

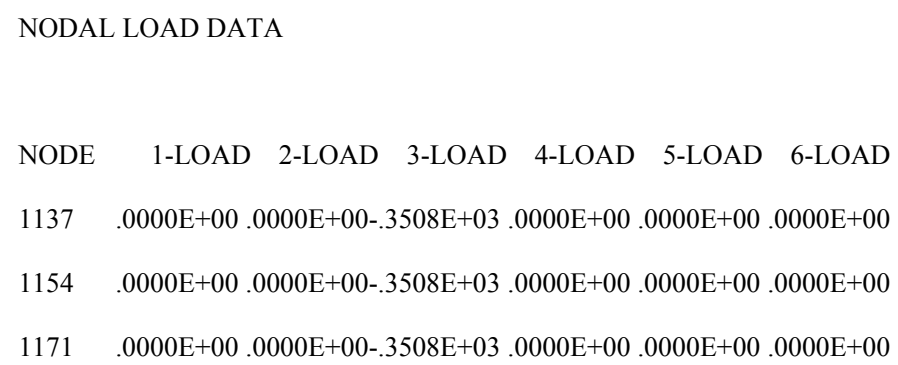




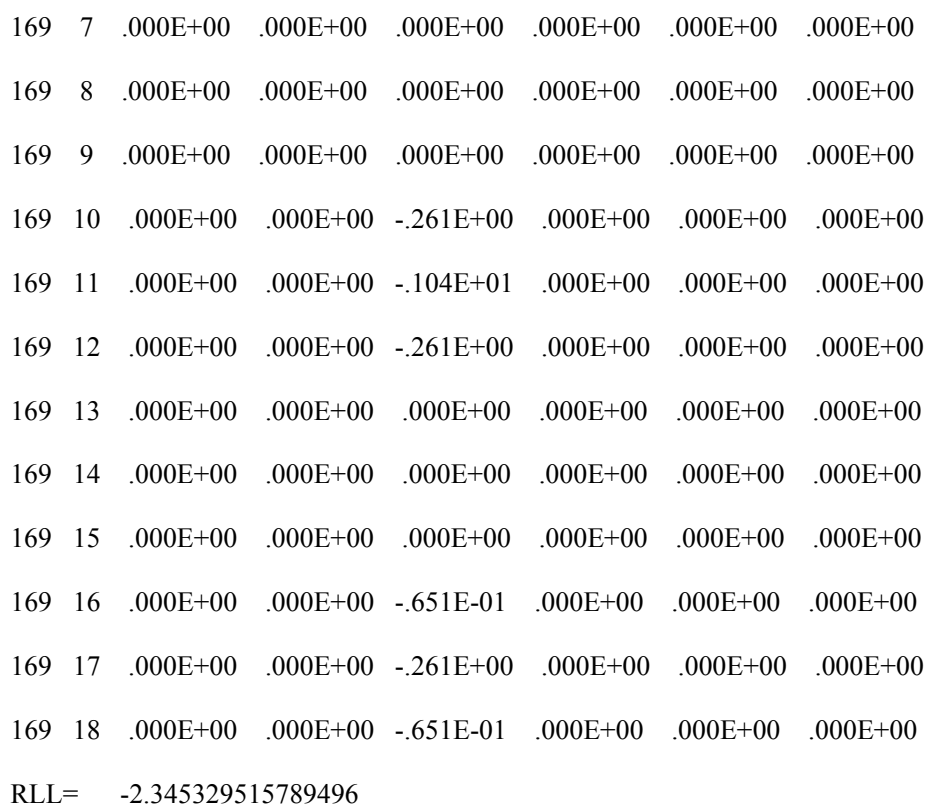


$\begin{array}{llllllll}170 & 18 & .000 \mathrm{E}+00 & .000 \mathrm{E}+00 & -.651 \mathrm{E}-01 & .000 \mathrm{E}+00 & .000 \mathrm{E}+00 & .000 \mathrm{E}+00\end{array}$

$\mathrm{RLL}=-2.345329515789496$

ELEMENT LOAD VECTOR

$\begin{array}{lllllll}\text { ELEM NODE } & \mathrm{U} & \mathrm{V} & \mathrm{W} & \text { TOU-XZ } & \text { TOU-YZ } & \text { SIG-Z }\end{array}$

$\begin{array}{llllllll}171 & 1 & .000 \mathrm{E}+00 & .000 \mathrm{E}+00 & .000 \mathrm{E}+00 & .000 \mathrm{E}+00 & .000 \mathrm{E}+00 & .000 \mathrm{E}+00\end{array}$

$\begin{array}{llllllll}171 & 2 & .000 \mathrm{E}+00 & .000 \mathrm{E}+00 & .000 \mathrm{E}+00 & .000 \mathrm{E}+00 & .000 \mathrm{E}+00 & .000 \mathrm{E}+00\end{array}$

$\begin{array}{llllllll}171 & 3 & .000 \mathrm{E}+00 & .000 \mathrm{E}+00 & .000 \mathrm{E}+00 & .000 \mathrm{E}+00 & .000 \mathrm{E}+00 & .000 \mathrm{E}+00\end{array}$

$\begin{array}{llllllll}171 & 4 & .000 \mathrm{E}+00 & .000 \mathrm{E}+00 & -.651 \mathrm{E}-01 & .000 \mathrm{E}+00 & .000 \mathrm{E}+00 & .000 \mathrm{E}+00\end{array}$

$\begin{array}{llllllll}171 & 5 & .000 \mathrm{E}+00 & .000 \mathrm{E}+00 & -.261 \mathrm{E}+00 & .000 \mathrm{E}+00 & .000 \mathrm{E}+00 & .000 \mathrm{E}+00\end{array}$

$\begin{array}{llllllll}171 & 6 & .000 \mathrm{E}+00 & .000 \mathrm{E}+00 & -.651 \mathrm{E}-01 & .000 \mathrm{E}+00 & .000 \mathrm{E}+00 & .000 \mathrm{E}+00\end{array}$

$\begin{array}{llllllll}171 & 7 & .000 \mathrm{E}+00 & .000 \mathrm{E}+00 & .000 \mathrm{E}+00 & .000 \mathrm{E}+00 & .000 \mathrm{E}+00 & .000 \mathrm{E}+00\end{array}$

$\begin{array}{llllllll}171 & 8 & .000 \mathrm{E}+00 & .000 \mathrm{E}+00 & .000 \mathrm{E}+00 & .000 \mathrm{E}+00 & .000 \mathrm{E}+00 & .000 \mathrm{E}+00\end{array}$

$\begin{array}{llllllll}171 & 9 & .000 \mathrm{E}+00 & .000 \mathrm{E}+00 & .000 \mathrm{E}+00 & .000 \mathrm{E}+00 & .000 \mathrm{E}+00 & .000 \mathrm{E}+00\end{array}$

$\begin{array}{llllllll}171 & 10 & .000 \mathrm{E}+00 & .000 \mathrm{E}+00 & -.261 \mathrm{E}+00 & .000 \mathrm{E}+00 & .000 \mathrm{E}+00 & .000 \mathrm{E}+00\end{array}$

$\begin{array}{llllllll}171 & 11 & .000 \mathrm{E}+00 & .000 \mathrm{E}+00 & -.104 \mathrm{E}+01 & .000 \mathrm{E}+00 & .000 \mathrm{E}+00 & .000 \mathrm{E}+00\end{array}$

$\begin{array}{llllllll}171 & 12 & .000 \mathrm{E}+00 & .000 \mathrm{E}+00 & -.261 \mathrm{E}+00 & .000 \mathrm{E}+00 & .000 \mathrm{E}+00 & .000 \mathrm{E}+00\end{array}$

$\begin{array}{llllllll}171 & 13 & .000 \mathrm{E}+00 & .000 \mathrm{E}+00 & .000 \mathrm{E}+00 & .000 \mathrm{E}+00 & .000 \mathrm{E}+00 & .000 \mathrm{E}+00\end{array}$

$\begin{array}{llllllll}171 & 14 & .000 \mathrm{E}+00 & .000 \mathrm{E}+00 & .000 \mathrm{E}+00 & .000 \mathrm{E}+00 & .000 \mathrm{E}+00 & .000 \mathrm{E}+00\end{array}$

$\begin{array}{llllllll}171 & 15 & .000 \mathrm{E}+00 & .000 \mathrm{E}+00 & .000 \mathrm{E}+00 & .000 \mathrm{E}+00 & .000 \mathrm{E}+00 & .000 \mathrm{E}+00\end{array}$

$\begin{array}{llllllll}171 & 16 & .000 \mathrm{E}+00 & .000 \mathrm{E}+00 & -.651 \mathrm{E}-01 & .000 \mathrm{E}+00 & .000 \mathrm{E}+00 & .000 \mathrm{E}+00\end{array}$

$\begin{array}{llllllll}171 & 17 & .000 \mathrm{E}+00 & .000 \mathrm{E}+00 & -.261 \mathrm{E}+00 & .000 \mathrm{E}+00 & .000 \mathrm{E}+00 & .000 \mathrm{E}+00\end{array}$

$\begin{array}{llllllll}171 & 18 & .000 \mathrm{E}+00 & .000 \mathrm{E}+00 & -.651 \mathrm{E}-01 & .000 \mathrm{E}+00 & .000 \mathrm{E}+00 & .000 \mathrm{E}+00\end{array}$

$\mathrm{RLL}=\quad-2.345329515789496$

\section{ELEMENT LOAD VECTOR}

\begin{tabular}{ccccccccc}
\multicolumn{2}{l}{ ELEM NODE } & $\mathrm{U}$ & $\mathrm{V}$ & $\mathrm{W}$ & $\mathrm{TOU}-\mathrm{XZ}$ & $\mathrm{TOU}-\mathrm{YZ}$ & \multicolumn{2}{l}{ SIG-Z } \\
172 & 1 & $.000 \mathrm{E}+00$ & $.000 \mathrm{E}+00$ & $.000 \mathrm{E}+00$ & $.000 \mathrm{E}+00$ & $.000 \mathrm{E}+00$ & $.000 \mathrm{E}+00$ \\
172 & 2 & $.000 \mathrm{E}+00$ & $.000 \mathrm{E}+00$ & $.000 \mathrm{E}+00$ & $.000 \mathrm{E}+00$ & $.000 \mathrm{E}+00$ & $.000 \mathrm{E}+00$ \\
172 & 3 & $.000 \mathrm{E}+00$ & $.000 \mathrm{E}+00$ & $.000 \mathrm{E}+00$ & $.000 \mathrm{E}+00$ & $.000 \mathrm{E}+00$ & $.000 \mathrm{E}+00$ \\
172 & 4 & $.000 \mathrm{E}+00$ & $.000 \mathrm{E}+00$ & $-.651 \mathrm{E}-01$ & $.000 \mathrm{E}+00$ & $.000 \mathrm{E}+00$ & $.000 \mathrm{E}+00$ \\
172 & 5 & $.000 \mathrm{E}+00$ & $.000 \mathrm{E}+00$ & $-.261 \mathrm{E}+00$ & $.000 \mathrm{E}+00$ & $.000 \mathrm{E}+00$ & $.000 \mathrm{E}+00$
\end{tabular}




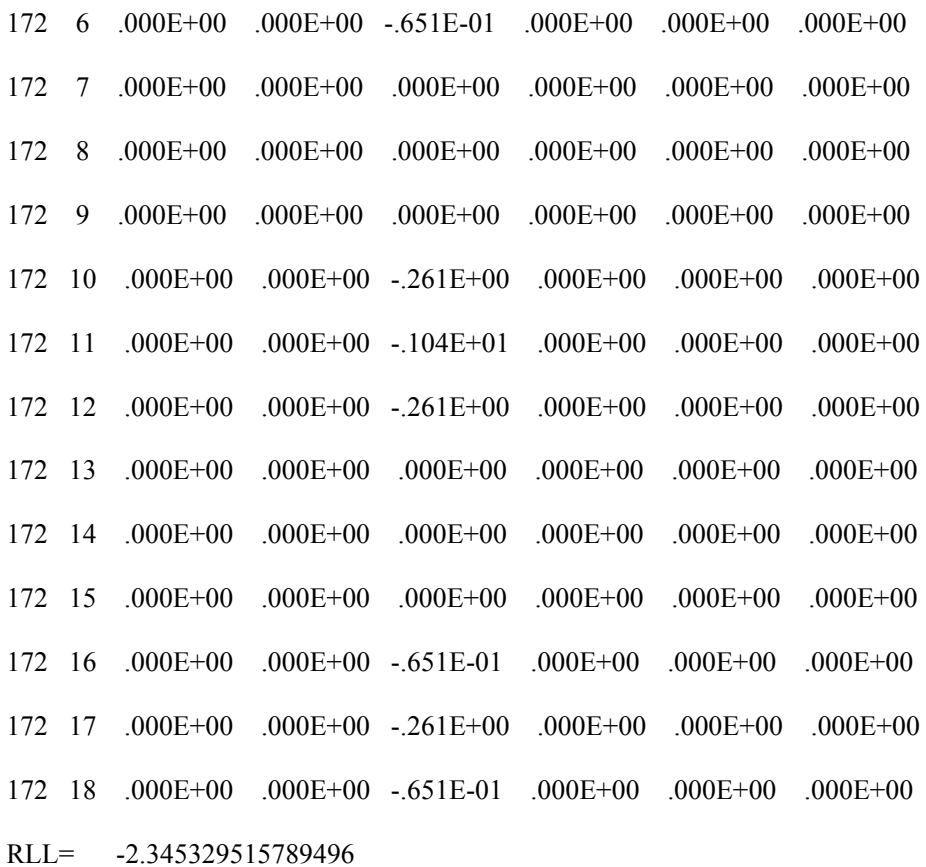


$\begin{array}{llllllll}173 & 18 & .000 \mathrm{E}+00 & .000 \mathrm{E}+00 & -.651 \mathrm{E}-01 & .000 \mathrm{E}+00 & .000 \mathrm{E}+00 & .000 \mathrm{E}+00\end{array}$

$\mathrm{RLL}=-2.345329515789496$

\section{ELEMENT LOAD VECTOR}

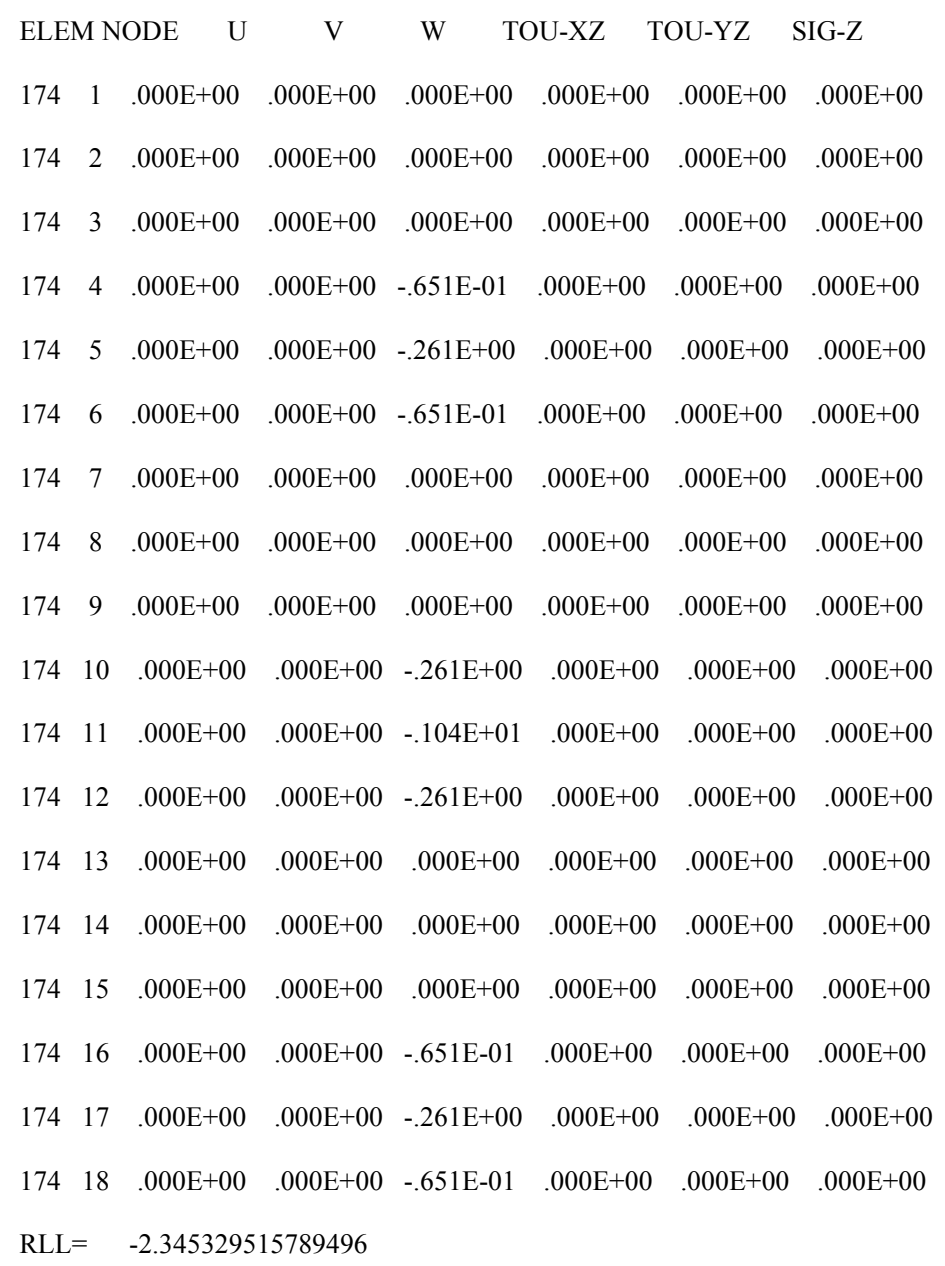

\section{ELEMENT LOAD VECTOR}

\begin{tabular}{ccccccccc}
\multicolumn{2}{c}{ ELEM NODE } & $\mathrm{U}$ & $\mathrm{V}$ & $\mathrm{W}$ & TOU-XZ & TOU-YZ & SIG-Z \\
175 & 1 & $.000 \mathrm{E}+00$ & $.000 \mathrm{E}+00$ & $.000 \mathrm{E}+00$ & $.000 \mathrm{E}+00$ & $.000 \mathrm{E}+00$ & $.000 \mathrm{E}+00$ \\
175 & 2 & $.000 \mathrm{E}+00$ & $.000 \mathrm{E}+00$ & $.000 \mathrm{E}+00$ & $.000 \mathrm{E}+00$ & $.000 \mathrm{E}+00$ & $.000 \mathrm{E}+00$ \\
175 & 3 & $.000 \mathrm{E}+00$ & $.000 \mathrm{E}+00$ & $.000 \mathrm{E}+00$ & $.000 \mathrm{E}+00$ & $.000 \mathrm{E}+00$ & $.000 \mathrm{E}+00$ \\
175 & 4 & $.000 \mathrm{E}+00$ & $.000 \mathrm{E}+00$ & $-.651 \mathrm{E}-01$ & $.000 \mathrm{E}+00$ & $.000 \mathrm{E}+00$ & $.000 \mathrm{E}+00$ \\
175 & 5 & $.000 \mathrm{E}+00$ & $.000 \mathrm{E}+00$ & $-.261 \mathrm{E}+00$ & $.000 \mathrm{E}+00$ & $.000 \mathrm{E}+00$ & $.000 \mathrm{E}+00$ \\
175 & 6 & $.000 \mathrm{E}+00$ & $.000 \mathrm{E}+00$ & $-.651 \mathrm{E}-01$ & $.000 \mathrm{E}+00$ & $.000 \mathrm{E}+00$ & $.000 \mathrm{E}+00$
\end{tabular}




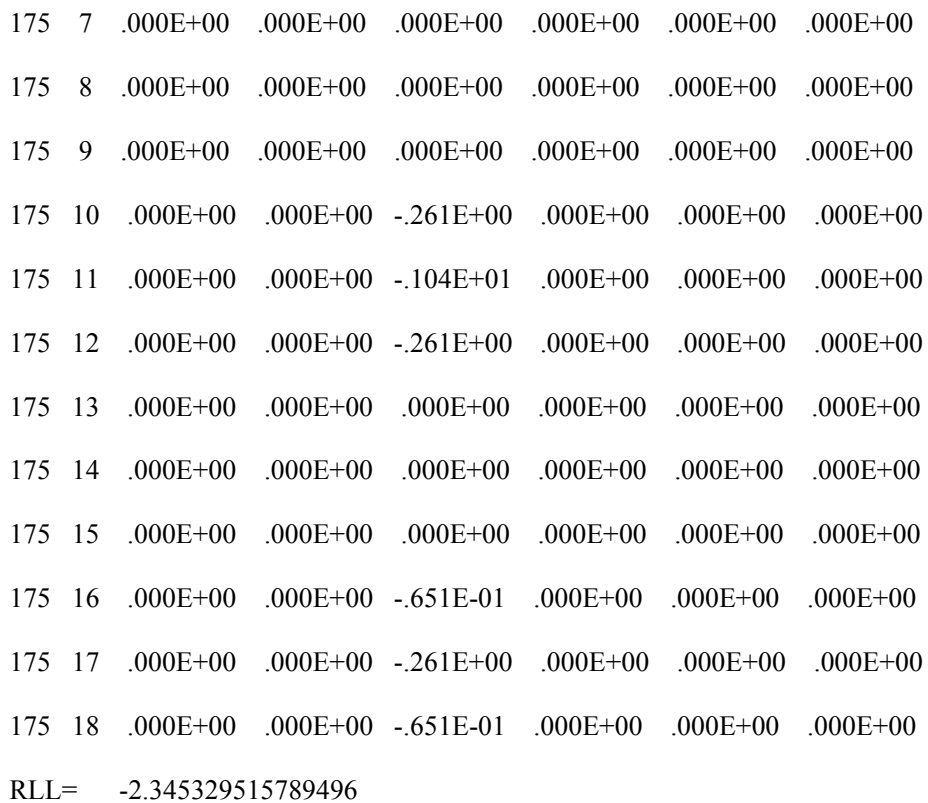




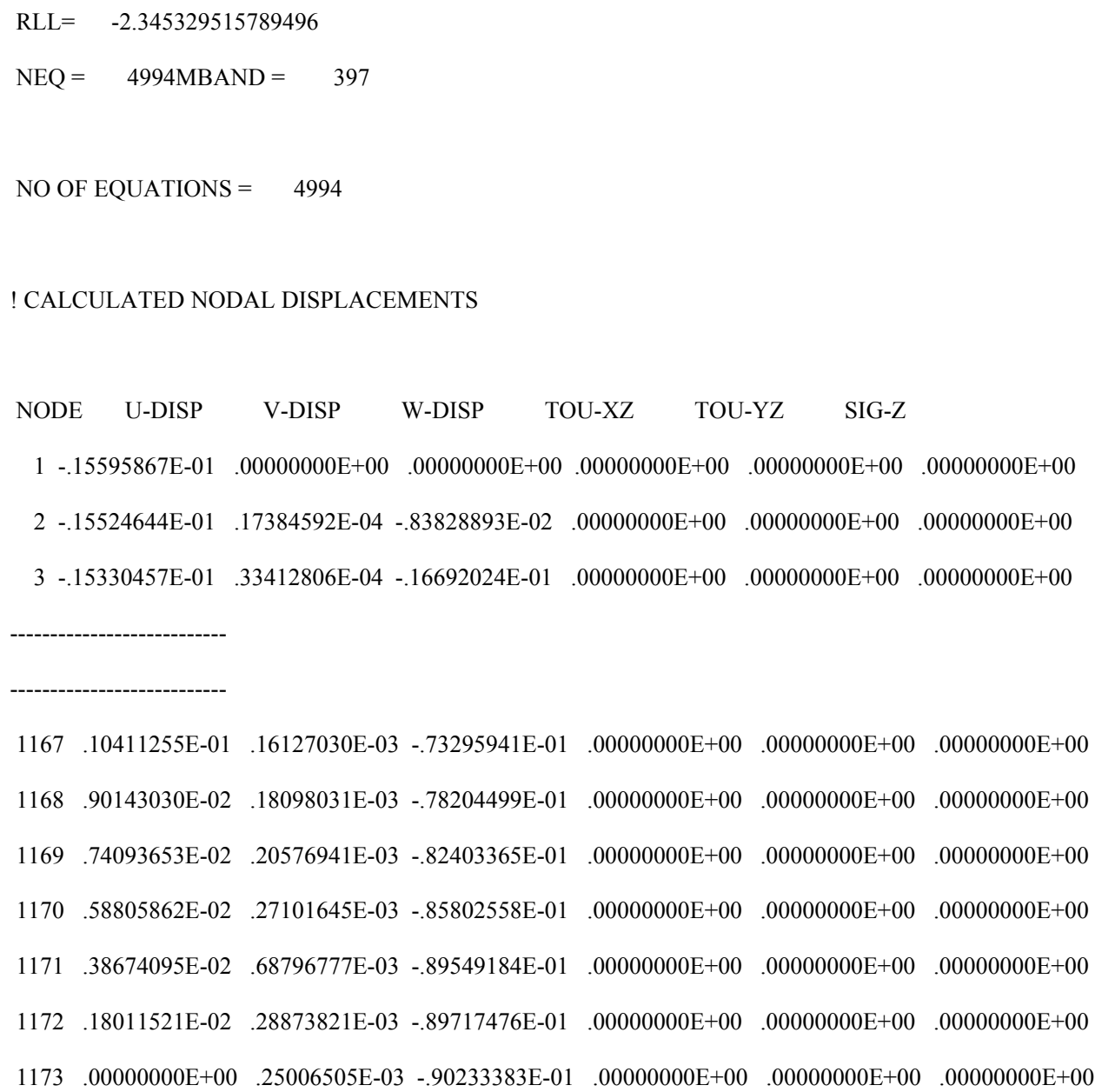

\section{! Continue load step}

